\title{
Eurômos : Rapport préliminaire sur les travaux réalisés en 2017
}

Abuzer Kızıl, Koray Konuk, Taylan Doğan, Didier Laroche, Enora Le Quéré, Vasilica Lungu, Francis Prost et Baptiste Vergnaud

\section{(2) OpenEdition}

1 Journals

Édition électronique

URL : https://journals.openedition.org/anatoliaantiqua/644

DOI : 10.4000/anatoliaantiqua.644

Éditeur

IFEA

Édition imprimée

Date de publication : 1 décembre 2018

Pagination : 165-208

ISBN : 9782362450747

ISSN : 1018-1946

Référence électronique

Abuzer Kızıl, Koray Konuk, Taylan Doğan, Didier Laroche, Enora Le Quéré, Vasilica Lungu, Francis Prost et Baptiste Vergnaud, "Eurômos : Rapport préliminaire sur les travaux réalisés en 2017 », Anatolia Antiqua [En ligne], XXVI | 2018, mis en ligne le 30 juillet 2019, consulté le 03 septembre 2021. URL: http://journals.openedition.org/anatoliaantiqua/644; DOI : https://doi.org/10.4000/anatoliaantiqua. 644 


\section{ANATOLIA ANTIQUA ESKI ANADOLU}

\section{XXVI}

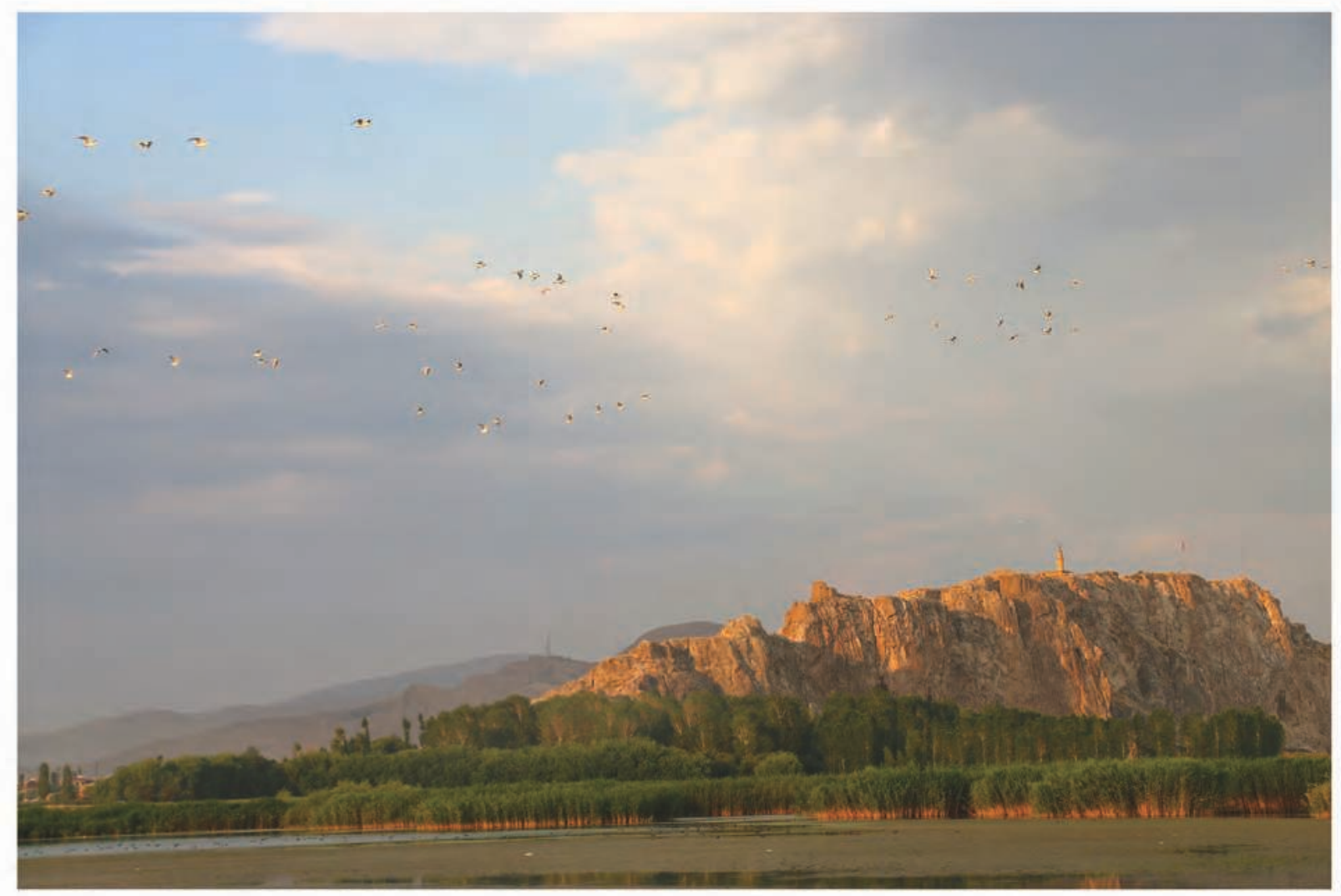

INSTITUT FRANÇAIS D'ETUDES ANATOLIENNES GEORGES-DUMEZIL

CNRS USR 3131

DE BOCCARD 


\section{TABLE DES MATIERES}

Alice VINET et Denis GUILBEAU

A First Glimpse of the Late Neolithic and Early Chalcolithic in Cappadocia through the Lithic

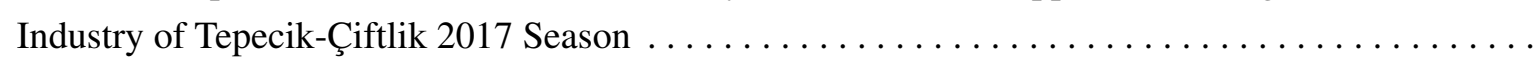

Ergül KODAŞ, Haluk SAĞLAMTIMUR et Yılmaz Selim ERDAL

Three Human Graves of the Hassuna Culture in Türbe Höyük

\section{Kevin PARACHAUD}

Les Galates en Asie Mineure au regard de la culture matérielle. Hellénisation, maintien, acculturation ? 23

H. Asena KIZILARSLANOĞLU et Erkan ALKAÇ

Hellenistic Amphora Stamps from Elaiussa . . . . . . . . . . . . . . . . . . . . .

Aygün EKİN MERİÇ

Late Roman Pottery from the Theatre of Nicaea in Bithynia $\ldots \ldots \ldots \ldots \ldots \ldots \ldots \ldots \ldots$

Nergis GÜNSENIN

La typologie des amphores Günsenin. Une mise au point nouvelle.

Nergis GÜNSENIN et Alessandra RICCI

Les amphores Günsenin IV à Küçükyalı (Istanbul). Un voyage entre monastères ? . . . . . . . . .

\section{CHRONIQUES DES TRAVAUX ARCHEOLOGIQUES EN TURQUIE 2017}

Erkan KONYAR, Bülent GENÇ, H. Banu KONYAR, Armağan TAN et Can AVCI

Excavations at the Old City, Fortress, and Mound of Van: Work in 2017 . . . . . . . . . . . . . .

\section{Çiğdem MANER}

Preliminary Report on the Fifth Season of the Konya Ereğli, Karapınar, Halkapınar and

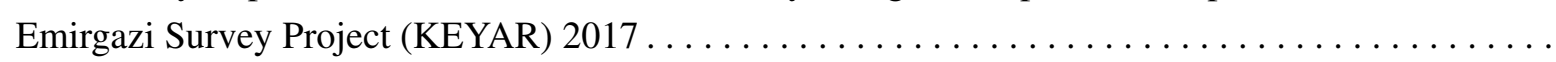

Abuzer KIZIL, Koray KONUK, Taylan DOĞAN, Didier LAROCHE, Enora LE QUERE,

Vasilica LUNGU, Francis PROST et Baptiste VERGNAUD

Eurômos : Rapport préliminaire sur les travaux réalisés en 2017

Olivier HENRY et E. ANDERSSON, J. BLID, Chr. BOST, Ö. ÇAKMAKLI, N. CARLESS-UNWIN, G. ÇİMEN, A. EYİGÖR, A. FRECCERO, A. FREJMAN, Cr. GEORGESCU, E. GOUSSARD, A.-M. GUIMIER-SORBETS, M. HAUCHART, R. HEDLUNG, N. LAMARE, V. LUNGU, Fr. MARCHAND-BEAULIEU, A. SITZ, I. STOJANOVIC, B. VERGNAUD 


\author{
Abuzer KIZIL, Koray KONUK, Taylan DOĞAN, Didier LAROCHE, \\ Enora LE QUERE, Vasilica LUNGU, Francis PROST et Baptiste VERGNAUD*
}

\title{
EURÔMOS : \\ RAPPORT PRELIMINAIRE SUR LES TRAVAUX REALISES EN 2017
}

La troisième campagne de la Mission archéologique française d'Eurômos du Ministère des Affaires étrangères et du Développement international eut lieu au mois d'août $2017^{1}$. Outre la campagne de fouille, nous avons poursuivi au mois de septembre le projet de prospection dans l'Eurômide et ses territoires voisins qui avait été initié l'année dernière sous la direction d'Abuzer Kızıl et autorisé par la Direction des biens culturels et des musées d'Anka$\mathrm{ra}^{2}$. Les membres de l'Institut Ausonius mènent depuis l'été 2012 des travaux épigraphiques et numismatiques ainsi que des prospections à Eurômos et ses environs grâce à l'appui financier du LabEx LaScArBx de l'université de Bordeaux et de l'Institut Ausonius (UMR 5607). Il convient aussi de mentionner les contributions de l'équipe "Mondes grecs archaïques et classiques" de l'UMR 7041 ArScAn (Université Paris 1-Panthéon Sorbonne) et du GRHis, EA 3831 de l'université de Rouen, qui aident spécialement au volet archéologique de la mission. Eurômos est un site antique de Carie qui se situe à $12 \mathrm{~km}$ environ au Nord de Milas (ancienne Mylasa) au Nord-Ouest du petit village de Kız1lcakuyu, au Sud-Est d'une plaine distincte de celle de Milas mais qui la prolonge. La situation d'Eurômos en fait la cité historique la plus importante au Nord de Mylasa jusqu'au littoral maritime antique qui ouvre sur Milet. Eurômos présente de ce fait une particularité étonnante car elle est la seule cité de Carie qui possède des vestiges substantiels qui n'ait jamais fait l'objet d'une étude spécifique, et qui ne dispose même d'aucun plan véritable, alors que tous les sites voisins comme Milet, Héraclée du
Latmos, Labraunda, Amyzon, Alinda, Stratonicée, Mylasa, Iasos ont été ou sont étudiés. Une autre originalité d'Eurômos est de présenter les vestiges d'un temple, celui de Zeus Lepsynos, sans doute le mieux conservé de toute la Carie et qui a été régulièrement dessiné puis photographié depuis les premiers voyages savants au $18^{\mathrm{e}}$ siècle.

La première section de ce rapport est un compte rendu sommaire des travaux effectués par nos collègues turcs.

\section{KAZI, RESTORASYON VE KONSERVASYON ÇALIŞMALARI}

(A. Kızıl ve T. Doğan)

T.C. Kültür ve Turizm Bakanlığı Kültür Varlıkları ve Müzeler Genel Müdürlüğü'nün destekleri ile yürütülen Euromos Antik Kenti 2017 y1lı Kaz1, Dokümantasyon, Restorasyon ve Yayın Hazırlık Çalışmaları; Bakanlığımız Kültür Varlıkları ve Müzeler Genel Müdürlügü̉nün 29.05.2017 tarih ve 94949537-160.01.01-E.108164 sayılı izin yazıs1 doğrultusunda, Euromos Kazısı Başkanlığınca 03. 07. 2017 - 26. 09. 2017 tarihleri arasında gerçekleştirilmiştir. Bilindiği üzere Kazı, Restorasyon ve Belgeleme çalışmaları oldukça uzun soluklu çalışmalardır. Kentte her yıl sürdürülen çalışmalar birbirinin devamı niteliğinde olup, her yıl yaklaşık olarak öngörülen çalışma programı çerçevesinde yapılmaktadır. 2017 yılı sezonunda belirlenen program çerçevesinde Kutsal Alan, Güney Nekropolis ve Agora sektörlerinde kazı, belgeleme ve katalog çalışmaları yapılmıştır.

*) La mission archéologique française d'Eurômos était composée en 2017 du chef de mission Koray Konuk, de Clément Coutelier, Joy Rivault et d'une doctorante : Julie Bernini (Institut Ausonius, UMR 5607 et LaScArBx) ; de Francis Prost, Laurent Costa et d'une doctorante : Linda Talatas (ArScAn, UMR 7041); de Didier Laroche (ENSAS); d'Enora Le Quéré (GRHis, EA3831); de Vasilica Lungu (Institut d'Etudes du Sud-Est Européen), de Baptiste Vergnaud (IFEA, Istanbul), travaillant sous l'autorité du directeur des fouilles Abuzer Kızıl, assisté de son adjoint Taylan Doğan (Université Sitkı Koçman de Muğla), avec l'autorisation de la Direction générale des biens culturels et des musées du Ministère de la culture et du tourisme d'Ankara.

1) Nous avons également bénéficié cette année d'une aide financière de l'Institut Universitaire de France via Patrice Brun, membre senior de IUF. La mission archéologique française d'Eurômos est associée à l'équipe archéologique turque dirigée par Abuzer Kız1l.

2) Le projet de prospection archéologique et épigraphique a réuni en 2017, Koray Konuk, Patrice Brun, Raymond Descat et Laurent Capdetrey (Institut Ausonius, UMR 5607 et LaScArBx), ainsi qu'Abuzer Kızıl (Université Sitkı Koçman de Muğla). 


\subsection{Kutsal Alan}

Kutsal alanda 2017 yılı kazı çalışmalarının kapsamını dört farklı çalışma alanı oluşturmaktadır. Birinci çalışma alanı ; tapınak naiskos'un içinde yer alan heykel kaidesinin iç dolgusudur. İkinci çalışma alanı; tapınağın hemen önünde yer alan sunağın iç dolgusundaki $2.20 \times 2.10 \mathrm{~m}$ ölçülerindeki sondajdır. Üçüncü çalışma alanı; kutsal alanda dağınık bir biçimde yer alan mimari elemanların ortaya çıkarılmasıdır. Son olarak dördüncü çalışma alanı ise tapınağın dört tarafında yer alan tahribata uğramış kesitlerdir.

\subsubsection{Naiskos Çalışmaları}

" $\Pi$ " formlu bir yapı sergileyen naiskos blokları ile koruma altına alınan kült heykeli kaidesi, günümüze kadar iyi derecede korunarak gelen Roma dönemi tapınağının merkezinde yer almaktadır. Kaide, her cephede bir tane olmak üzere dört adet bloğun bir araya getirilmesi, iç kısmının moloz taşlar ile doldurulması ve üzerinin düz bloklar ile kapatılmasında oluşmaktadır (Fig. 1). 1.54 x 1.54 $\mathrm{m}$ boyutuyla kare bir form sergileyen kaidenin, birçok bloğu günümüze kadar korunabilmiş olsa da, üzerinde herhangi bir bezeme veya profilin işlenmemiş olması, kaideyi tarihlendirmeyi olanaklı kılmamaktadır. Sikke betimlerinden hareketle, kaide üzerinde, olasılıkla bir elinde mızrak, diğerinde çift ağızlı balta tutan Zeus'un heykeli yer almaktayd ${ }^{3}$. Kaideye ilişkin, ilk verileri Ü. Serdaroğlu'ndan edinmekteyiz. Ü. Serdaroğlu, naiskos ile aynı mermerden yapılan ve mermer bir kırma çatı ile örtülü olması gereken kaidenin, kırılmış olmakla beraber, in situ olduğunu ve benzer örneklerinin, Didymaion ve Kastabos Hemitheia Tapınăğ'nda olduğunu belirtmekte, ancak kaide için herhangi bir tarih önermemektedir ${ }^{4}$. S. Ateşlier ise kült heykel kaidesinde görülen işçiliğin tapınağın diğer mimari bloklardan farklı olduğunu belirtmektedir. $\mathrm{Bu}$ farklılığın sebebini ise Mykale Arkaik tapınakta, Samos Heraion'unda, Artemision'da ve Didymaion'da olduğu gibi Euromos'ta da eski yapıya saygı amacıyla yeni yapı içinde koruma amacına bağlamakta ve kaideyi Arkaik döneme tarihlendirmektedir ${ }^{5}$. Araştırmacılar tarafından kült heykel kaidesi için sunulan bu önerilerin doğruluğunu veya yanlışlığını test etmek amacıyla kaide içinde

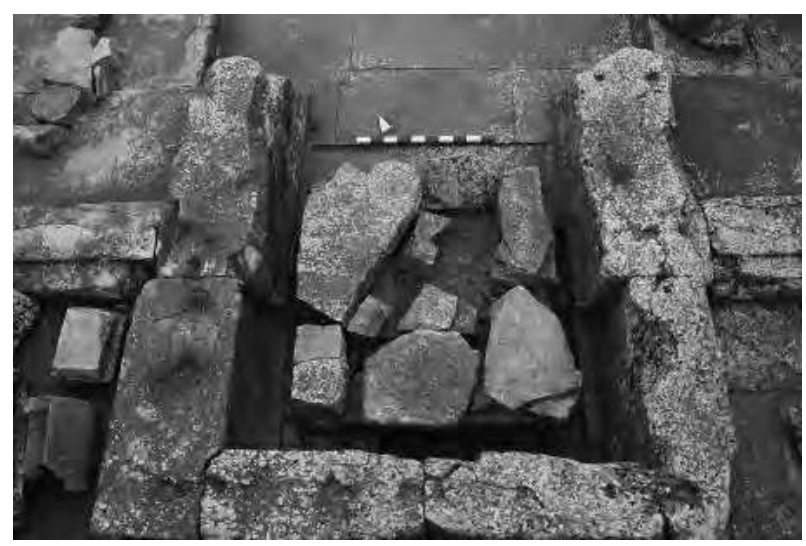

Fig. 1 : Naiskos (A. K1z1l).

kazı çalışmaları gerçekleştirilmiştir. Kaide içinde $48.14 \mathrm{~m}$ seviyesinde kum bulunmaktaydı. Olasilıkla bu kum Serdaroğlu tarafından, kaide içine doldurulmuştu ve yer yer değişmekle birlikte kumun 47.73 $\mathrm{m}$ seviyesine kadar, devam ettiği görülmüştür. Kaide içindeki kum tamamen dişarı çıkarıldıktan sonra, kimi yarı işlenmiş kimi moloz olan ortalama $0.15 \mathrm{x}$ $0.25 \mathrm{~m}$ ölçülere sahip taşlarla karşılaşılmıştır. Üst seviyesi $47.97 \mathrm{~m}$ olan taşların fotoğraf ile belgeleme çalışmaları bitirilmiş ve kısmen kaldırılmaya hazır hale getirilmişlerdir. Ancak temele ait olduğu düşünülen taşların, büyük bölümünün naos stylobatı altına doğru devam etmesi, alanda çalışmayı mümkün kılmamıştır. Taşlar arasında yapılan detaylı temizlik ve kısmen kazı çalışmaları sonucunda, küçük bir bölümde $47.12 \mathrm{~m}$ seviyesine kadar inilebilmiş ise de herhangi bir buluntu ele geçmemiştir. Kaide içinde, herhangi bir buluntunun ele geçmemesi, kaideyi kesin olarak tarihlendirmeyi olanaklı kılmamıştır. Dolayısıyla, şu anki veriler 1şı̆̆ında, kaidenin naos ile aynı aksta olmaması nedeniyle Didyma örneğinde olduğu gibi mevcut Roma dönemi tapınağından daha erken olabileceğini söyleyebilmekteyiz. Ancak Arkaik evreye mi yoksa Hellenistik evreye mi ait olduğunu gösterecek herhangi bir veri elde edilememiştir.

\subsubsection{Sunak Çalışmaları}

Sunak ile ilgili yapılan literatür araştırmaları sonucunda sırasiyla Serdaroğlu, Mitchell-McNicoll ve Bean'in sadece tapınağın doğu ucunda geç Hellenistik döneme ait büyük bir sunağın ortaya çıkarıldığını belirtmekle yetindikleri' ${ }^{6}$ Ateşlier'in

3) Laumonier 1958: 168.

4) Serdaroğlu 2004: 124.

5) Ateşlier 2011: 127.

6) Serdaroğlu 1971: 48; Mitchell ve McNicoll 1978-79: 81; Bean 1987: 44. 
ise gerek yapısis ${ }^{7}$ gerekse tarihi ${ }^{8}$ hakkında çeşitli öneriler sunduğu görülmüştür9 ${ }^{9}$.

Euromos kutsal alanında, kısmen ana kaya üzerinde duran ve düz bir alana konumlanan sunak, Roma dönemi tapınağının hemen doğusunda yer almaktadır. Sunak kuzey-güney doğrultusunda 6.72 $\mathrm{m}$ genişliğe, doğu-batı doğrultusunda $7.00 \mathrm{~m}$ derinliğe sahiptir. Üst üste konumlandırılmış üç taş sırası halinde korunan sunağın toplam yüksekliği $0.78 \mathrm{~m}$ olarak ölçülmüştür. 1970 yılında Serdaroğlu çalışmaları sırasında tapınağın doğu ucunda ortaya çıkarılan sunağın ${ }^{10}$ temel bloklarının tapınak giriş krepidoma'sına olan uzaklığı yer yer değişmekle birlikte ortalama $0.15 \mathrm{~m}$ olarak ölçülmüştür. Oldukça tahrip olan sunağın temel taş sırası ve euthynteria seviyesindeki blokları tam olarak korunurken, birinci basamağın yaklaşık yarısı korunabilmiştir (Fig. 2a).

Sunağı dar bir zaman dilimi içinde olarak tarihlendirmek amacıyla sunağın içinde ve dışında 2017 yılında kazı çalıșmaları gerçekleştirilmiștir. Sunak içinde $2.20 \times 2.10 \mathrm{~m}$ ölçülerinde açılan bir sondajda ana kayaya kadar kazı çalışmaları yapılmış ve birkaç amorf monokrom seramik dişında herhangi bir veriye rastlanmamıştır. Sunağı tarihlendirmeye yönelik iç dolgunun herhangi bir veri sunmaması nedeniyle kazı çalışmaları sunağın hemen dışına kaydırılmıştır. Sunağın doğusunda ve batısında ana kayaya kadar yapılan kazı çalışmaları sonucunda sunak temel seviyesinde steril bir tabaka ile karşılaşılmıştır. Söz konusu tabakadan ele geçen malzeme çeşitli formlardaki kase ve balık tabaklarında ibaret olup M.Ö. 4. yüzyılın son çeyreğine tarihlendirilmişlerdir (Fig. 2b). Kazı çalışmaları sırasında ayrıca sunağın doğusunda ona yapışık biçimde konumlandırılmış bir heykel kaidesi de temel bloklarına kadar açığa çıkarılmıştır. Kazı çalışmaları sonucunda sunak ile aynı kodda yer aldığı görülen heykel kaidesi üzerinde lesbos kymation bezemesi işlenmiştir
(Fig. 2c). Lesbos kymation'una ilişkin olarak yapılan stil kritik araştırmalar sonucunda, kaideyi M.Ö. 4. yüzyılın sonlarına tarihlendirmenin olanaklı olduğu görülmüştür ${ }^{11}$. Bu veriler dışında ayrıca kutsal alanda sunağa ait olduğu düşünülen iki taç bloğu ${ }^{12}$ üzerinde işlenen İon kymation bezemesinin de benzer örneklerinin M.Ö. 4. yüzyılın son çeyreğine ait oldukları görülmüştür (Fig. 2d) ${ }^{13}$. Sonuç olarak, sunağı seramik ve mimari bezemeler ışığında M.Ö. 4. yüzyılın son çeyreğine tarihlendirmek mümkündür.

\subsubsection{Tapınak Çevresi Mimari Elemanların Ortaya Çıkarılması}

Tapınak çevresinde yer alan yüzlerce mimari blok üzerinde yapılan gözlemler sonucunda, tapınağ 1 oluşturan blokların büyük çoğunluğunun varlığ1 tespit edilmiştir. Ancak söz konusu bloklardan özellikle tapınağın güney ve güneydoğusuna ait birçoğunun büyük oranda toprak altında yer alması, bunların çizim ve fotoğraf ile belgeleme işlemlerini engellemekteydi. Tapınağın restitüsyon ve restorasyon çalışmalarının yapılabilmesi amacryla tapınağın güneydoğusunda kazı çalışmaları gerçekleştirilmiştir. Çalışmalar sonucunda, tapınağın güneydoğu köşe frizi, arşitravı ve sütun başl1ğ 1 ile çeşitli mimari elemanlar ortaya çıkarılmıştır (Fig. 3).

\subsubsection{Kesit Çalışmaları}

Ü. Serdaroğlu çalışmaları döneminde tapınağın etrafının kısmen kazıldığı ve tapınağın dört tarafında yer alan kesitlerin zamanla yağmur ve rüzgar gibi doğal etkenler neticesinde oldukça bozulduğu görülmektedir. Gerek alana estetik bir görünüm kazandırmak gerekse çalışmalar sonucunda ele geçecek buluntular ile kutsal alanın stratigrafik yapılan-

7) Ateşlier, ikinci taş sırasına ilişkin olarak, sunak ile tapınağın cephesindeki podyum basamakları arasında çok dar bir mesafenin olduğunu ve batı kenarında yer alan dış kenar temel bloklarının kenar çerçevelerinin perdahlanmış, orta kısımlarının ise anathyrosis'e sahip olduğunu bildirmektedir. Söz konusu blokların aslında sunağın orijinal dış kenar blokları olmadığını, çünkü anathyrosis işçiliğine sahip blokların bir diğer taşa birleştirme için bu şekilde işlendiğini belirtmektedir. Kendisi sunağın batı kenarı boyunca en az bir sıra daha blok yer alması gerektiğini ve bu durumda tapınağın cephe podyum basamakları ile sunağın batı kenarının üst üste bineceğini söylemektedir. Sunak ve tapınak podyumu arasındaki bu ilişkiyi ise sunağın tapınaktan daha erken olması ve tapınak inşa edilirken sunağın batı kenarından en az bir sıra bloğun yerinden çıkarılarak tapınağa yer kazandırıldı ̆̆ı biçiminde açıklamaktadır (Ateşlier 2011: 125-126).

8) Ateşlier, sunakta kullanılan kenetlerin farklı biçimlere sahip olmasından hareketle sunağın en az iki evreye sahip olması gerektiğini ifade etmektedir. Araştırmacı, sunak temel blokları üzerinde görülen kırlangıç kuyruğu tipindeki kenet yuvaları sunağın ilk evresine (Arkaik döneme) tarihlerken, üçüncü sıra bloklar üzerinde görülen düz kenetleri ise ikinci evreye (Hellenistik döneme) tarihlemektedir (Ateşlier 2011: 126).

9) Ateşlier 2006: 60; Ateşlier 2011: 125-126.

10) Serdaroğlu 1971: 48; Mitchell ve McNicoll 1978-79: 81; Bean 1987: 44; Ateşlier 2006: 60.

11) Erder 1967: 33, 76, 135, 148, Lev. XXXI.b; Wegner 1966: 22, 95, Taf. 1b.

12) Taç bloklarından bir daha önce N. Kürüm tarafından "Hellenistik Çağ Anadolu Mimarisindeki Karia Bölgesinde İon Kymationu'nun Gelişimi” isimli Yüksek Lisans Tezi kapsamında ele alınmış ve M.Ö. 323-300 yılları arasına tarihlendirilmiştir (Kürüm 2006: 17, 59, Resim 3).

13) Koçhan 1995: Kat. № 46-50, Levha 18a-d, 19a. 

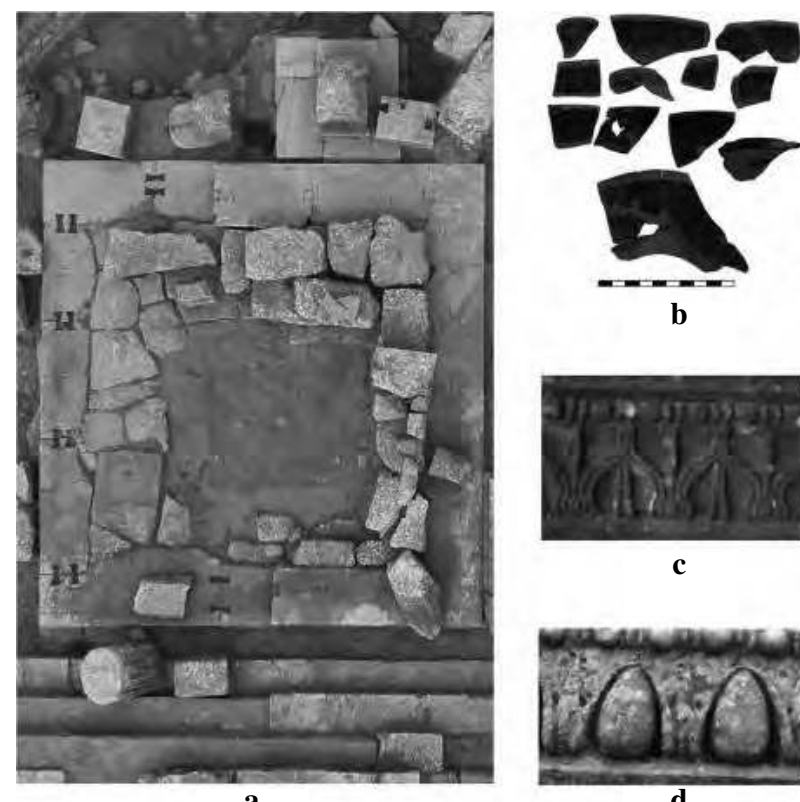

b
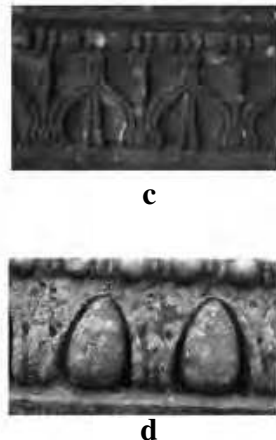

d

Fig. 2 : Sunak ve sunak ile ilişkili veriler (A. Kızıl).

masına ilişkin veriler elde etmek amacıyla tapınak çevresinde kesit düzeltme çalışmaları gerçekleştirilmiştir. Sunağın hemen doğusunda yer alan kesitte yapılan kazı çalışmaları sonucunda, toprak yapısı ve ele geçen malzeme 1şı̆̆ında 5 farklı tabakanın varlığı saptanmıştır. 1. Tabaka: en üst kısımda, yüzey veya tarım toprağı olarak bilinen tabaka olup, bu tabadan Arkaik, Hellenistik ve Roma dönemlerine ait seramikler ele geçmiştir. 2. Tabaka: toprağın kül rengine yakın, gevşek bir yapıya sahip olduğu ve içinde küçük taşlar barındırdığı tabaka olup, bu tabakadan Roma dönemine ait seramikler ele geçmiştir. 3. Tabaka: yoğun olarak mermer parçalarını barındıran bir dolgu olup, içinden oldukça az sayıda Roma dönemine ait seramikler ele geçmiştir. 4. Tabaka: bu tabakada toprak rengi kahverengine dönüşmüş ve toprak üst katmana göre biraz daha sert bir yapıya dönüşmüştür. Sunağın temel taşları ile aynı kodda yer alan bu tabakada ele geçen malzeme arasında 1 adet Arkaik döneme ait mimari terrakotta parçası, birkaç tane Roma dönemine ait seramik parçası yer alırken, geriye kalan onlarca seramik parçasının tamamının Hellenistik döneme ait olduğu görülmüsştür. Sunağın oturma düzlemi ile aynı kotta yer alan 5. tabaka, steril bir tabaka olup ele geçen malzemenin tamamı Hellenistik döneme tarihlendirilmiştir (Fig. 4).

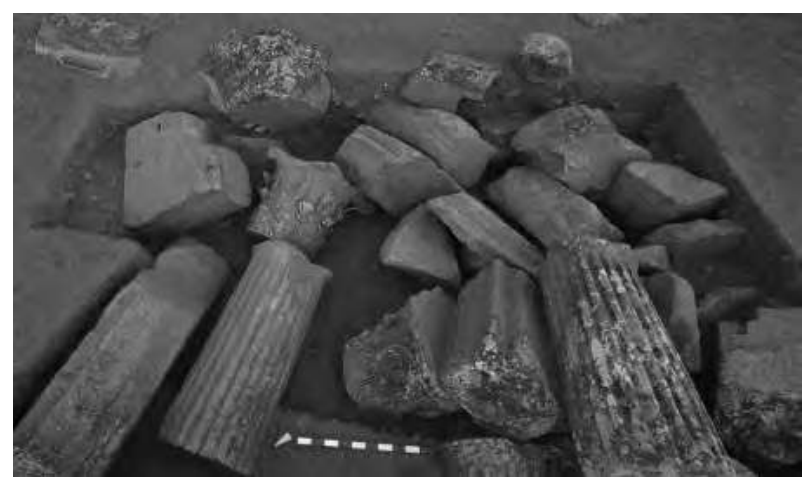

Fig. 3 : Tapınağa ait mimari elemanlar (A. Kizil).

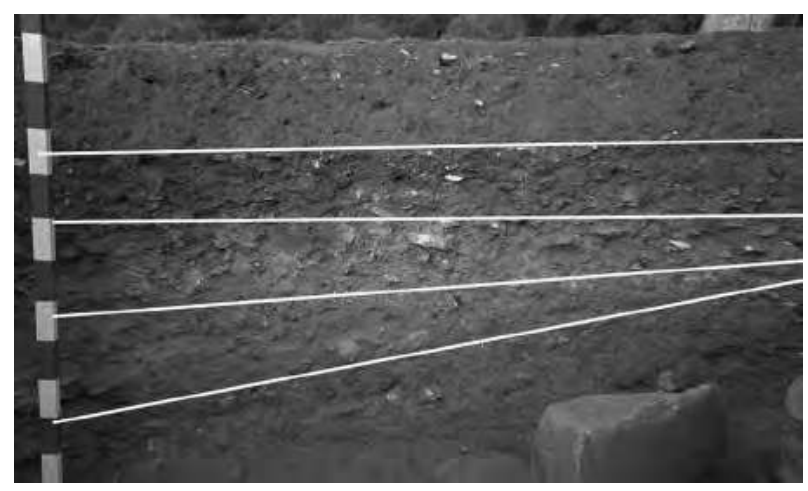

Fig. 4 : Kutsal alan kesit stratigrafisi (A. Kizıl).

\subsection{Güney Nekropolis}

2017 yılı kazı sezonunda, Euromos Ören Yeri için yapılması planlanan Karşılama Merkezi’nde, kazı çalışmaları gerçekleştirilmiş̧ir (Fig. 5). Çalışmalar sonucunda, 2 tanesi amphora, 3 tanesi kiremit ve 5 tanesi taş lahit olmak üzere toplam 10 adet mezar ortaya çıkarılmıştır. Ortaya çıkarılan taş lahit mezarların tamamının defineciler tarafından tahrip edilmesi ve amphora ile kiremit mezarların buluntu barındırmaması nedeniyle mezarların kesin olarak tarihlendirilmesine olanak tanımamıştır. Bununla birlikte, gerek mezarların çevresinde gerekse mezarların dışında ele geçen buluntular, Güney Nekropolis'in kullanım süreci ve kısmen de mezarların tarihleri hakkında bir fikir yürütmemize olanak sağlamıştır. Mezar dışında ele geçen seramik, sikke ve metal buluntular Güney Nekropolis'in bu alanının Arkaik, Hellenistik, Roma ve Bizans dönemlerinde kullanıldığına işaret etmektedir (Fig. 6). Nitekim 2013 yllında Tonozlu Anıt Mezar çevresinde yapılan çalışmalarda da Güney Nekropolis'in Geç Geometrik dönemden Roma'nın geç dönemlerine kadar kullanım gördüğü tespit edilmişti ${ }^{14}$. Çalışmalar sırasında ortaya çıkarılan bütün mezarların kuzey-güney doğrultulu olarak bir 


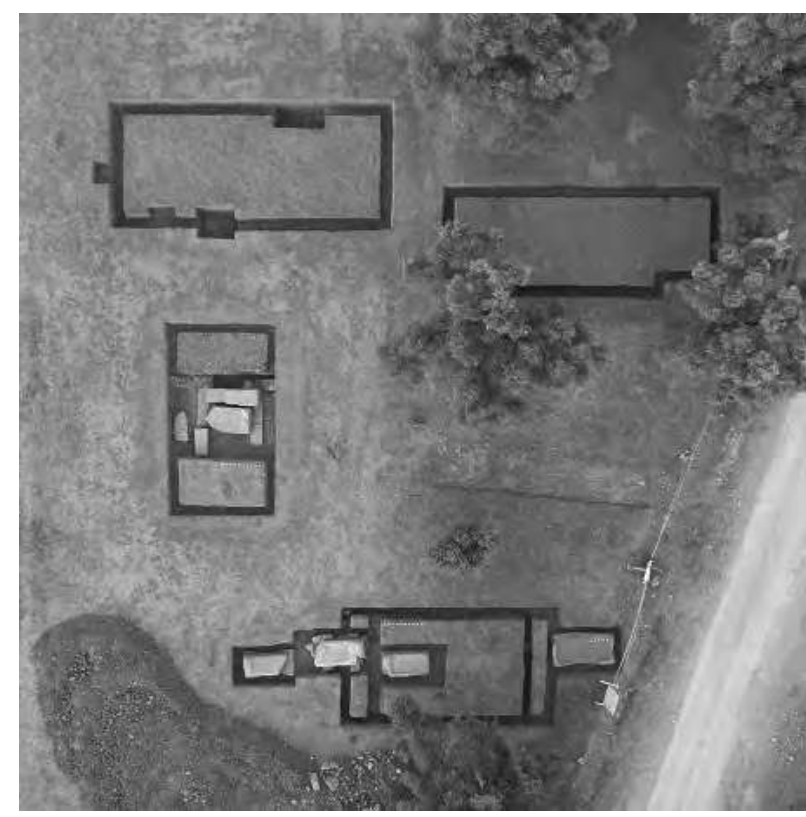

Fig. 5 : Güney Nekropolis çalışma alanı ve taş lahitler (K. Konuk).

yön birliğine sahip oldukları görülmüştür. Bu alanda ele geçen sikkeler arasında, ön yüzünde sağa dönük Zeus Osogos başlı ve arka yüzünde MY lejandlı trident üzerinde yunus balıklı M.Ö. 400-350 yıllarına ait bronz bir sikke dikkat çekmektedir $(12 \mathrm{H}, 1.26 \mathrm{~g}$, Fig. 7) ${ }^{15}$. Agorada diğer bir örneğin bulunması bu sikkelerin büyük bir olasılıkla Mylasa'da darp edildiklerini göstermektedir.

\subsubsection{Taş Lahit Mezarlar (Fig. 5)}

Ortaya çıkarılan taş lahit mezarların tamamının defineciler tarafından tahrip edildiği görülmektedir. Bir tekne ve kapaktan ibaret olan mezarların tekne kısımları oldukça tahrip olurken, kapaklardan küçük bir parça dışında hiçbirinin korunmadığı görülmektedir. Mezarların uzunlukları $2.25 \mathrm{~m}$ ile $3.00 \mathrm{~m}$ arasında, genişlikleri $1.06 \mathrm{~m}$ ile $1.50 \mathrm{~m}$ arasında ve derinliklerinin ise $0.70 \mathrm{~m}$ ile $0.97 \mathrm{~m}$ arasında değişiklik arz ettikleri görülmektedir. Mezarlardan bazılarının uzun ve kısa cephelerinde plastik olarak üzüm salkımları işlenirken, bazılarının düz bir biçimde bırakıldıkları görülmektedir. Mezar çevrelerinde ele geçen seramik ve metal buluntularının Roma dönemine ait oldukları görünmektedir.

\subsubsection{Amphora Mezarlar (Fig. 8)}

Biri $0.70 \mathrm{~m}$, diğeri 0.74 yüksekliğinde olan her iki amphora'nın da kısmen iyi derecede korunduğu

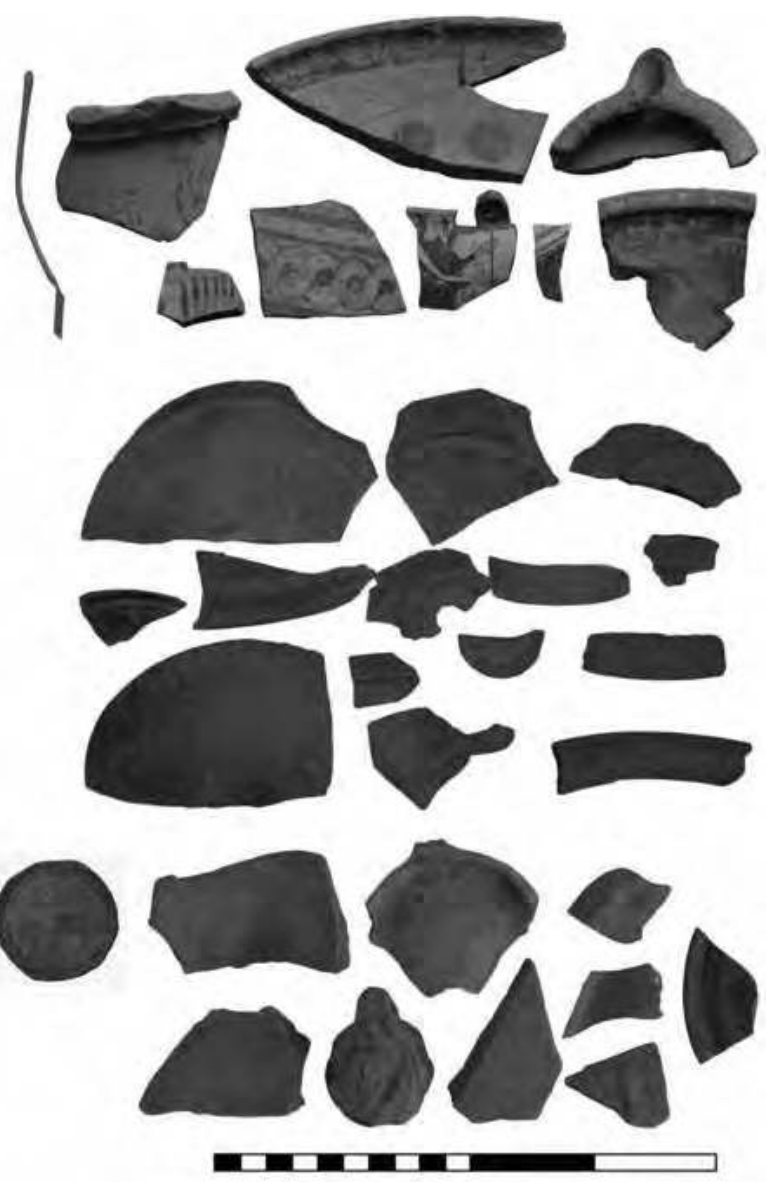

Fig. 6 : Güney Nekropolisten ele geçen buluntular (A. Kizil).

görülmektedir. Amphora' ların omuzdan aşağısı parçalar halinde de olsa tam korunurken, boyun ve ağız kısmı korunmamıştır. Olasılıkla inhumasyon tarzda olan bebeğin amphora'ya sığabilmesi için kabın ağız ve boyun kısımları kırılmış ve buraya bir adet tuğla kapama kiremidi olarak konulmuştur. Sivri dipli amphora' ların kullanılması ile oluşturulan mezarların içinde herhangi bir buluntu ele geçmezken, mezar sahibine ait az miktarda kemik ele geçmiştir. Amphora' ların formlarından hareketle mezarları Geç Antik Çağ’a tarihlendirmek olanaklıdır.

\subsubsection{Kiremit Mezarlar (Fig. 9)}

Kismen iyi derecede korunan mezarların uzunlukları $1.12 \mathrm{~m}$ ile $1.88 \mathrm{~m}$ arasında, genişlikleri 0.35 $\mathrm{m}$ ile $0.50 \mathrm{~m}$ arasında ve derinliklerinin ise $0.70 \mathrm{~m}$ ile $1.06 \mathrm{~m}$ arasında değişiklik arz ettikleri görülmektedir. Mezarların uzun kenarlarında tam kiremitler kullanılırken, kısa kenarlarda ise kırık kiremit parçaları veya taş plakalar kullanılmıştır. Uzun kenar-

15) Sikke tipi icin bkz. Historia Numorum Online, № 735. 

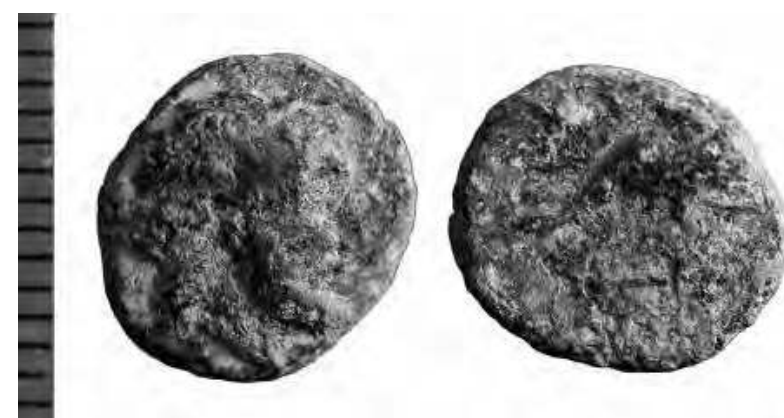

Fig. 7 : Güney Nekropoliste ele geçen bir bronz sikke (K. Konuk).
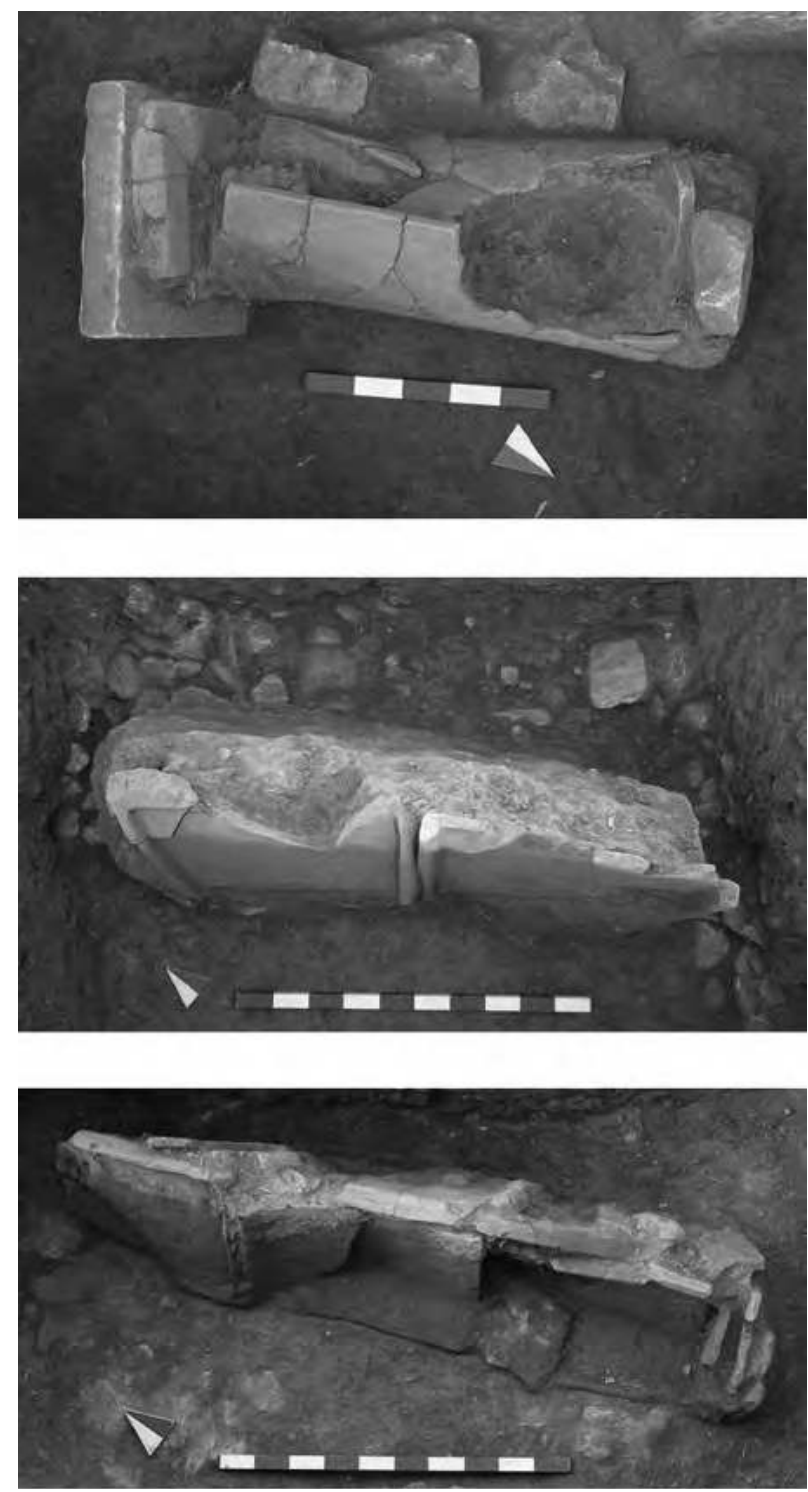

Fig. 9 : Kiremit mezarlar (A. Kiz1l).
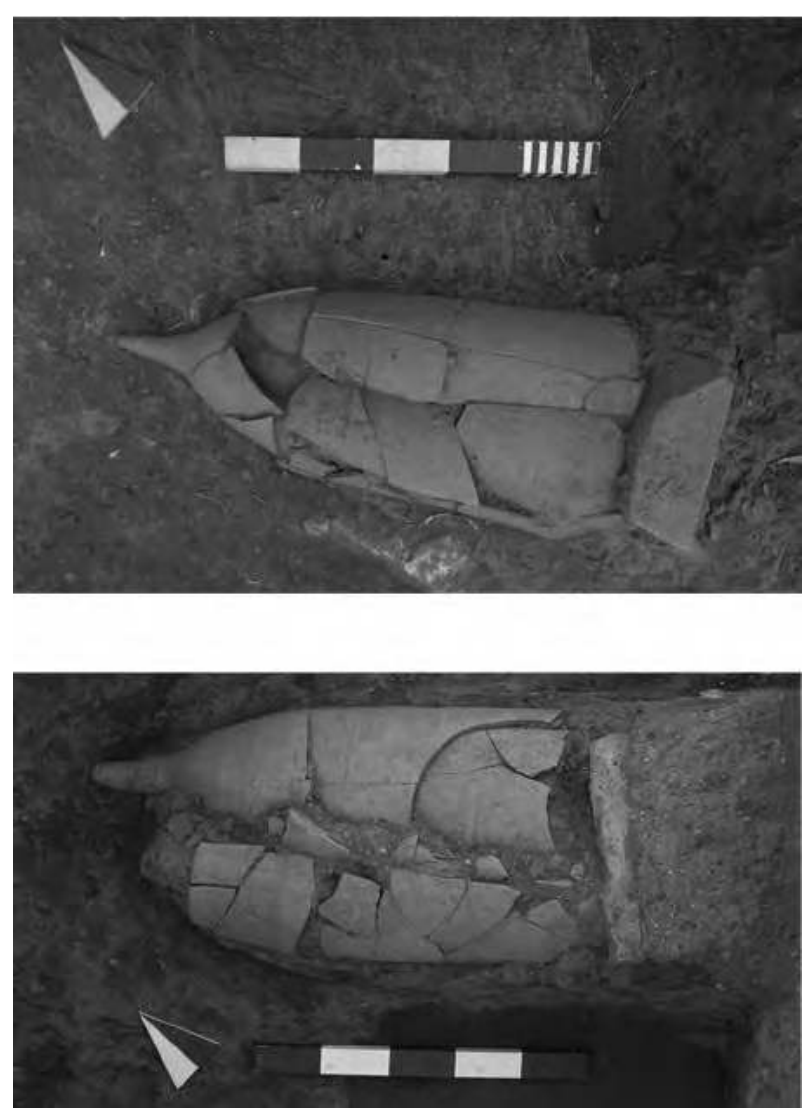

Fig. 8 : Amphora mezarlar (A. Kiz1l).
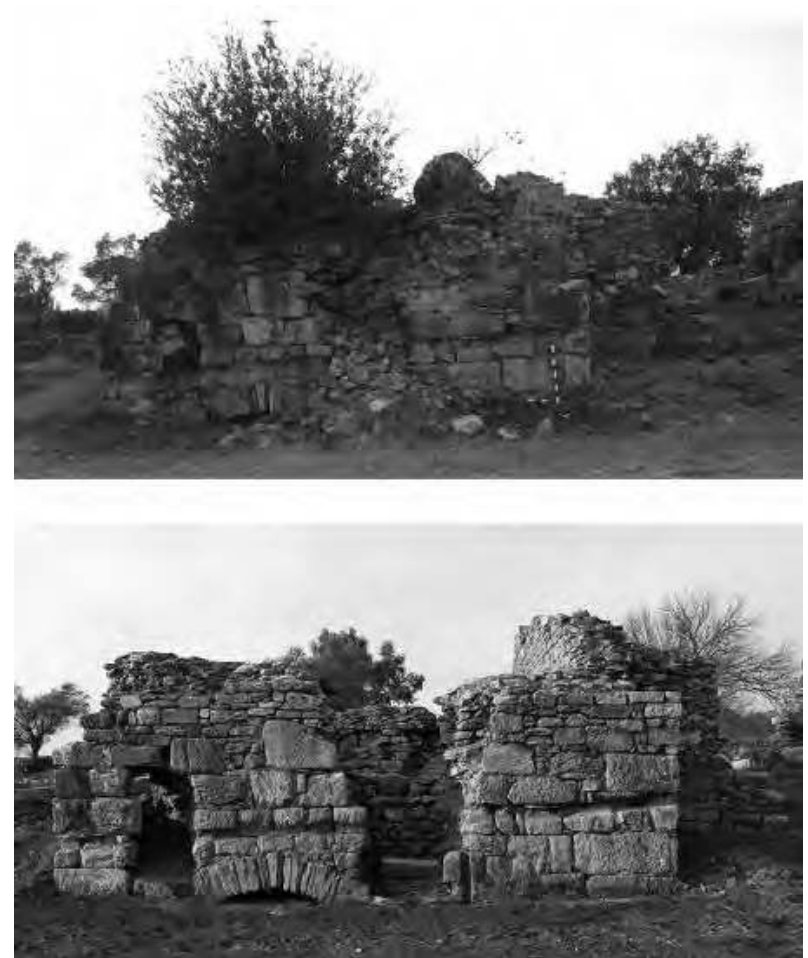

Fig. 10 : Hamam restorasyon öncesi ve sonrası (A. Kizil). 
larda kullanılan kiremit sayıları değişkenlik arz etmektedir. Birinci mezarın uzun kenarlarında birer, ikinci mezarda ikișer ve üçüncü mezarda ise üçer kiremit kullanılmıştır. Mezar sahiplerine ait kemikler iyi derecede korunurken, mezarların herhangi bir buluntu içermedikleri görülmektedir. Mezarların çevresinde Arkaik, Hellenistik ve Roma dönemlerine ait seramik ve metal buluntular ele geçmiştir.

\subsection{Agora}

Agora sektörü çalışmalarındaki temel hedefler, alanda yapılması planlanan restorasyon çalışmaları öncesinde gerekli bütün belgeleme çalışmalarını bitirmek, plan tespitini yapmak ve bu çalışmalar sonuncunda bilimsel veriler elde etmektir. Bu bağlamda 2013 yılından itibaren devam eden çalışmalar ${ }^{16}$, 2017 yılında da belgeleme ve kısmi kazı çalışmaları biçiminde gerçekleştirilmiştir. Çalışmaların birinci önceliği agorada stylobat bloklarının özellikle kilit noktalarda ortaya çıkararak, mümkün olduğunca eksiksiz ve doğru bir vaziyet planı ortaya koymaktır. Daha detaylı bilgi için 2. bölüme bkz.

\subsection{Mimari restorasyon ve konservasyon çalışmaları}

Mimari öğelere ilişkin olarak Agora'da 2014 ve 2015 yıllarında anastylosis çalışmaları gerçekleştirilmiştir. 2015 ve 2016 yılı sezonlarında Agora'da restorasyon çalışmalarının gerçekleştirilebilmesi için temel hazırlık aşaması olan blokların numaralandırılmaları ve belgelendirilmeleri çalışmaları yapılmış ve söz konusu çalışmalar devam etmektedir. Hamam'da ise 2016 yılında restorasyon çalışmalarının yapılabilmesi için Hamam'ın rölöve çalışmaları bitirilmiş ve Muğla Kültür Varlıklarını Koruma Bölge Müdürlüğü onayından geçmiştir. Gönderilen ödenek çerçevesinde 2018 yılının ilk çeyreğinde hamamın kısmi restorasyon ve sağlamlaştırma çalışmaları gerçekleştirilmiştir (Fig. 10).

\section{L'AGORA}

(Fr. Prost et E. Le Quéré)

Entre le 13 et le 26 août 2017, une campagne d'études de l'agora d'Eurômos a pu être conduite par une équipe composée de Laurent Costa, ingénieur topographe du CNRS (ArScAn, UMR 7041), d'Enora Le Quéré (maître de conférences d'Histoire grecque, Université de Rouen, EA 3831 GRHis) et de Francis Prost (professeur d'Archéologie classique, Université Paris 1-Panthéon Sorbonne, ArScAn, UMR 7041). Elle a reçu le soutien de Joy Rivault, d'une doctorante de l'Université Bordeaux Montaigne : Julie Bernini, d'une doctorante de l'Université Paris 1 : Linda Talatas, ainsi que de quatre étudiants de l'Université de Muğla : Ekrem Cengiz, Ömer Faruk Karagöz, Gözde Lafcı et Alp Yapici.

La campagne 2017 sur l'agora d'Eurômos a été consacrée à l'ouverture de trois sondages, ainsi qu'à la poursuite de l'inventaire des blocs architecturaux. Il s'agissait 1) de poursuivre l'inventaire systématique de tous les blocs actuellement disponibles sur le site pour la mise en œuvre d'une reconstitution des portiques et de l'espace dans son ensemble: cette année, c'est le Portique Sud qui a été l'objet de l'inventaire; 2) d'obtenir des réponses aux questions qui avaient été posées l'an passé à propos de l'articulation entre le Portique Est et le Portique Sud, ainsi que sur l'éventualité d'une porte au Portique Ouest.

\subsection{Inventaire des blocs du Portique Sud de l'Agora}

Dans le sillage du travail lancé l'année dernière, J. Bernini et J. Rivault ont poursuivi l'inventaire des blocs disponibles.

Ce travail a pris la forme d'une base de données enregistrant systématiquement tous les blocs architecturaux de l'agora. Durant cette campagne 2017, c'est sur le Portique Sud que se sont concentrés les efforts, et plus spécifiquement sur la colonnade dorique en façade. Ce portique est délimité au Nord par un pilier cordiforme qui assure la jonction avec le Portique Ouest. Il présente un relativement mauvais état de conservation sur sa façade : nous disposons de plusieurs blocs de l'entablement, ainsi que de quelques fragments de colonnes. Sur le stylobate, on a repéré plusieurs traces de colonnes bien visibles, qui permettent de calculer l'entrecolonnement.

Une partie seulement des blocs architecturaux visibles constituant le portique, pour la plupart effondrés sur place lors de la destruction de l'agora, a été répertoriée et inventoriée lors de cette campagne. Il s'agit des blocs situés dans la partie est du portique. Chacun des blocs a donc été numéroté (numérotation continue allant de A600 à A771, portée à la fois sur la pierre et sur le plan), identifié, mesuré, décrit avec un maximum d'informations, dessiné

16) 2013 yılından itibaren agora'da yapılan kazı, belgeleme ve anastylosis çalışmaları için bkz. Kızıl ve Doğan 2014: 411-412; 2015: 212-214, 221-223; 2016: 498-420, 502-506; 2017: 626-629; K1z1l et al. 2016: 321-325; 2017: 161-166. 
sous forme de croquis et photographié. L'ensemble de ces informations ont été ensuite consignées dans une base de données réalisée à l'aide du logiciel File Maker Pro, comportant une fiche par bloc architectural et intégrant tous les dessins et photographies. Cette base permet ainsi une utilisation scientifique de toutes ces données, et devrait, à terme, considérablement faciliter la reconstitution architecturale des quatre portiques de l'agora.

Nous ne pouvons donner pour le moment le résultat de cet inventaire du Portique Sud encore inachevé : il sera poursuivi l'an prochain.

\subsection{Le sondage à l'angle sud-est (Sondage 1A et 1B, US 100+ et US 200+)}

La campagne de cette année a été encore l'occasion d'apporter des éléments de compréhension nouveaux, en vue d'une reconstitution des Portiques Est, Sud et Ouest de l'agora.

Le premier sondage, appelé sondage $1 \mathrm{~A}$, a été implanté à l'Est du Portique Sud. Il a été accompagné d'un petit sondage (1B) entre l'emplacement de la colonne la plus à l'Est du Portique Sud, et la colonne la plus au Sud du Portique Est (Fig. 11). Les objectifs étaient : 1) de repérer si nous avions bel et bien une entrée, hypothèse que nous avions formulée les années précédentes et qui avait trouvé un début de confirmation avec la mise au jour d'un passage dans le fond du Portique Est ; 2) de trouver, dans l'axe de la colonnade du Portique Est et de la première colonne du Portique Sud, une base de colonne de la colonnade centrale du Portique Sud, de façon à comprendre quelle relation était établie entre la colonnade de façade et la colonnade centrale du Portique Sud ; 3 ) le but était là aussi de dégager un niveau de sol qui puisse fournir quelques repères chronologiques.

Les premières investigations menées entre les colonnes du Portique Est et du Portique Sud ont été fructueuses (sondage 1B) : aucun stylobate n'a été mis en place, ce qui confirme bien que l'endroit était aménagé pour une entrée dans l'agora, et surtout que le Portique Est était bien conçu comme séparé du Portique Sud (Fig. 12). Il y a une rupture dans le dispositif du stylobate : le bloc du stylobate à l'Est a été grossièrement taillé, le bloc du stylobate du Portique Sud a lui aussi été découpé, mais l'un et l'autre ont été disposés perpendiculairement, en ménageant un vide correspondant à la largeur de l'entrée repérée dans le mur de fond du Portique Est. Un niveau de sol, à quelque $5 \mathrm{~cm}$ en dessous des stylobates, a pu être repéré : le matériel a livré très peu de céramique, et une monnaie (Fig. 13). Il s'agit d'une monnaie en bronze frappée par la cité de Mylasa, datant de ca. 400-350 av. J.-C., représentant au droit la tête barbue et laurée de Zeus Osogos et au revers un dauphin au-dessus d'un trident $(11 \mathrm{H} ; 1,45 \mathrm{~g})^{17}$.

Le sondage $1 \mathrm{~A}$, quant à lui, a permis en outre, dans le Portique Sud, de dégager, après une couche épaisse de remblais formé de tuiles, de fragments d'amphores, de tessons de céramique d'époque impériale romaine, une fondation de base de colonne centrale en place (Fig. 14). Cette fondation prend la forme de deux grands blocs formant une large surface carrée, mesurant hors tout $1,20 \times 1,20 \mathrm{~m}$, et dont le centre est situé exactement à $6,90 \mathrm{~m}$ du stylobate du Portique Sud et à $6,90 \mathrm{~m}$ du mur de fond de ce portique : ces deux blocs identiques taillés à la grosse pointe sont joints par deux scellements. On repère sur la surface supérieure la trace du premier tambour d'une colonne, ainsi que deux cavités qui ont permis de le sceller à ces fondations. Cette fondation est exactement dans l'axe de la colonnade du Portique Est et de la première colonne la plus à l'Est du Portique Sud. On peut supposer que le système de la colonnade ionique centrale était d'une colonne ionique toutes les deux colonnes doriques en façade.

\subsection{Le sondage au Portique Ouest (Sondage 2A et 2B, US 300+ et 400+)}

Le deuxième sondage, appelé sondage 2 , a été implanté dans le Portique Ouest, de manière transversale au portique (Fig. 15) : l'objectif était de repérer le stylobate à l'Est et de repérer à l'Ouest quelques vestiges du mur de fond du portique. En outre, il s'agissait de repérer un sol d'occupation, puisque, jusqu'à présent, nous ne disposions d'aucun repère sur le niveau de sol associé aux constructions de l'agora. Nous avons divisé ce sondage en deux carrés de 2 x 2 m, l'un à l'Est, l'autre à l'Ouest : nous avions observé l'an passé l'affleurement au sol de pierres dressées qui pouvaient être interprétées comme l'un des rares vestiges encore en place du mur de fond du Portique Ouest: les travaux de construction de la route à proximité ont beaucoup perturbé le reste de la zone et empêchent d'enquêter ailleurs pour ce portique.

17) Pour le type, voir Historia Numorum Online, $n^{\circ}$ 1833. La légende MY du revers, début de l'ethnique, a donné lieu à des attributions incertaines à plusieurs ateliers de Carie ou d'Ionie du Sud parmi lesquels Myndos, Mylasa, Mygissos et Myonte. Or, la découverte d'un second exemplaire dans les fouilles de la nécropole sud d'Eurômos rend désormais très vraisemblable une attribution à Mylasa. K. Konuk prépare actuellement une étude sur cette série. 


\section{Euromos, Agora 2017}

Sondage $1 \mathrm{~A}$ et $1 \mathrm{~B}$

Vue en plan de la zone de connection entre le portique est et le portique sud (relevé manuel d'après orthophotographie)
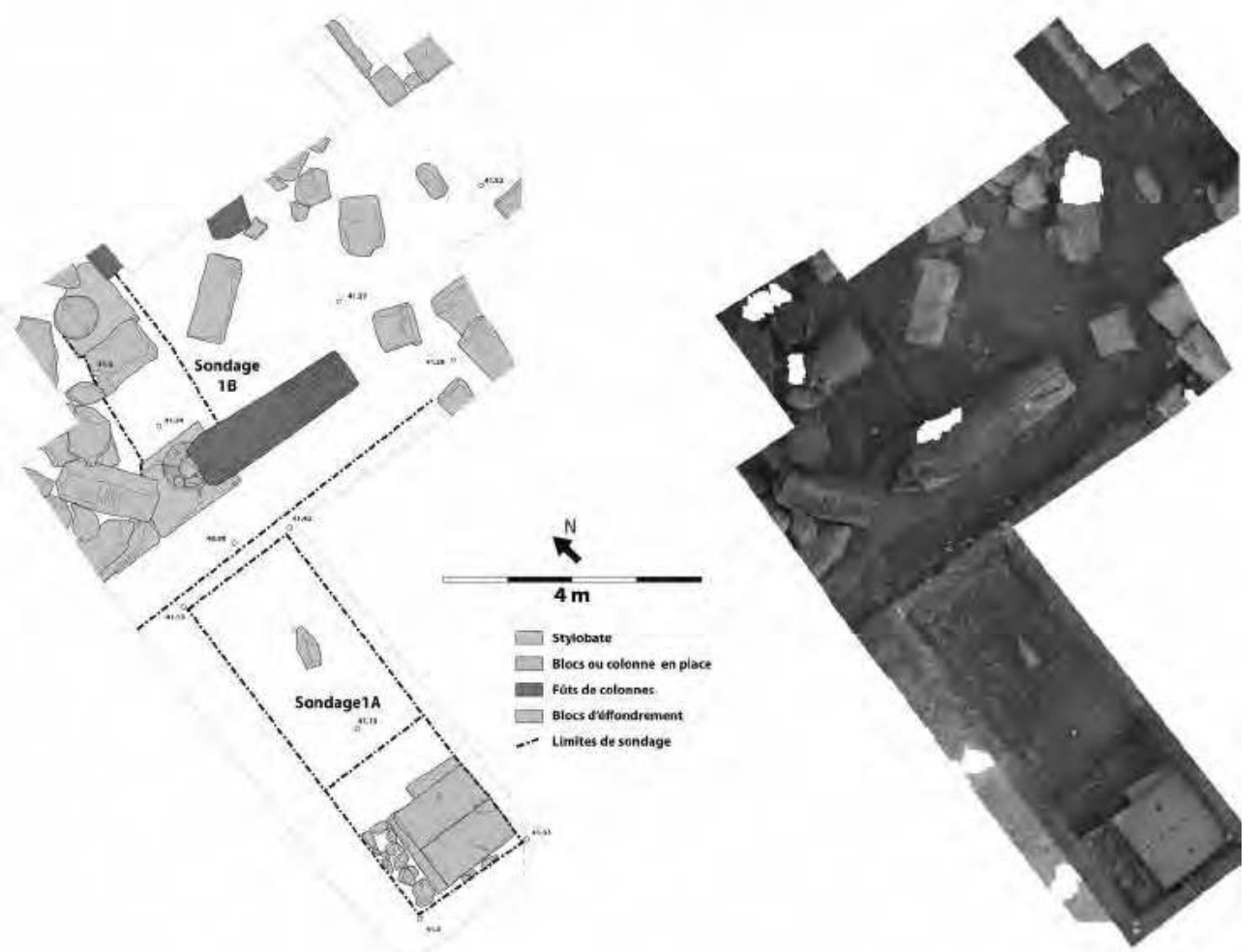

Fig. 11 : Relevé du sondage 1A et 1B à l'angle sud-est de l'agora (relevé : L. Costa ; photo : K. Konuk).

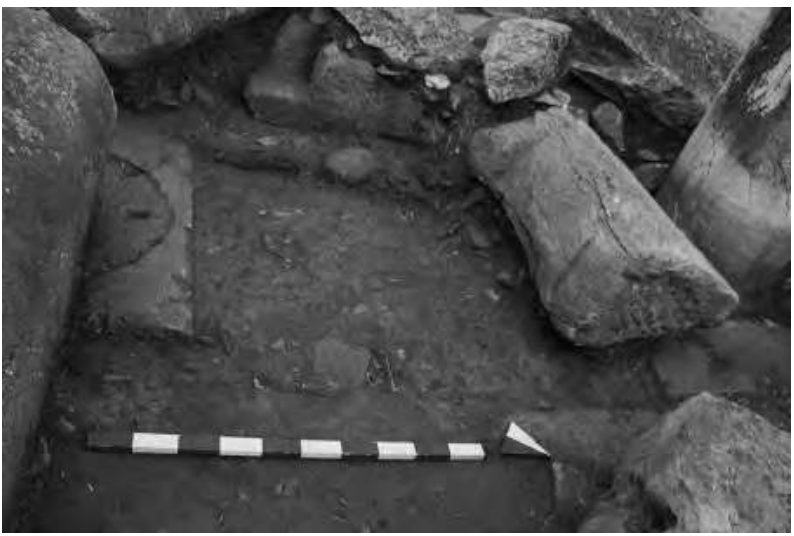

Fig. 12 : Vue du sondage 1B au Sud du Portique Est (Fr. Prost).

Fig. 14 : Vue du sondage $1 \mathrm{~A}$ à l'Est du Portique Sud (L. Talatas).
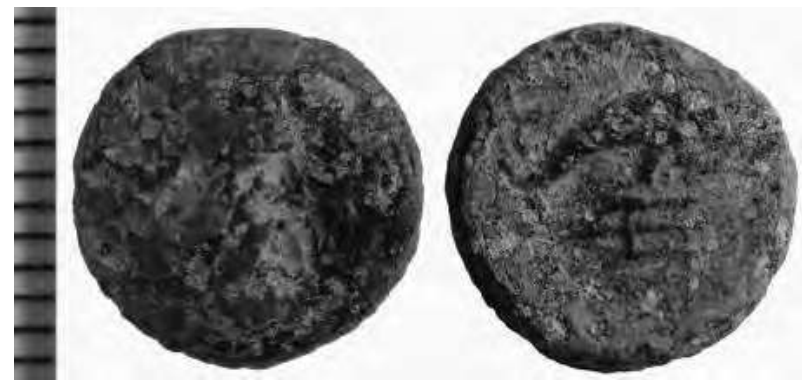

Fig. 13 : Monnaie provenant du sondage 1B (K. Konuk).

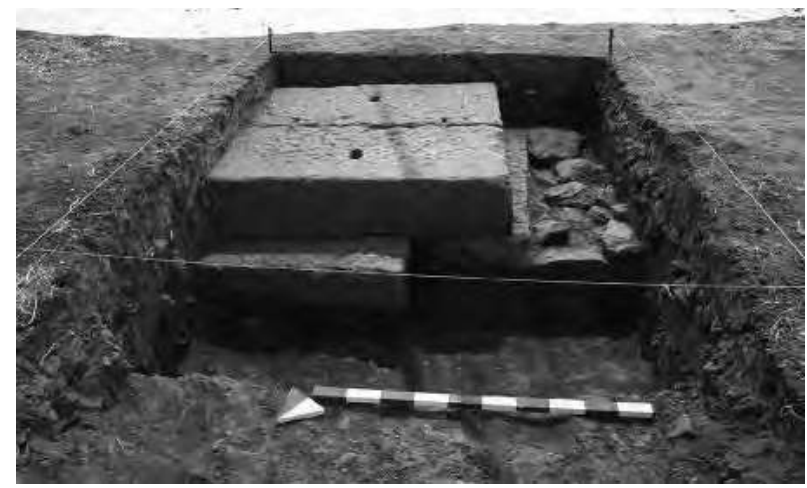


Le premier carré, le plus à l'Est (appelé 2A), a très vite livré les résultats attendus (Fig. 16) : les fouilleurs ont atteint le stylobate, conservé en grande partie mais coupé au Nord du sondage. Le niveau de sol repéré a livré de nombreux fragments de tuiles, des fragments de céramique essentiellement commune et culinaire, ainsi que quelques tessons d'amphores, le tout allant du $2^{\mathrm{e}} \mathrm{s}$. av. J.-C. à l'époque impériale. Une monnaie en bronze a également été retrouvée, portant une contremarque quadripartite sur les deux faces (Fig. 17). Elle présente au droit la tête laurée de l'empereur Septime Sévère, et au revers Athéna Alkidémos debout, tenant une lance dans la main droite et un bouclier dans la main gauche, une chouette à ses pieds $(06 \mathrm{H} ; 8,40 \mathrm{~g})$.

L'autre carré de ce sondage (appelé 2B) a lui aussi livré des résultats intéressants : les blocs qui apparaissaient au sol étaient ceux d'un mur, strictement parallèle au stylobate, et un seuil a pu être dégagé en partie (Fig. 18). La technique de construction du mur, blocs de calcaire équarris disposés sur double cours - et donc tout à fait différente de la construction du mur de fond du Portique Sud- ainsi que la présence d'une porte, de dimensions relativement étroites (le seuil dégagé permet de restituer une porte de 1,60 m maximum), conduisent à penser qu'il s'agit d'une porte de boutique, et non d'une porte dans l'élévation du mur de fond du portique. Cette hypothèse est soutenue par le fait que le mur de fond du Portique Sud se poursuit bien au-delà de l'axe perpendiculaire formé par ce mur percé d'une porte : il y avait certainement une rangée de boutiques à l'arrière du Portique Ouest ; seule est conservée l'entrée de l'une d'elles. Le niveau de sol associé à ce mur interne au Portique est exactement de même nature que celui de l'autre carré : repéré juste à la hauteur des fondations, il contenait du matériel céramique de la fin de l'époque hellénistique et de l'époque impériale, quelques clous et de nombreux fragments de verre coloré provenant essentiellement d'unguentaria de différentes tailles, formes et couleurs. Une monnaie en bronze datable du règne de Caracalla a également été retrouvée (Fig. 19), frappée par la cité de Stratonicée. Elle présente au droit les bustes de Caracalla et de Plautille en regard, avec un autre buste en contremarque, et au revers Hécate debout, tenant une torche dans la main gauche et une phiale dans la main droite $(06 \mathrm{H} ; 28,99 \mathrm{~g})$.

\subsection{Sondage à l'angle nord-est de l'Agora (Sondage 3, inv. 500+)}

Enfin, un troisième sondage a pu être implanté à l'angle nord-est de l'agora (Fig. 20). Bien que contraint par les délimitations des propriétés privées et du chemin placés à proximité de cette zone de l'agora, il a été possible de retrouver la jonction entre le Portique Nord et le Portique Est. L'objectif était de vérifier si, comme au Sud-Est, nous n'avions pas de stylobate et si, par conséquent, une seconde entrée avait été aménagée à l'angle nord-est.

Ce sondage, établi sur un terrain contraint par les blocs architecturaux des portiques effondrés, a la forme d'un rectangle de $3,5 \times 4 \mathrm{~m}$ et a ouvert, très rapidement, sur des murs tardifs (habitations ?) qui avaient utilisé l'angle pour se caler contre la colonnade est ou parallèlement à la colonnade sud (Fig. 21). Surtout, le stylobate sud a pu être atteint, ainsi que le stylobate est. Contrairement à l'angle sud-est, il $\mathrm{y}$ avait donc bien à l'angle nord-est un stylobate qui venait buter contre le stylobate du Portique Sud. Il n'était pourtant pas ajusté à lui : un espace de $10 \mathrm{~cm}$ environ a été laissé entre les deux pierres.

On peut supposer, en tout cas, qu'il n'y avait pas de passage à cet endroit du Portique Est et que, pour le moment, la seule entrée assurée dans l'agora est l'entrée située à l'angle sud-est.

\subsection{Fabrication du plan général des murailles d'Eurômos}

L'objectif de la campagne conduite par L. Costa (CNRS, UMR 7041ArScAn), B. Vergnaud et Cl. Coutelier (Institut Ausonius, Université Bordeaux Montaigne) a été de produire un plan topographique des murailles du site d'Eurômos. Les travaux ont été structurés en deux grands axes.

A) La topographie des sondages archéologiques sur la zone de l'agora. Les trois sondages ont été relevés à l'aide du GPS différentiel par $\mathrm{Cl}$. Coutelier et une couverture photogrammétrique a été réalisée (L. Costa) (Fig. 11, 15, 20). Chaque sondage pourra ensuite être replacé dans le relevé général de l'agora réalisé l'année dernière pour enrichir notre base de données spatiale et asseoir l'analyse architecturale et archéologique des quatre portiques et, ainsi, proposer des restitutions 3D. A ce titre une couverture photogrammétrique complémentaire en drone du stylobate du Portique Sud permettra de préciser la restitution de ce portique.

B) La correction du tracé de l'enceinte. Sur la base d'un plan topographique au $1 / 2000^{\mathrm{e}}$ numérique, réalisé entre 2010 et 2012 car antérieur à la construction de la maison de fouille qui n'y figure pas, un travail d'analyse archéologique et d'examen systématique du tracé de l'enceinte d'Eurômos a pu être engagé. Les parties sud, est et nord de l'enceinte ont fait l'objet d'une observation systématique et d'un 

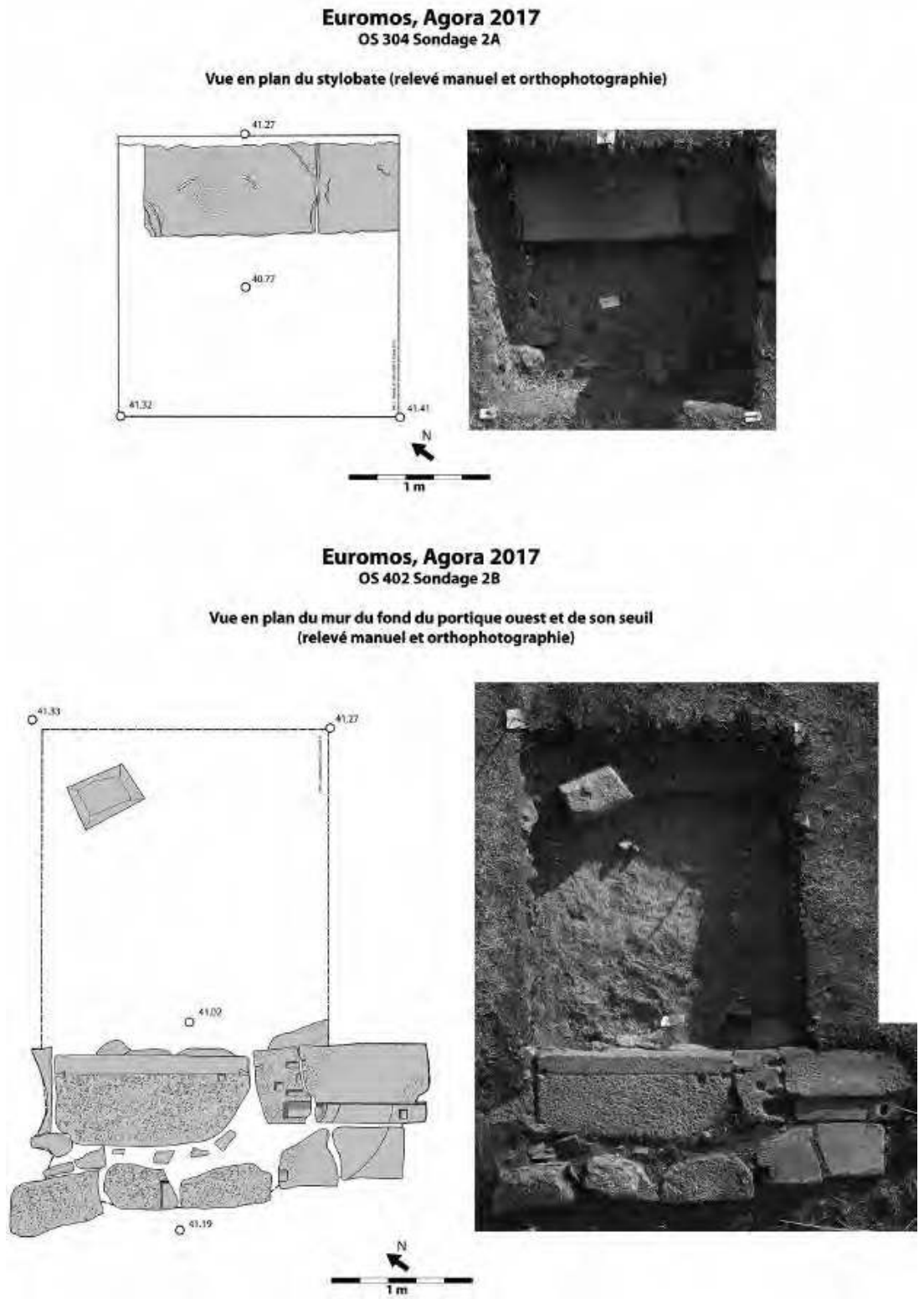

Fig. 15 : Relevé des sondages 2A et 2B dans le Portique Ouest (relevés : L. Costa ; photos: K. Konuk).

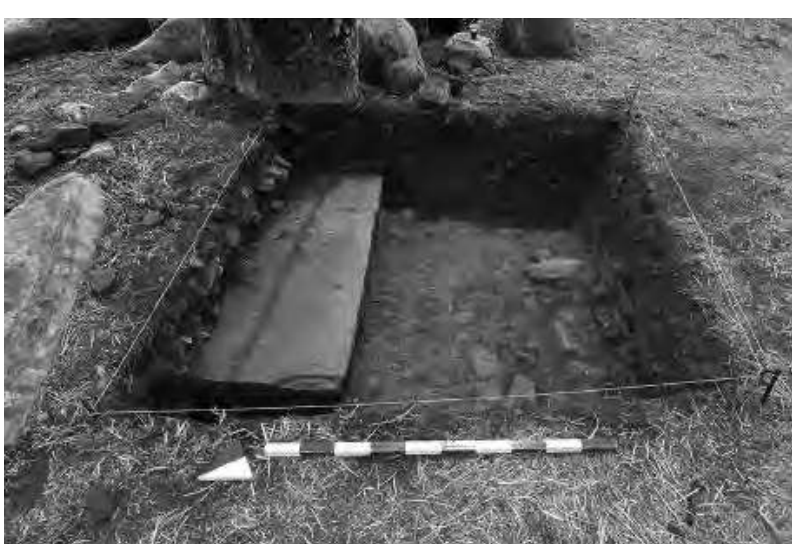

Fig. 16 : Vue du sondage 2A dans le Portique Ouest (L. Talatas).

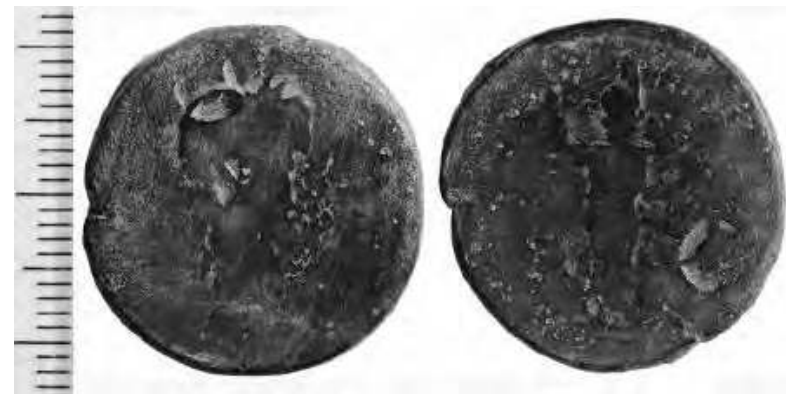

Fig. 17 : Monnaie provenant du sondage 2A (K. Konuk). 


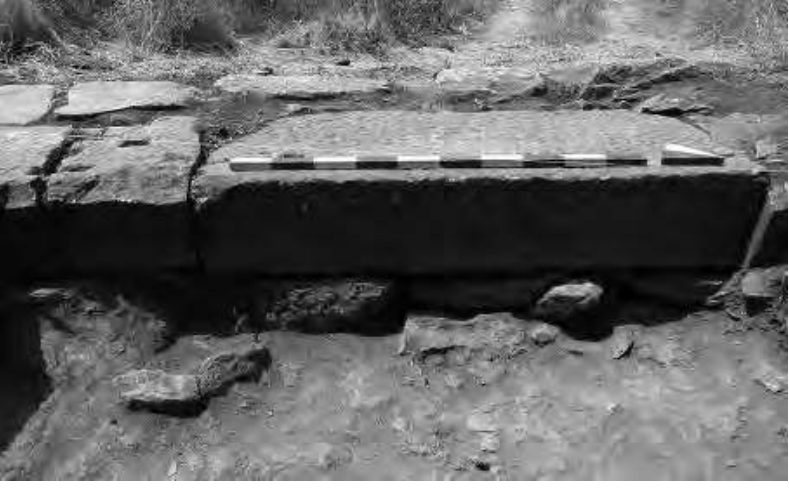

Fig. 18 : Seuil et premiers blocs du toichobate dans le sondage 2B dans le Portique Ouest (E. Le Quéré).

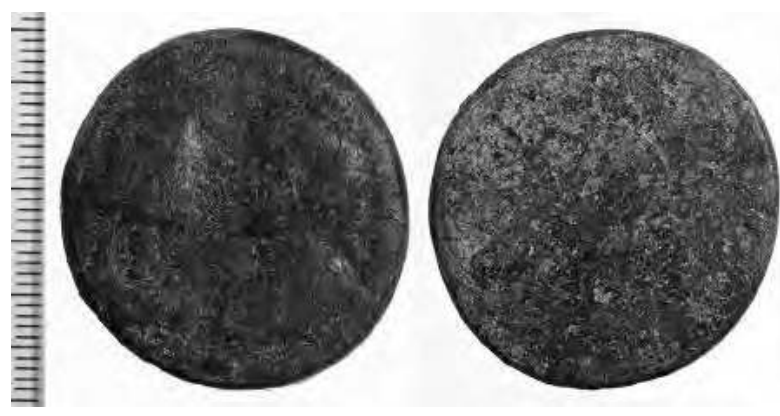

Fig. 19 : Monnaie provenant du sondage $2 B$ (K. Konuk).

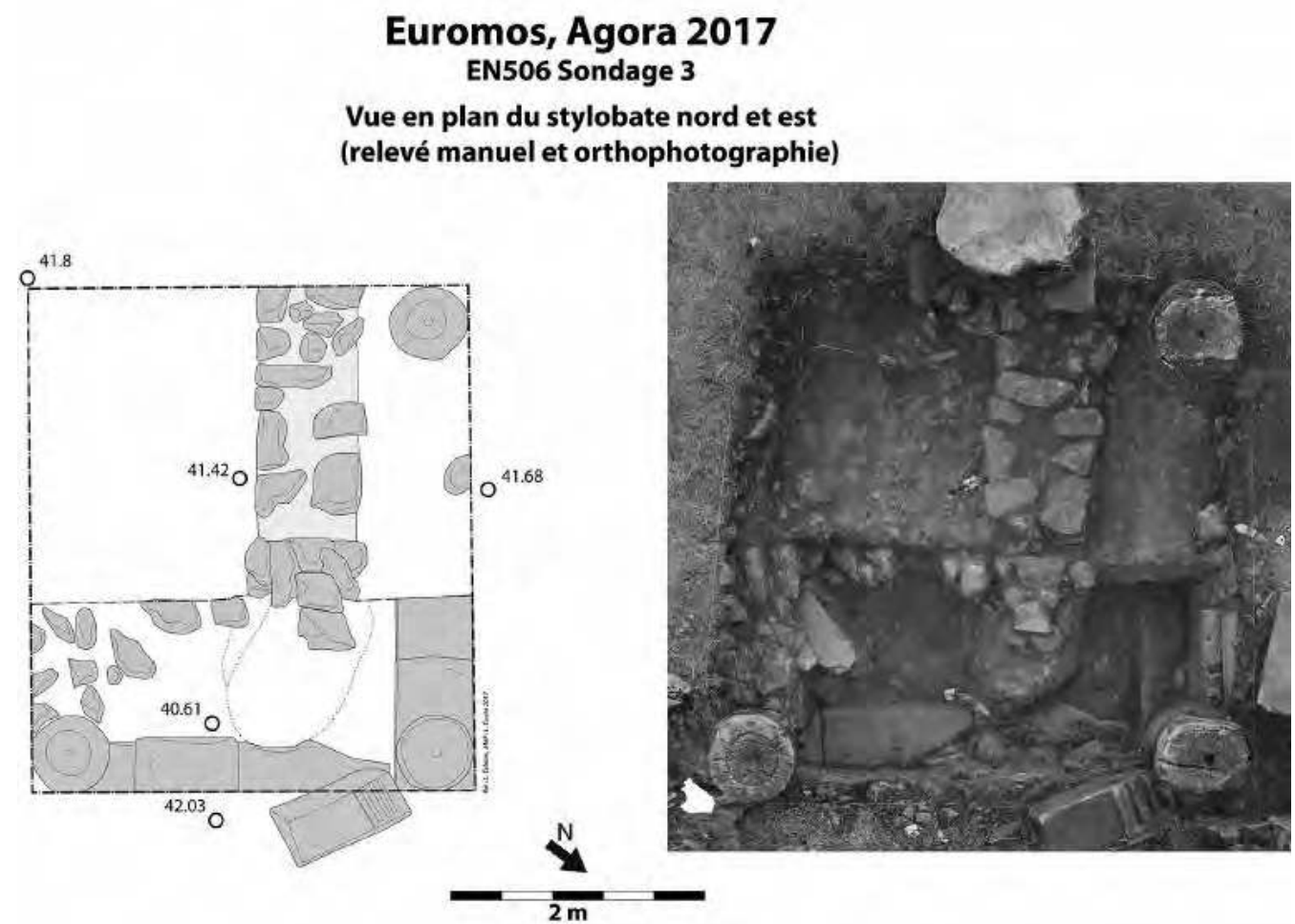

Fig. 20 : Relevé du sondage 3 à l'angle nord-est de l'agora (relevé : L. Costa ; photo : K. Konuk).

Fig. 21 : Vue aérienne du sondage 3 à l'angle nord-est de l'agora (K. Konuk).

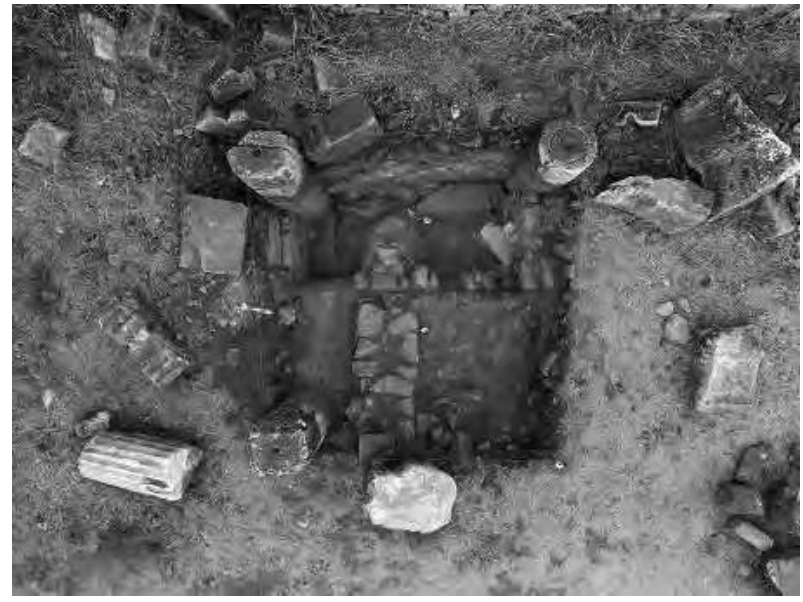




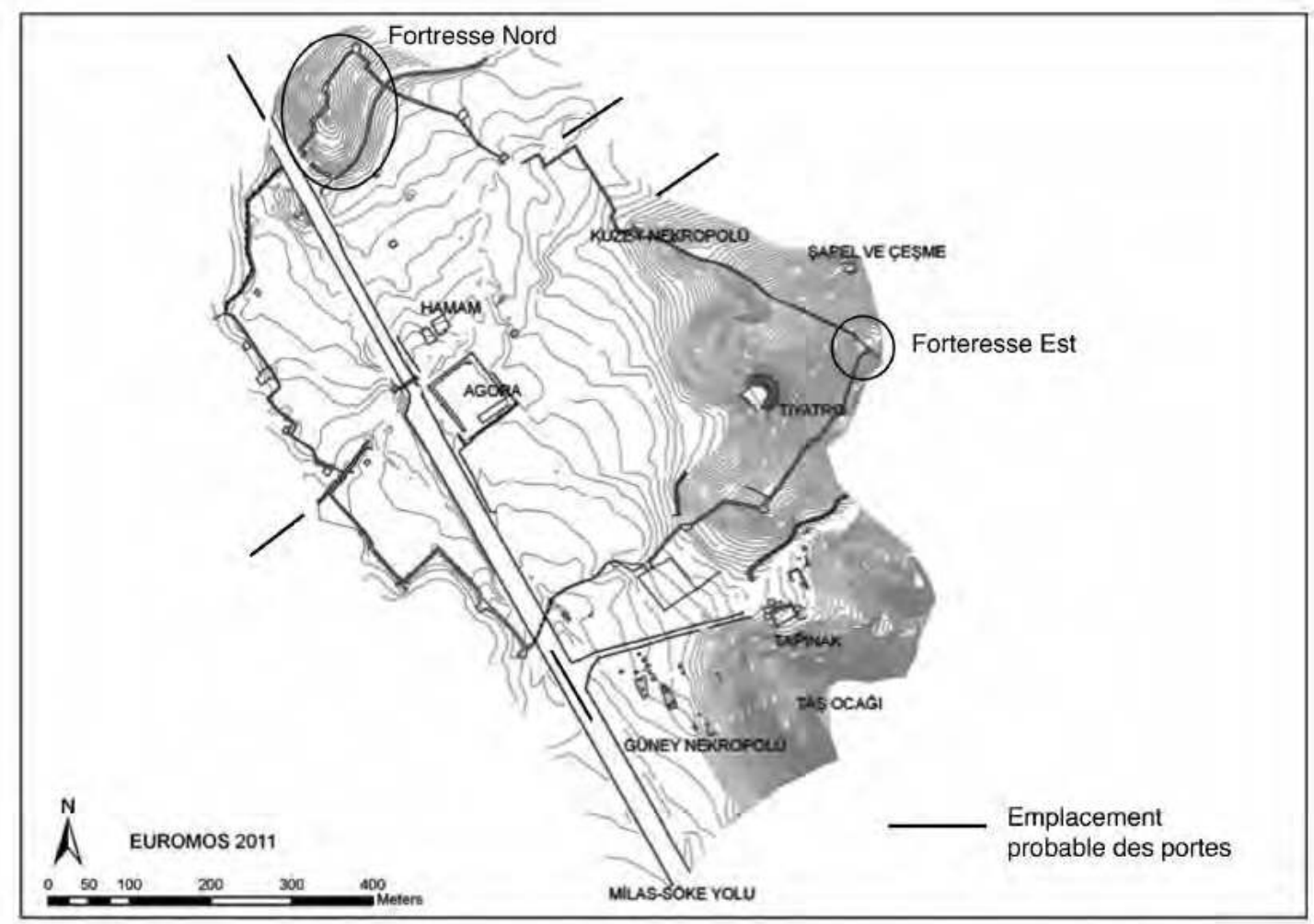

Fig. 22 : Plan de la cité et de ses défenses (Mission archéologique d'Eurômos, 2011).

enregistrement descriptif avec photos et correction des tracés de l'enceinte. Quarante-quatre sections ont été distinguées et ont permis à la fois de mettre au jour différents aménagements non connus jusqu'alors -deux fortins, des poternes, des décrochements, etc.et de formuler des hypothèses sur des portes ou des tours complémentaires. La campagne a été l'occasion de mieux cerner le fonctionnement global de l'enceinte. La partie ouest de l'enceinte, faute de temps, n'a pas pu être analysée cette année.

Il faut souligner enfin que le plan topographique d'Eurômos, d'une grande valeur en termes d'informations, va être restructuré pour permettre la constitution d'une base de données géographiques susceptible de mettre en perspective à la fois les données collectées sur l'agora et celles liées à l'enceinte. Cette démarche permettra de réfléchir de manière globale aux circulations au sein de la cité et à la liaison entre les différents ensembles architecturaux connus de la ville.

\section{LA MURAILLE}

(B. Vergnaud et L. Costa)

La campagne 2017 à Eurômos a consisté en une étude du tracé de la muraille à partir d'un relevé topographique de la cité qui méritait d'être complété par une étude minutieuse et systématique sur le terrain. Il s'agissait notamment de vérifier l'exactitude du tracé de la muraille et de procéder à une interprétation archéologique de certains secteurs peu documentés ; l'objectif étant de produire un plan précis mettant en lumière les particularités techniques du système défensif le plus complexe de la Carie intérieure. La semaine de travail sur place nous a permis d'étudier les deux tiers de la muraille située à l'Est de la route moderne Milas-Söke et nous a permis de faire la découverte de deux forteresses ou citadelles situées sur les deux collines dominant la cité et incluses dans le tracé de l'ouvrage. Le tiers restant, particulièrement difficile d'accès car en terrain privé et obstrué par la végétation, sera étudié dans le cadre de la campagne 2018.

\subsection{Principales données architecturales}

La muraille d'Eurômos est une enceinte urbaine de 2,5 km de long (Fig. 22). Elle est établie principalement dans la plaine mais elle inclut deux collines situées à l'Est et au Nord-Ouest de la cité. L'épaisseur de l'ouvrage oscille entre 2,30 et 3,20 $\mathrm{m}$ de long. Il est pseudo-isodome, construit en une alternance de carreaux et boutisses sur la quasi-totalité du tracé. De manière générale, les blocs 
présentent un bossage en coussin, une ciselure périmétrale et sont chanfreinés (Fig. 23). Cependant, la qualité de traitement des blocs varie d'un secteur à l'autre de la muraille et on observe certaines irrégularités sur le tracé. Des assises isodomes sont notamment visibles dans le voisinage de la tour ronde située au-dessus du secteur du temple. Dans ce secteur, les assises présentent également d'importants décrochements de même que le module des blocs est parfois très irrégulier en comparaison avec le reste de la muraille (Fig. 24).

L'état de conservation de la fortification est très inégal. Comme la quasi-totalité des monuments de la cité, la muraille a servi de carrière et ses blocs ont été réutilisés. Dans certains secteurs, seul le remplissage permet de deviner le tracé du mur, notamment sur la crête de la colline au Nord du temple (Fig. 25). Le mur a totalement disparu sur la partie orientale de la cité (de la colline orientale jusqu'à la maison de fouille située plus au Nord). Les parties les mieux conservées se situent dans le secteur du temple jusque dans le secteur de la tour ronde (secteur sud) et au Nord (secteur du décrochement). Dans ce secteur et celui qui inclut la tour hexagonale, la tour ronde et une tour carrée, le tracé est aisément lisible mais l'élévation est faible (deux assises au maximum) (Fig. 26). Il est difficile d'évaluer la situation dans le secteur ouest, celui situé de l'autre côté de la route. S'il est difficile de le suivre, deux tours, une ronde et une carrée, sont visibles.

Le nombre de tours sur l'enceinte est à ce jour inconnu. Sept tours ont pu être identifiées avec certitude. Les campagnes précédentes se sont notamment intéressées à la section nord-est du rempart (Fig. 27). Celle-ci comprend une tour hexagonale (Fig. 28), une tour ronde (Fig. 29) et une tour carrée ${ }^{18}$. Elles sont dans un faible état de conservation mais leur plan est lisible. De très longues sections de la muraille ne présentent pas de trace de tours, cependant, elles ont très probablement disparu car les systèmes de flanquements étaient indispensables pour assurer la défense, en particulier dans les secteurs où le mur était établi en terrain plat. Il y a peu d'espoir de trouver des tours sur la partie orientale de l'enceinte où le mur a été totalement épierré mais l'espoir reste entier en ce qui concerne la partie ouest des défenses. Il nous semble possible d'évaluer le nombre de tours à environ une vingtaine sur le tracé de l'enceinte. La défense de flanc était également assurée par les nombreux décrochements visibles sur le tracé, en particulier dans la partie sud et ouest des défenses (Fig. 22). Leur présence s'explique dans certain cas par la nécessité d'adapter le cours du mur à la topographie du terrain. Cependant, en terrain plat, les décrochements étaient créés artificiellement pour accroître la défense des zones vulnérables en augmentant les possibilités de tirs de flanc.

\subsection{Les forteresses}

La prospection systématique que nous avons menée en 2017 a également révélé l'existence de deux forteresses ou citadelles situées sur les deux collines comprises dans la muraille (Fig. 22). Dans les deux cas, leur plan est difficile à lire. Celle située sur la colline orientale était probablement équipée de tours et hébergeait peut-être des baraquements (Fig. 30). Quelques murs de faible épaisseur révélés par des fouilles clandestines pourraient appartenir à de tels aménagements. Depuis cette colline, la forteresse possède une vue dominante dans toutes les directions, à la fois vers l'extérieur et l'intérieur de la cité. Elle fut aussi probablement construite pour défendre l'approche relativement aisée depuis l'Est. La seconde forteresse semble avoir été de dimensions très importantes. Construite au sommet de la colline septentrionale, elle surplombait la cité et surveillait l'accès au Nord de la cité. La route moderne ayant sans doute repris en partie le tracé de la voie ancienne, il est très probable que cette forteresse participait à la défense de la porte nord de la cité.

\subsection{Portes et poternes}

La localisation des portes demeure inconnue. Cependant, si l'on se penche sur le tracé du mur, la topographie de la cité et l'orientation de certains espaces urbains en particulier l'agora, il est possible de suggérer que la cité disposait de quatre portes principales liées aux voies de circulation parcourant la cité d'Est en Ouest et du Nord au Sud, suivant les côtés nord et ouest de l'agora. Trois portes secondaires ou poternes ont été découvertes dans le cadre de l'étude de la muraille. Une poterne avait été découverte à l'arrière de la tour hexagonale (Fig. 28), un dispositif presque systématiquement associé à la tour d'artillerie de l'époque hellénistique. Une autre poterne de même type semble avoir été associée à un bastion qui appartenait à la forteresse nord. Le plan de l'ensemble est cependant peu lisible du fait de l'état de conservation mais aussi parce que le secteur a fait l'objet d'une destruction liée à des fouilles illégales. Une porte secondaire a 


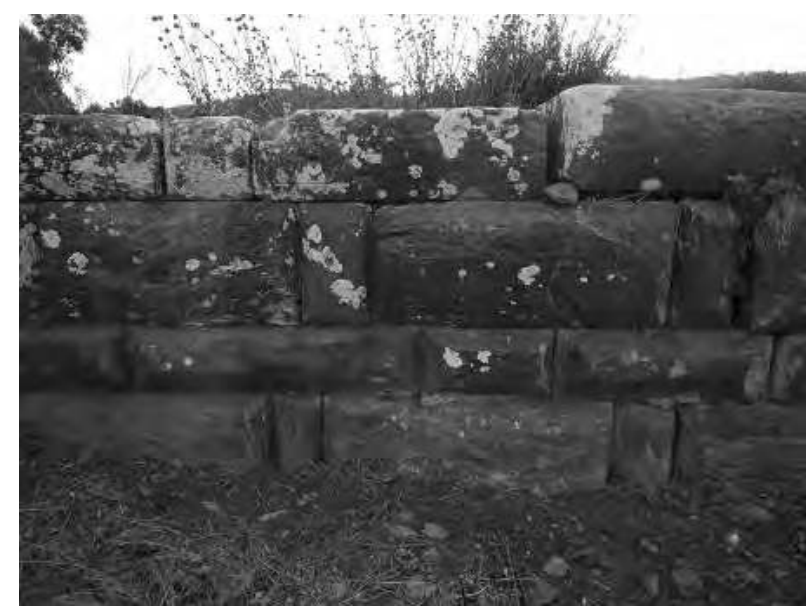

Fig. 23 : Tour carrée sud, détail (B. Vergnaud).

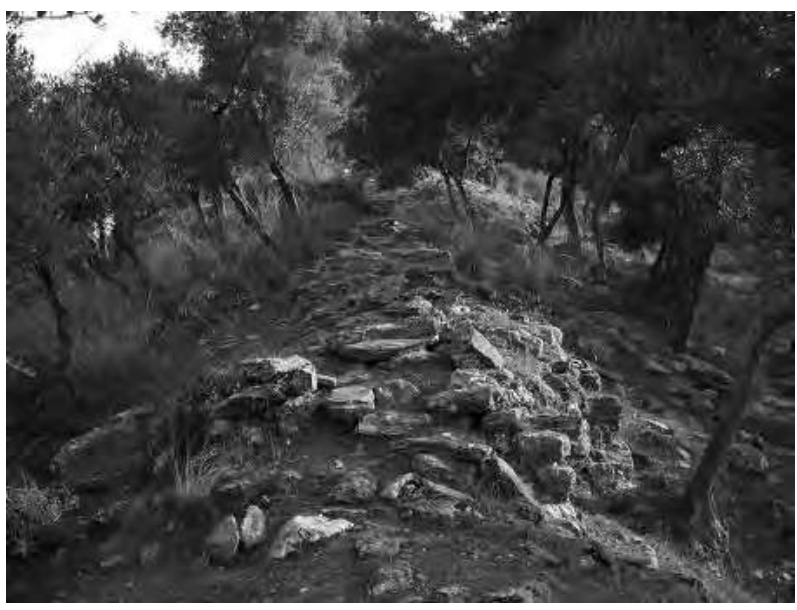

Fig. 25 : Remplissage du mur entre la tour semi-circulaire et la forteresse est (BV).

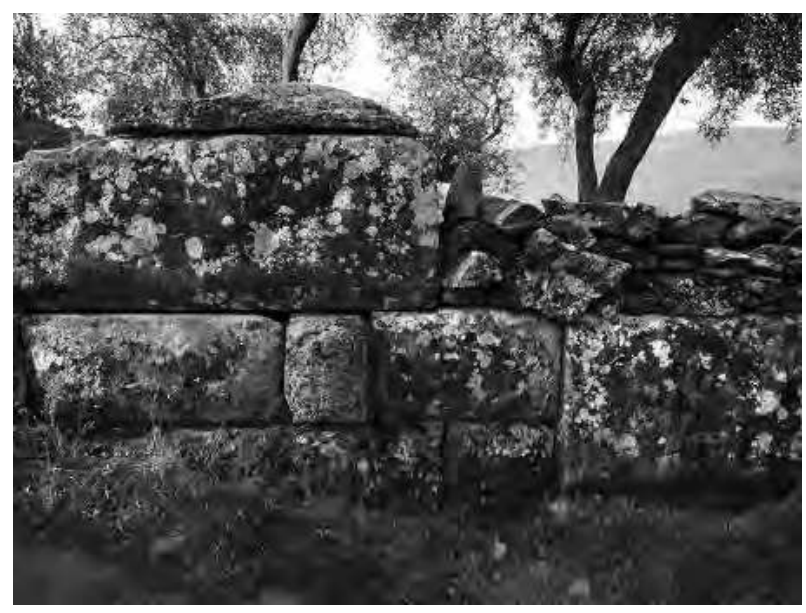

Fig. 24 : Mur dans le secteur de la tour semi-circulaire (BV).

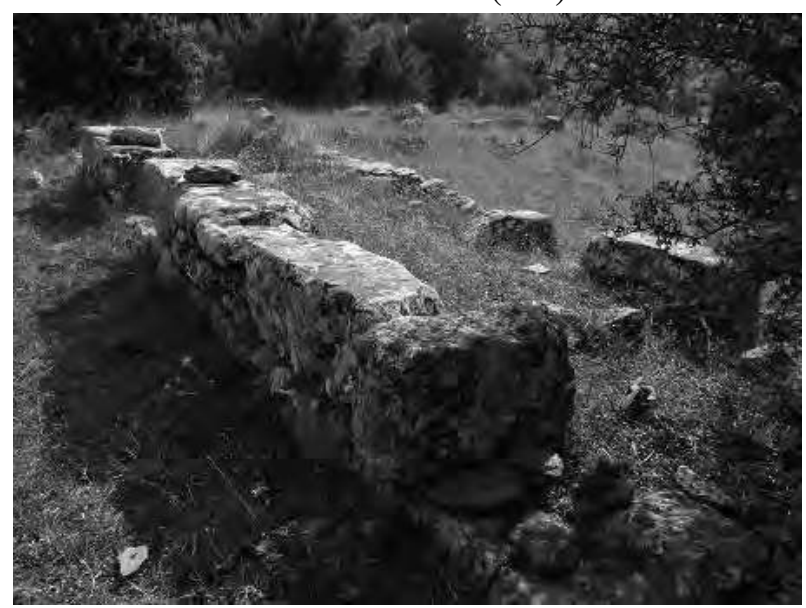

Fig. 26 : Mur dans le secteur nord (BV).
Fig. 27 : Section nord-est du rempart

(L. Costa).

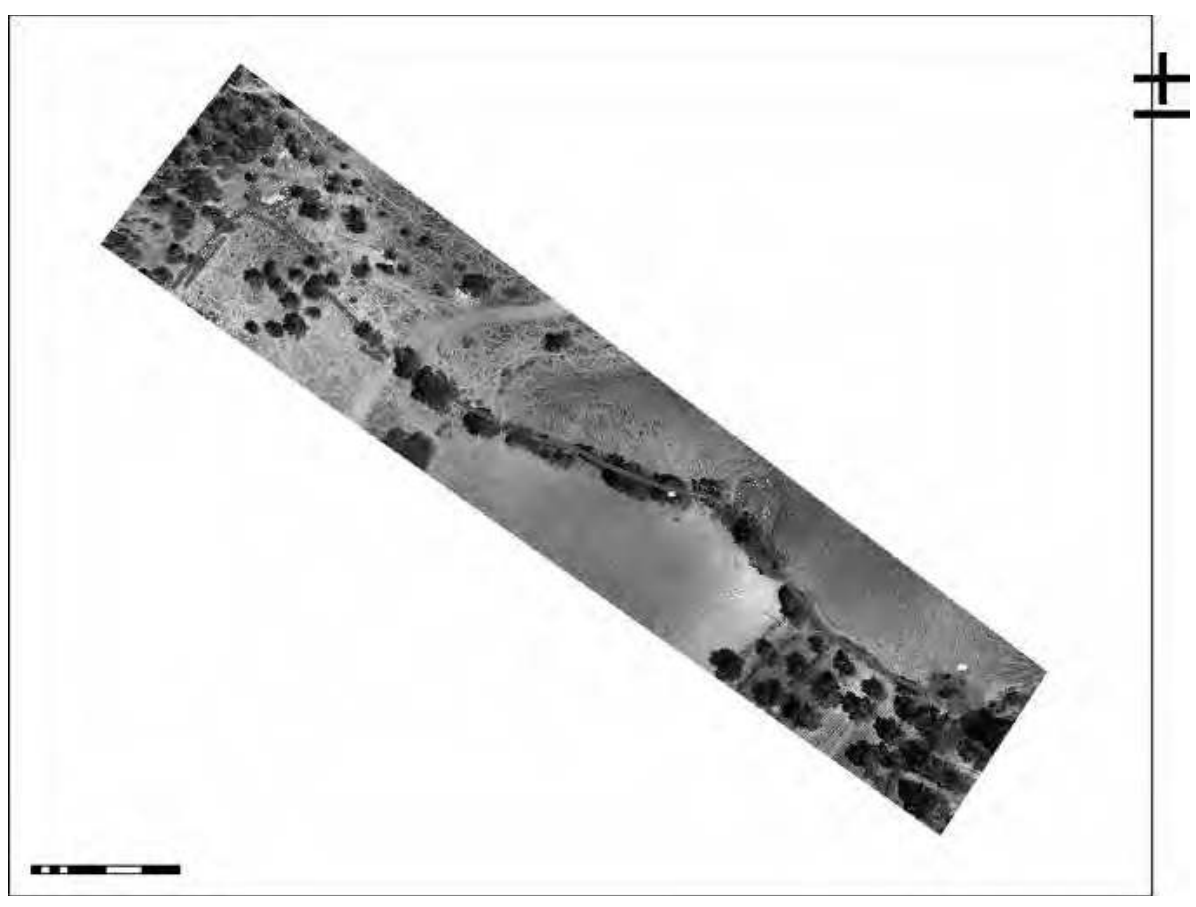




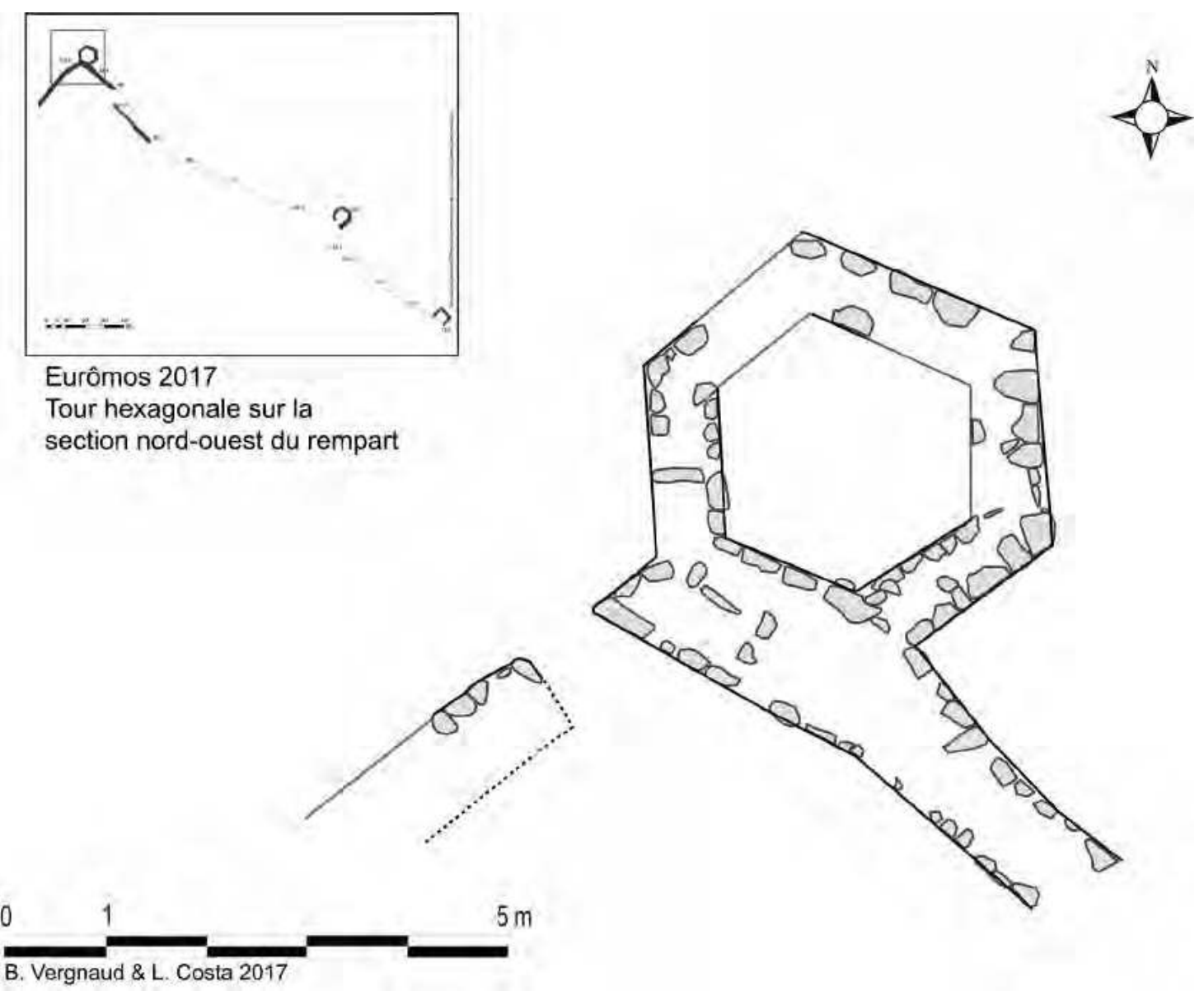

Fig. 28 : Plan de la tour hexagonale (BV/LC).

été découverte à environ $20 \mathrm{~m}$ au Nord de la tour semi-circulaire située en hauteur au dessus du temple (Fig. 31). Elle est suffisamment éloignée de la tour pour ne pas être considérée comme étant directement associée à cette dernière. Sa largeur comme celle de la précédente ne peut être évaluée car l'un des jambages est manquant. Enfin, un autre accès a été identifié qui devait permettre la circulation depuis l'intérieur de la cité vers la forteresse nord. Aucun bloc n'est en place mais sa présence est attestée par des entailles dans le rocher.

\subsection{Rampe et contreforts}

La prospection de la campagne 2017 a également permis de découvrir un dispositif encore inconnu dans le système de défense d'Eurômos. A l'arrière de la tour ronde située dans le secteur nord-est, un long mur a été mis en évidence. Celui-ci s'étend sur une longueur de $20 \mathrm{~m}$ environ en direction du Nord. Il court parallèlement au mur de fortification principal, doublant son épaisseur ${ }^{19}$. L'angle de ce mur au niveau de la tour ronde présente une plumée d'angle (Fig. 32). Cette construction est difficile à interpréter mais il pourrait s'agir d'une plateforme de défense destinée à renforcer la défense dans cette partie de la cité particulièrement vulnérable aux attaques puisqu'établie en terrain plat. Par le passé, de tels massifs construits contre la face interne de la muraille avaient été découverts, mais ils sont de dimensions réduites et peuvent être interprétés soit comme des contreforts, soit comme des supports pour des rampes d'accès au chemin de ronde de la muraille (Fig. 33).

\subsection{Conclusion}

La campagne 2017 s'est révélée extrêmement fructueuse. Elle nous a permis d'examiner de manière minutieuse une très grande partie de l'enceinte urbaine et d'obtenir une image plus précise de son tracé. Nous devrions être en mesure de publier un

19) Cet aménagement sera matérialisé sur le plan final. La végétation qui le recouvre le rend peu lisible sur les photographies. 


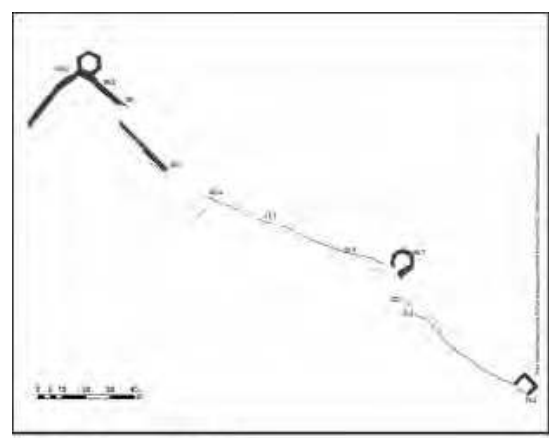

Eurômos 2016

Tour circulaire sur la section nord-ouest du rempart

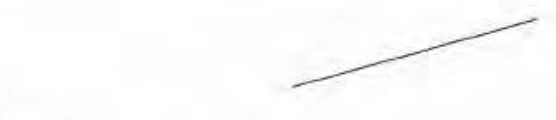

0

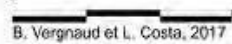

Vergnaud et $\mathrm{L}$, costa. 2017
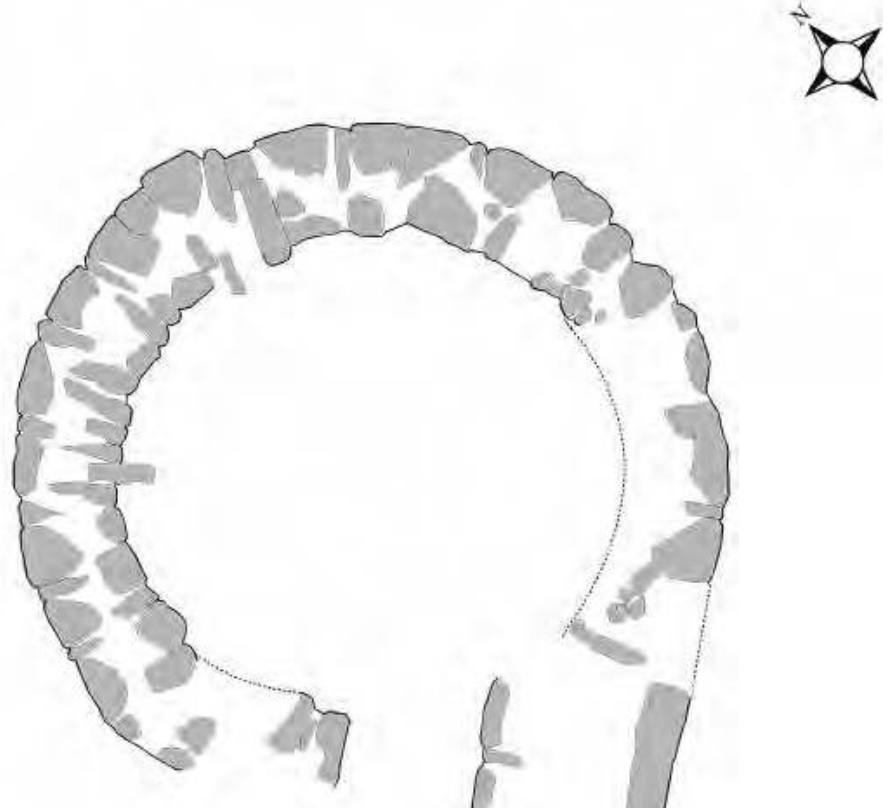

Fig. 29 : Plan de la tour ronde (BV/LC).

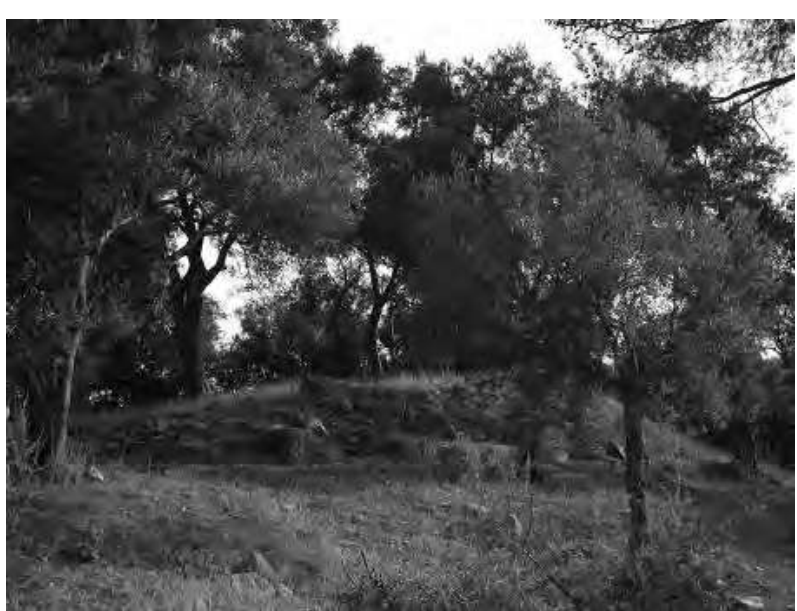

Fig. 30 : Partie sud de la forteresse est vue vers le Nord (BV).

plan archéologique des fortifications de la cité après avoir étudié la partie inexplorée située à l'Ouest de la route moderne. La découverte la plus notable de cette année est celle de deux forteresses comprises dans le tracé de l'enceinte et dominant les collines est et nord-ouest. Il est encore impossible de savoir

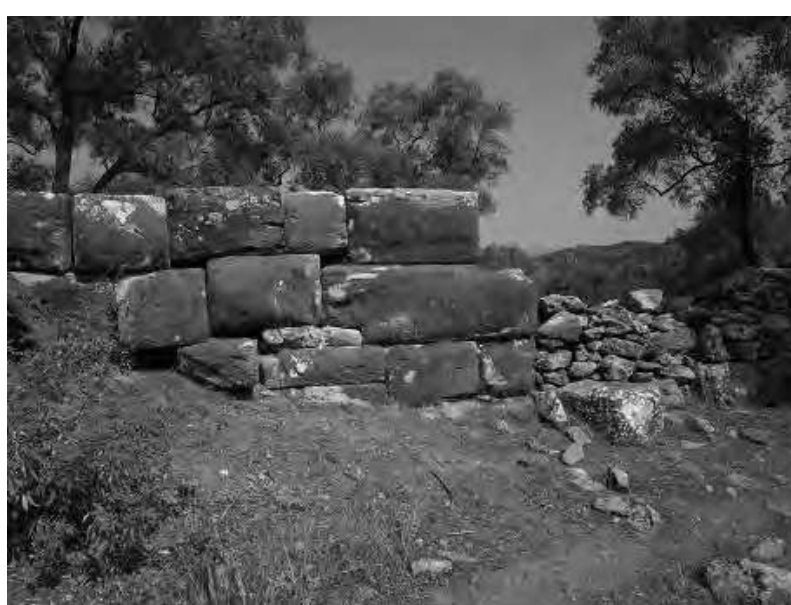

Fig. 31 : Porte secondaire au Nord de la tour semi-circulaire (BV).

quelle était la fonction exacte de ces forteresses et ce que leurs murs renfermaient exactement. La présence de murs à l'intérieur de ces espaces fortifiés suggère que l'espace était occupé par des maisons, peut-être les baraquements des soldats en charge de la défense de la cité. 


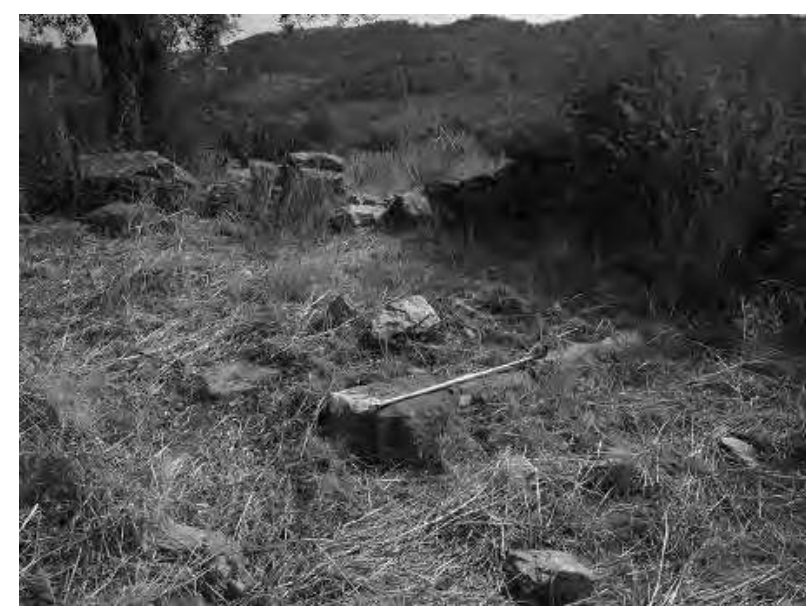

Fig. 32 : Mur de la plateforme avec plumée d'angle derrière la tour ronde (BV).

Dans l'état actuel des recherches et après la campagne de cette année, nous maintenons les observations chronologiques exprimées dans les derniers rapports. Il est vraisemblable que cette enceinte a subi des transformations au cours de son histoire, notamment l'adjonction de tours. La tour ronde étudiée en 2016 semble en effet être un ajout postérieur au projet de construction initial.

\section{LE TEMPLE DE ZEUS LEPSYNOS}

(D. Laroche)

Le travail présenté ici correspond aux séjours sur place en août et au travail de traitement des données en cours. Il s'agissait cette année, après les deux premières missions qui avaient pour objet de dresser l'état des ruines in situ, de commencer l'étude des blocs errants avec comme première étape la réalisation d'un catalogue des blocs non en place disposés sur et autour du temple. Ces blocs sont à peu près pour moitié dans des dépôts constitués dans les années soixante-dix (leur numéro ancien n'étant plus visible, nous ne connaissons pas leur position avant déplacement malgré l'existence d'un plan général), pour moitié dans leur position de chute lors de la destruction du monument.

En plus des 750 blocs numérotés l'an dernier par Sönmez Alemdar, une cinquantaine de nouveaux blocs sont apparus à la suite des fouilles effectuées avant notre arrivée par le directeur de la mission, M. Abuzer Kızıl, soit 800 numéros environ $^{20}$. La position actuelle des blocs, qu'il est prévu de modifier afin de les regrouper par types, ce qui permettra de réaliser des rapprochements matériels,

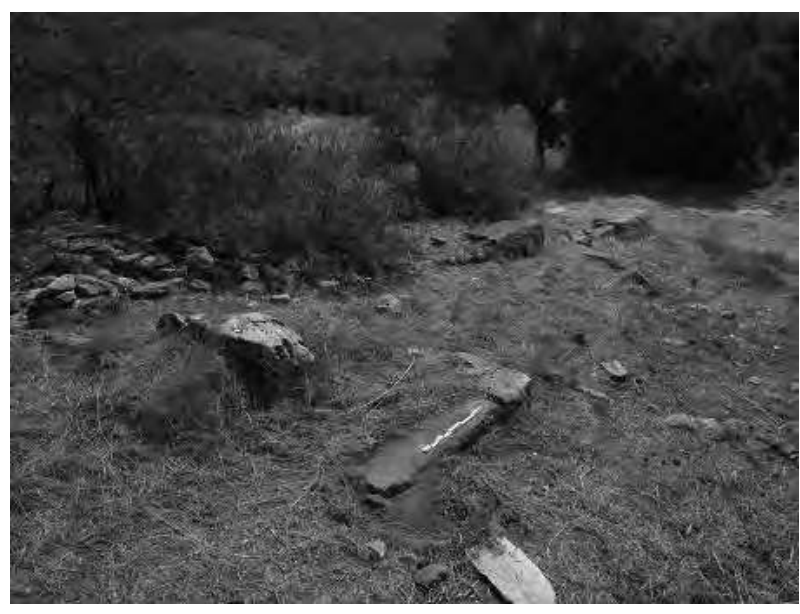

Fig. 33 : Contrefort ou support de rampe dans le secteur nord-est (BV).

a été enregistrée grâce à plusieurs couvertures photographique effectuées par drone par Koray Konuk. Un plan général est en cours de réalisation, à partir de ce relevé 3D (Fig. 34).

Tous les blocs, enregistrés sur un fichier Filemaker, font l'objet d'une première identification, qui inclut un croquis et une photo, reportés sur les fiches. L'intérêt principal de cette première étape est de contrôler la provenance des blocs (car ils ne proviennent pas tous du temple), d'identifier leur type et, si possible, de retrouver leur place exacte dans le monument.

\subsection{L'autel}

Gisant autour de sa fondation, nous avons pu ainsi regrouper un certain nombre de blocs provenant de l'autel (plaques d'oves et parpaings, dont plusieurs angulaires avec pilastre) qui laissent espérer la possibilité d'une restitution graphique de ce monument. Les relevés effectués permettent de dresser un plan de l'état actuel, dont le plan, pratiquement carré, est assez atypique (Fig. 35).

Ces blocs indiquent clairement une date plus haute que celle du temple, hellénistique, probablement à situer vers 330-300 av. J.-C. d'après les trouvailles archéologiques décrites plus haut par A. Kızıl et T. Doğan. L'axe de l'autel n'est pas celui du temple actuel ; il correspond probablement à celui du temple antérieur (sans soute archaïque). Il sera intéressant d'examiner le rapport topographique qu'entretient cet autel avec les bases hellénistiques trouvées à proximité, alignées suivant une direction encore différente de celle du temple et de l'autel. 


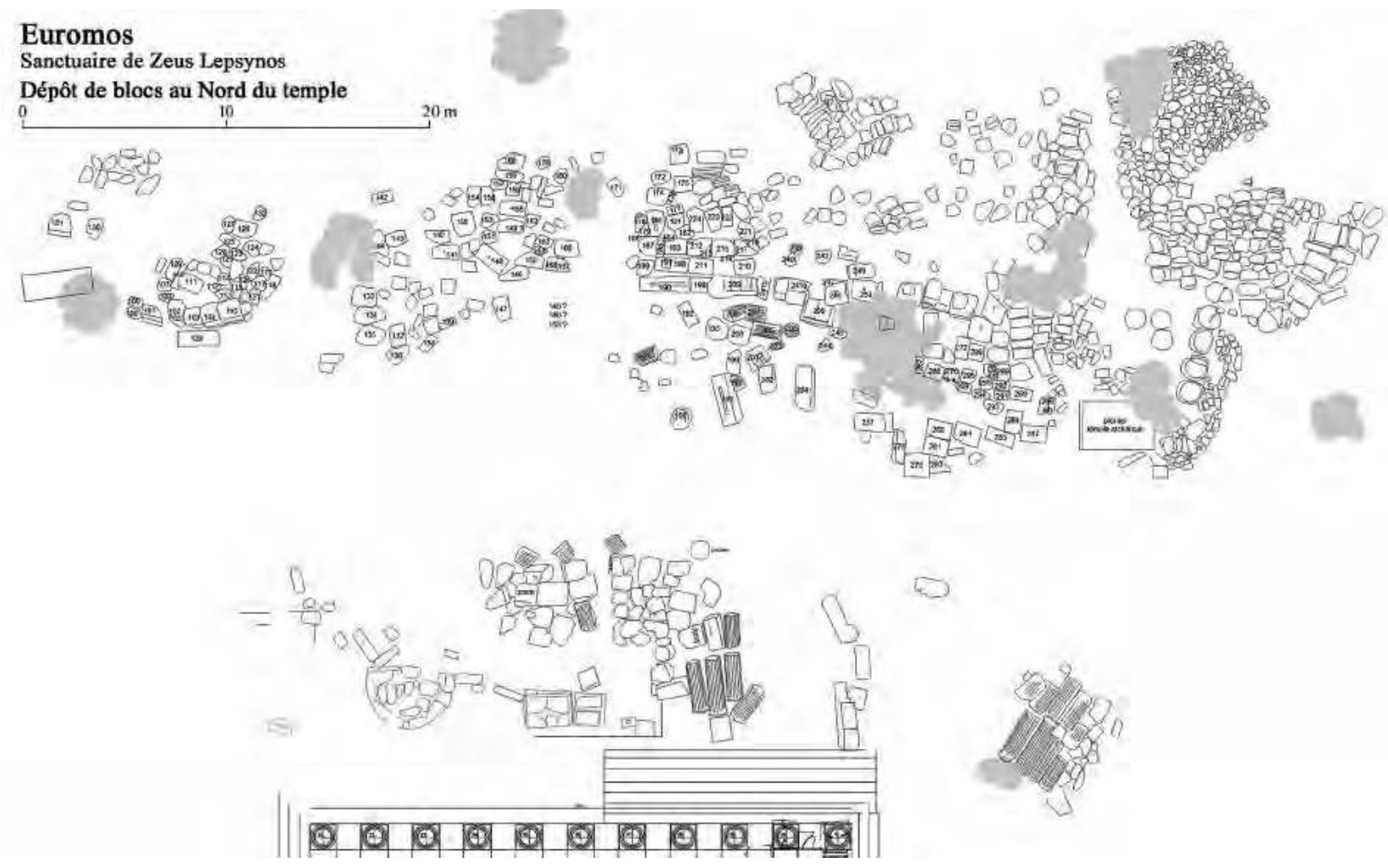

Fig. 34 : Exemple de repérage des blocs errants dans les dépôts autour du temple (D. Laroche).

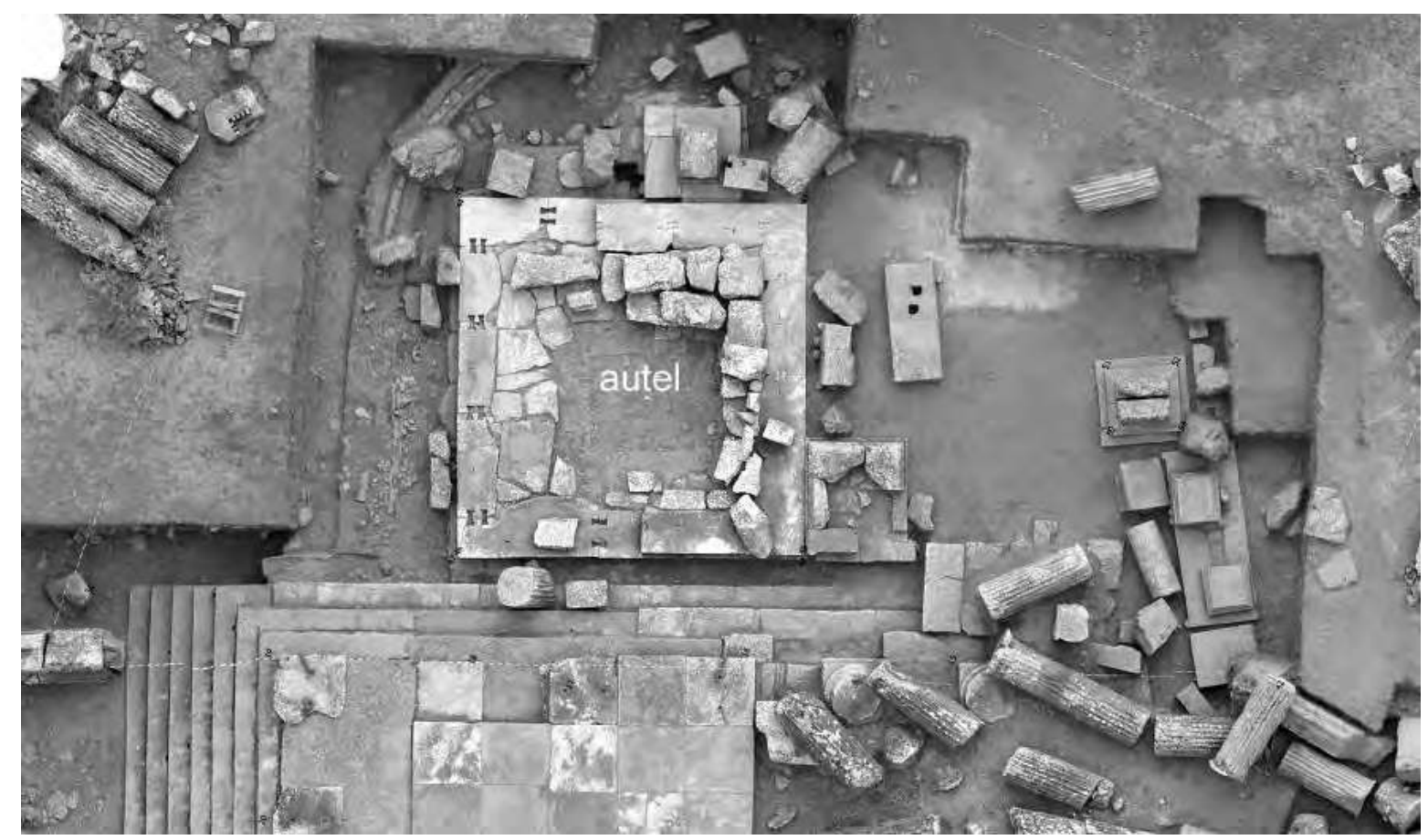

Fig. 35 : Zone de l'autel, orthophoto (C. Duvette, UMR 7044 Strasbourg). 


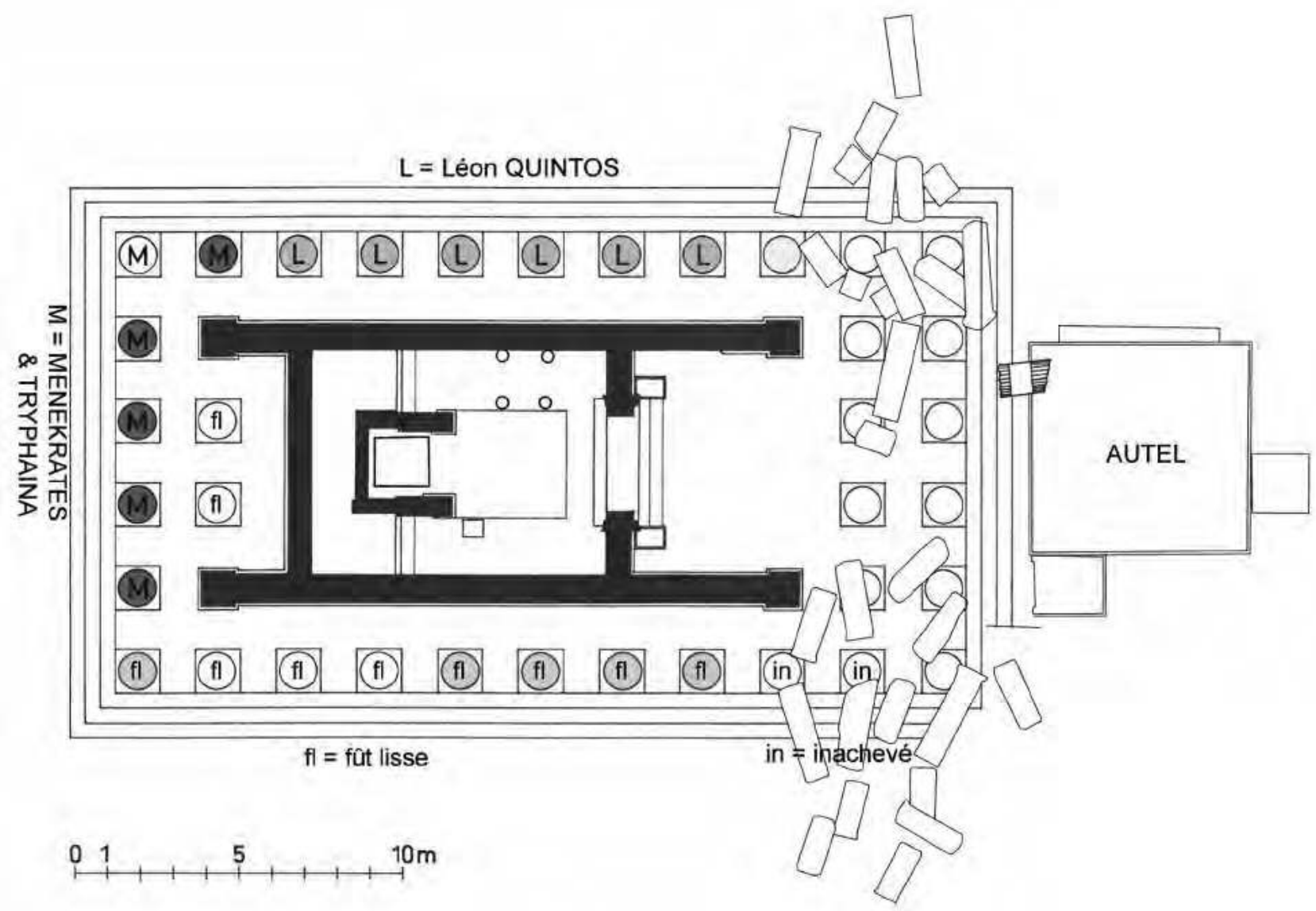

Fig. 36 : Situation des colonnes portant des inscriptions (M, L), des colonnes inachevées (fl, in).

\subsection{Le temple}

La grande majorité des blocs provient cependant du temple ${ }^{21}$, et il apparaît que les colonnades périphériques sont complètes, mais dans un état dégradé pour les blocs tombés à terre (Fig. 36). Les murs sont moins biens conservés, ce qui confirme l'hypothèse avancée l'an dernier sur une réutilisation partielle des blocs des murs à la fin de l'antiquitée ${ }^{22}$. En fait, concernant les murs, il faut prendre en compte les centaines de débris informes, rassemblés dans des pierriers séparés, et pour lesquels l'absence de toute modénature rend l'attribution aux parpaings des murs très probable. Ces fragments concassés montrent que les parpaings ont gravement souffert de la récupération des pierres du temple et, de plus, qu'il est illusoire d'espérer retrouver dans un état reconnaissable une part importante des blocs des murs de la cella.

Sachant que l'élévation extérieure ne pose pas, fondamentalement, grâce à l'état de conservation exceptionnelle de la colonnade ${ }^{23}$, de problème de restitution ${ }^{24}$, nous avons cherché à identifier en priorité les blocs des murs. En dehors de l'assise haute (epicranitis), se terminant par un couronnement, les murs sont composés d'assises hautes (orthostates) et basses, dont nous cherchons à trouver l'agencement exact, afin de restituer l'élévation de la cella. Il paraîtrait logique de tabler sur un appareil semblable à celui qu'on voit sur de nombreux monuments de la région (porte à la double hache de Mylasa,

21) Nous avons bénéficié, comme l'an dernier, d'échanges avec Taylan Doğan (Université de Muğla) qui prépare une thèse sur ce monument, sous la direction d'Abuzer Kizıl.

22) J'ai présenté, sur cette question de la ruine et de la réutilisation des éléments de constructions (pierre, métal, etc.) une intervention au sein du cycle de conférences mis en place par le directeur de la mission, cycle qui s'adresse en priorité aux étudiants français et turcs participant au chantier.

23) A l'exception notable des blocs de crépis, dont peu sont conservés, et qui ont dû être les premiers blocs récupérés après abandon du lieu de culte.

24) Néanmoins les variations importantes dans l'exécution des blocs conduisent à une restitution dont les cotes sont fluctuantes. A cette époque, ces approximations ne doivent pas nous surprendre (Amy et Gros 1979) mais elles créent une difficulté pour le projet de reconstruction, car les blocs ne sont pas interchangeables. 
bouleutérion de Stratonicée pour les sites les plus proches) à savoir une alternance régulière de blocs hauts et bas. Mais l'exemple du temple d'Athéna à Héracleia du Latmos (assises basses intercalées entre trois assises hautes), également très proche, doit nous rendre prudent : plusieurs variantes de cet appareil alterné ont été utilisées dans l'antiquité.

La prochaine étape consistera, une fois identifiés tous les blocs des assises hautes, à mesurer très précisément leur épaisseur aux lits de pose et d'attente, sachant que le fruit du mur ${ }^{25}$ doit en principe nous permettre de restituer leur profil en coupe. La diminution d'épaisseur, sur les assises basses, est trop faible pour être prise en compte, mais, en revanche, leur épaisseur moyenne doit pouvoir corroborer la proposition de restitution des murs en coupe. Concernant les orthostates, j'ai écrit "en principe" car, dans la pratique, si les trois murs ont des épaisseurs distinctes, le classement des orthostates est rendu compliqué par l'incertitude pour assigner tel bloc à tel côté de la cella. D'où l'importance de consigner la place actuelle du bloc qui, dans le cas où il n'a pas été déplacé lors des travaux de dégagement menés par Ümit Serdaroğlu, témoigne de son emplacement d'origine. Pour les blocs déplacés par Ü. Serdaroğlu, qui se trouvent dispersés dans les dépôts périphériques, on peut raisonnablement tabler sur le fait qu'une majorité provient du mur nord.

Un certain nombre d'encastrements (parfois de grandes dimensions) sur ces blocs de murs ne trouvent, pour l'instant, pas d'explication. Certains seulement sont des réparations.

D'autres problèmes sont apparus, notamment la difficulté d'attribuer au temple des blocs dont les dimensions ne conviennent pas. C'est par exemple le cas de caissons de plafond qui ne semblent pas provenir de la couverture du péristyle, qui semble avoir été en bois. Leur trop faible dimension oriente soit vers l'autel (hypothèse peu probable) soit vers le naiskos qui se trouve dans la cella et qui contenait probablement le xoanon, ou du moins la statue de culte la plus ancienne de Zeus Lepsynos. Cette incertitude concerne également d'autres blocs non identifiés avec certitude et qui pourraient provenir de l'une ou l'autre de ces constructions d'échelle moindre (encadrements de baies : fenêtre ou porte ?).

Je signalerai également une observation que l'on peut faire sur l'état d'achèvement du temple. On admet généralement que les colonnes qui comportent une inscription relative à un/e donateur/trice montrent que certaines colonnes étaient financées par des évergètes, d'autres pas. Ce raisonnement ne fonctionne pas car on voit bien que la donation mentionnée dans les inscriptions concerne les colonnes cannelées, les colonnes lisses ne portant pas d'inscription. La donation concerne donc l'achèvement de la colonne avec taille des cannelures, opération extrêmement coûteuse ${ }^{26}$, mais qui pouvait se faire au moment voulu, après achèvement du temple. La répartition peu logique des financeurs (chacun six colonnes placées sans souci de logique architecturale) montre cependant qu'on a privilégié les colonnes visibles de loin lors de l'approche du temple (côtés ouest et nord) ; le travail de ravalement des colonnes de façade était en cours, mais celui de la colonnade sud (pourtant celle qui recevait le plus de lumière) n'a pas été réalisé.

Cela montre que le financement des cannelures était davantage une démonstration de piété qu'une nécessité esthétique ou architecturale ${ }^{27}$. Deux lots de six colonnes ont été financés par des particuliers. Trois lots supplémentaires de six colonnes auraient permis de compléter l'opération sur les trente colonnes que comporte l'édifice. Ajouté à l'observation, faite l'an dernier, de l'absence de fronton à l'Ouest ${ }^{28}$, nous avons là un exemple de la difficulté, à l'époque impériale, d'achever les programmes de rénovation des sanctuaires entamés surtout sous Hadrien, à qui on attribue la construction de nombreux temples, du fait de son philhellénisme et de sa propension à installer son culte auprès de celui de Zeus.

L'étude du temple, entreprise avec des moyens pour l'instant réduits, nécessitera un personnel plus nombreux, ne serait-ce que pour le relevé des blocs épars. En effet, si le relevé des blocs les mieux conservés suffit en principe pour restituer l'allure du bâtiment, pour une restauration, l'état matériel de chaque bloc doit être renseigné, ce qui nécessite une observation et un enregistrement manuel et numérique.

25) Diminution de l'épaisseur du mur obtenue par l'inclinaison de la face extérieure.

26) Opération connue par les comptes d'Epidaure : Roux 1961.

27) Les cannelures du trésor des Athéniens à Delphes, reconstruit en 1905, ne furent taillées qu'en prévision des fêtes du centenaire de l'Ecole d'Athènes, en 1946, soit 40 ans après la réédification du bâtiment !

28) Aussi surprenant que cela puisse paraître, il n'y a aucun doute que ce fronton, dont les blocs ne présentaient pas le moindre intérêt en terme de réutilisation (voir l'état complet du fronton est) n'ont jamais été taillés ni mis en place. On peut, en théorie, imaginer une toiture à pan remplaçant un fronton. Ce trait d'archaïsme serait toutefois surprenant pour un édifice d'époque impériale. L'existence d'une couverture dont pourtant aucun fragment, ni en pierre ni en terre cuite, n'a jamais été retrouvé, semble attestée par la présence d'encoches pour une charpente à l'arrière des chéneaux, sauf si ces encoches avaient été préparées sans que la charpente soit mise en place. 
Le premier objectif est de pouvoir réorganiser rapidement les dépôts de façon méthodique en regroupant les blocs de la même espèce, afin de réaliser les rapprochements et, quand c'est possible, le recollage des fragments jointifs.

Clément Coutelier (Institut Ausonius, Bordeaux), topographe de la mission, a relevé une série de points géodésiques sur le temple et sur l'autel, destinés à caler les différentes photos 3D prises l'an dernier et complétées par une nouvelle couverture réalisée avant le lever du soleil pour corriger les "trous" générés par les ombres propres et les ombres portées sur les clichés de l'an dernier. Ces nouvelles images seront traitées, comme les précédentes, avec l'aide de Catherine Duvette, architecte archéologue CNRS, membre de l'UMR Archimède de l'Université de Strasbourg. Le programme "Sanctuaires antiques, questions environnementales", qui inclut le site d'Eurômos dans ses préoccupations a été accepté comme composante de l'axe 2 de ce laboratoire. Nous sommes, à partir de ces travaux de terrain, en train de construire un modèle 3D de l'état actuel du temple qui, confronté à la maquette théorique du temple dans son état initial, permettra d'élaborer divers scenarii d'intervention sur l'édifice.

\section{EURÔMOS DU HAUT}

(K. Konuk et Cl. Coutelier)

Sis en hauteur à environ un kilomètre et demi à vol d'oiseau au Nord-Est du centre urbain d'Eurômos, ce site d'habitat inédit nous est connu depuis 2014. Il est établi à l'Ouest d'une ligne de crête (à environ $260 \mathrm{~m}$ d'altitude) qui est visible depuis le site du bas. Des travaux d'arasement au bulldozer par le service des forêts afin d'aménager une bande pare-feu, ont fortement endommagé le site le long de la ligne de crête. Comme nous l'avions constaté les années précédentes, le site est malheureusement victime de fouilles clandestines dont de nombreuses traces sont visibles en divers endroits du site (Fig. 38). Notre travail en 2017 a principalement consisté à relever à l'aide d'un GPS différentiel (Trimble Geo XH 6000) le tracé du chemin antique qui est bien conservé en contrebas du site vers l'Ouest, ainsi qu'à effectuer le relevé des structures défensives du site et de quelques lignes de murs de structures diverses (Fig. 37). Nous avons également procédé à une campagne de photographies aériennes de toute la zone d'habitat et des alentours au moyen du drone de la mission.

Situé en contrebas à l'Ouest du site et orienté sur un axe Nord-Sud, le chemin qui date vraisemblablement de la période antique, peut être suivi sur presque trois kilomètres et permet de rejoindre le centre urbain d'Eurômos (Fig. 39-40). On perd parfois sa trace lorsque par exemple le terrain présente un dénivelé important comme il en existe un au Sud du site (Fig. 37). Au Nord, la piste moderne rejoint le tracé du chemin antique dont les structures ont été oblitérées par celle-ci à une époque récente (Fig. 37). Nous avons pu relever le tracé de ce chemin sur une longueur d'environ un kilomètre.

Le site présente une muraille qui est très mal conservée mais dont le tracé peut être suivi sur la quasi-totalité de sa partie occidentale. La plupart du temps, seul le remplissage permet de distinguer le tracé du mur. Sa partie orientale a été fortement endommagée par les travaux d'arasement qui ont suivi la ligne de crête et dont le tracé correspond à celui de la muraille. En contrebas, à l'Est de la bande forestière pare-feu, se trouve une tour dont quatre lignes de blocs sont conservées (Fig. 41). Sa partie sud a été réaménagée à une époque récente avec des blocs plus petits (Fig. 42). La bande parefeu passant un peu au-dessus de la tour, les murs qui rejoignent celle-ci ont été épargnées, même si en surface on ne les distingue plus que par leurs blocs de remplissage (Fig. 43). Au Nord de la tour et de ses aménagements immédiats, le mur a été complètement détruit, bien qu'il soit raisonnable de supposer qu'il continuait jusqu'à un endroit présentant une concentration de tuiles et un angle de murs (tour nord ? Fig. 44). Au delà de cet endroit, la présence de céramique décroit d'ailleurs fortement. Au Sud du site, la muraille forme une excroissance rectangulaire qui suit en fait la forme naturelle du relief (Fig. 45). A l'intérieur, on peut distinguer en surface un certain nombre de lignes de murs de divers bâtiments (Fig. 46).

L'état de destruction avancé de cette muraille suscite naturellement des questions. La quasi-disparition de sa partie orientale est le fait d'aménagements modernes ; pour ce qui est des autres parties, en revanche, la dégradation s'explique plus difficilement. Etant donné que l'accès au site n'est pas particulièrement aisé, l'on peut se demander si cette muraille n'a pas été sciemment démantelée à une époque qu'il n'est pas possible de déterminer actuellement. En dépit de son mauvais état, nous sommes tout de même parvenus à suivre le mur sur environ $950 \mathrm{~m}$ et l'on peut estimer sa longueur d'origine à environ $1.750 \mathrm{~m}$. La superficie intra-muros est d'environ $78.500 \mathrm{~m}^{2}$. Pour l'heure, nous n'avons aucune indication chronologique sur l'époque de sa construction, mais nous espérons que nos futures campagnes permettront d'apporter quelques éléments de réponse. 


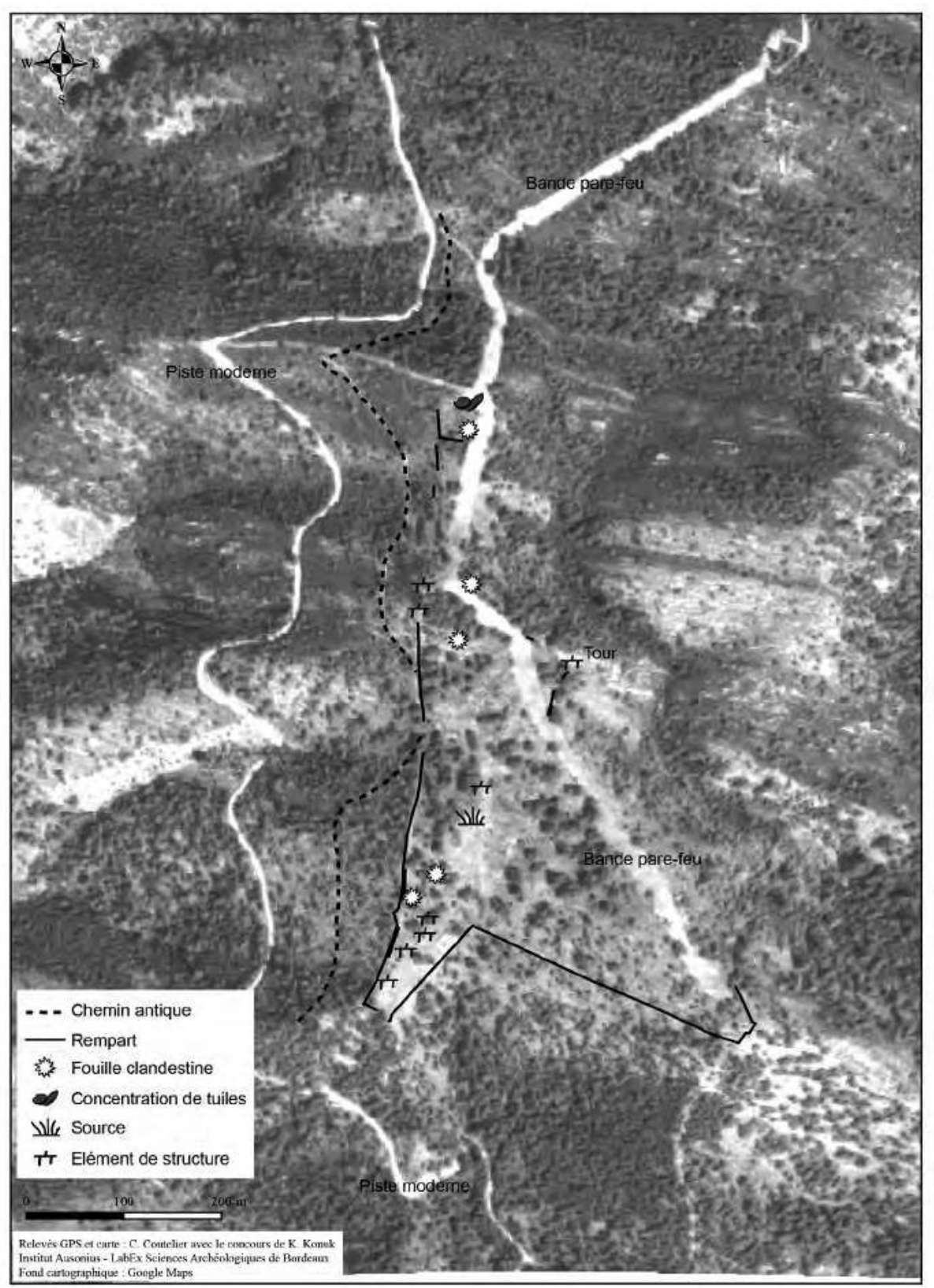

Fig. 37 : Carte d'ensemble du site d'Eurômos du haut (Cl. Coutelier et K. Konuk).

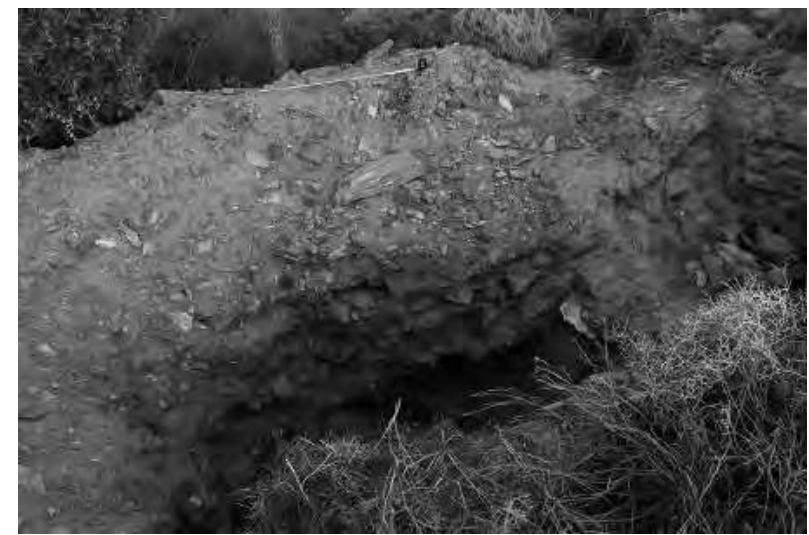

Fig. 38 : Fouilles clandestines récentes (K. Konuk).

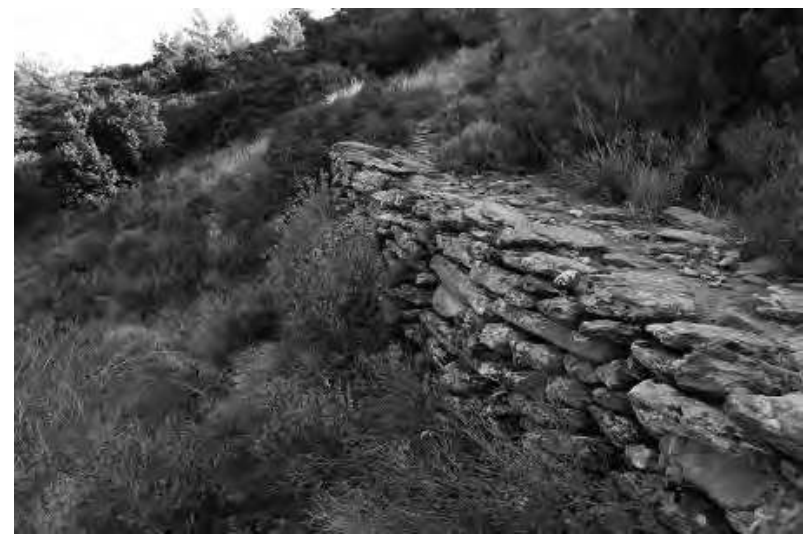

Fig. 39 : Vue latérale du chemin antique en contrebas à l'Ouest du site (K. Konuk). 


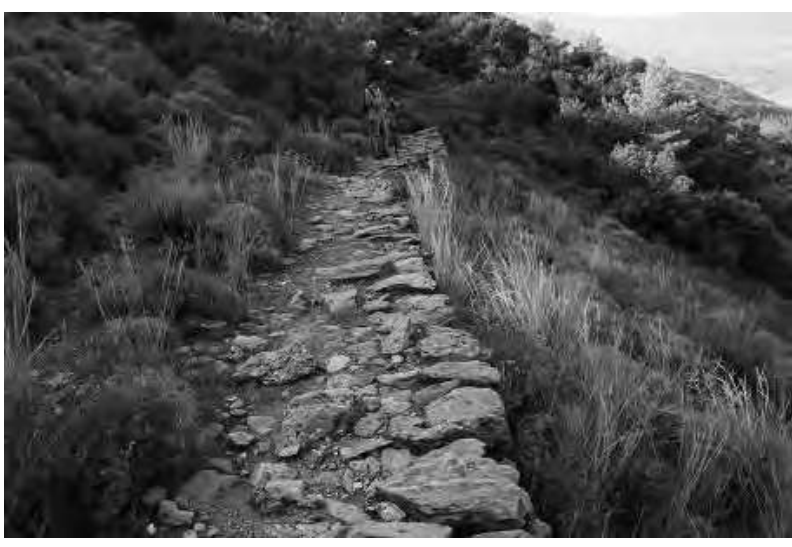

Fig. 40 : Chemin antique en contrebas à l'Ouest du site $(\mathrm{K}$. Konuk)

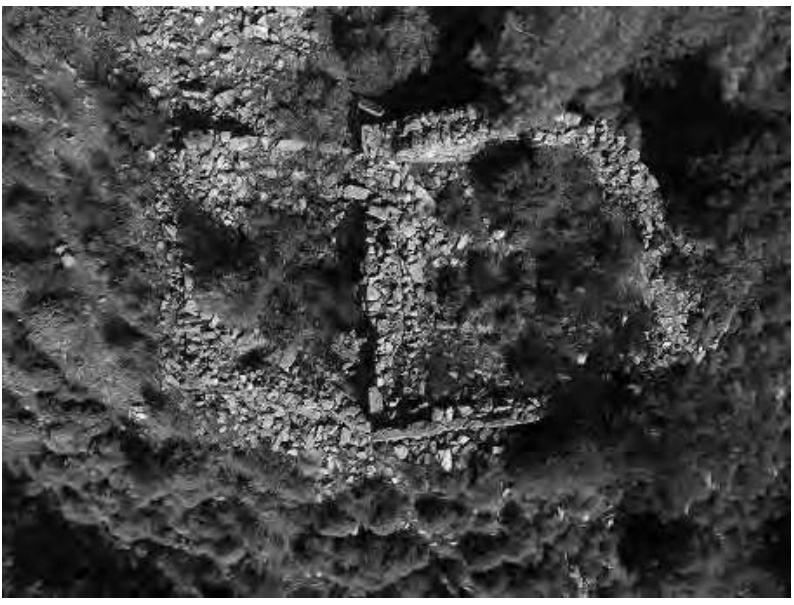

Fig. 42 : Vue zénithale de la Tour Est (K. Konuk).

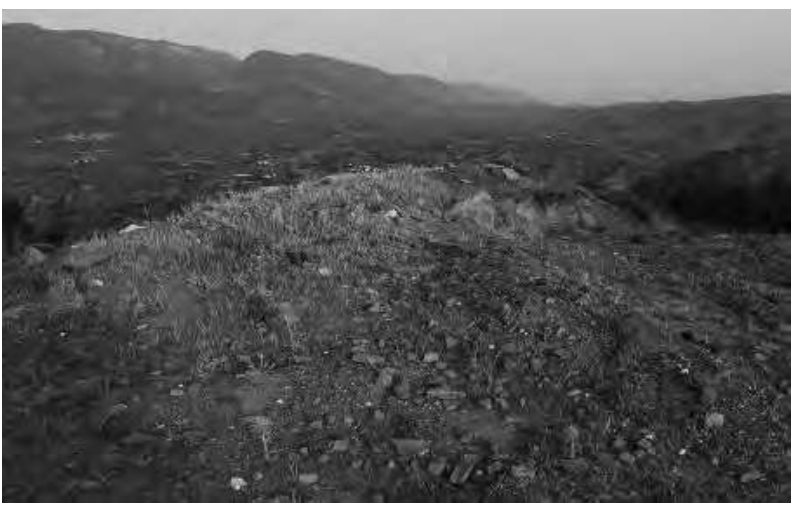

Fig. 44 : Concentration de tuiles et de céramiques diverse au Nord du site (tour ?) (K. Konuk).

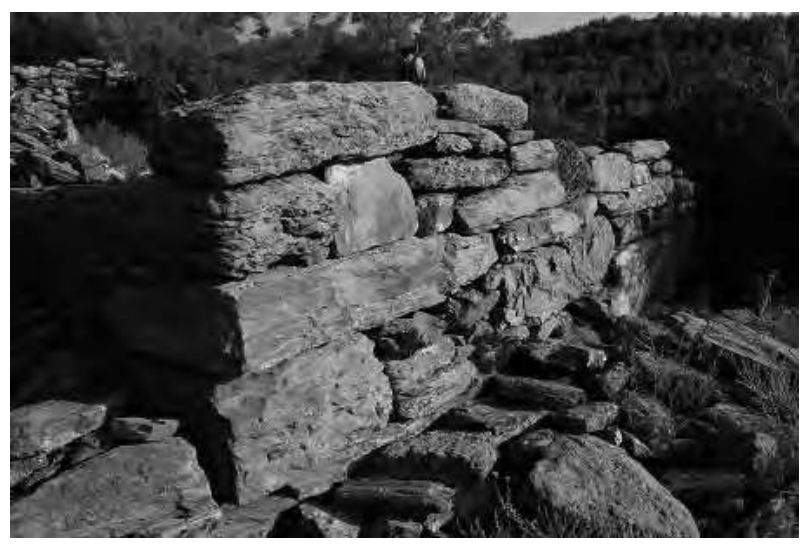

Fig. 41 : Angle S-E de la Tour Est (K. Konuk).

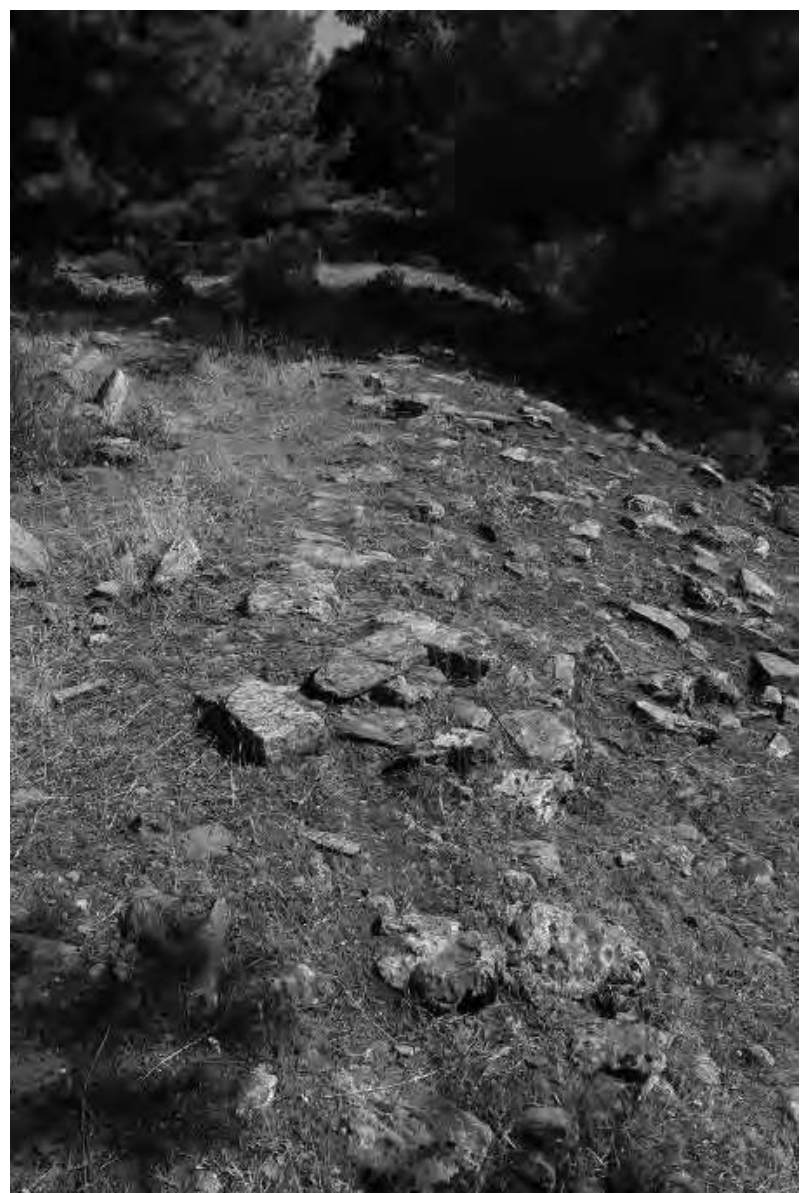

Fig. 43 : Mur du rempart à proximité de la Tour Est (K. Konuk). 


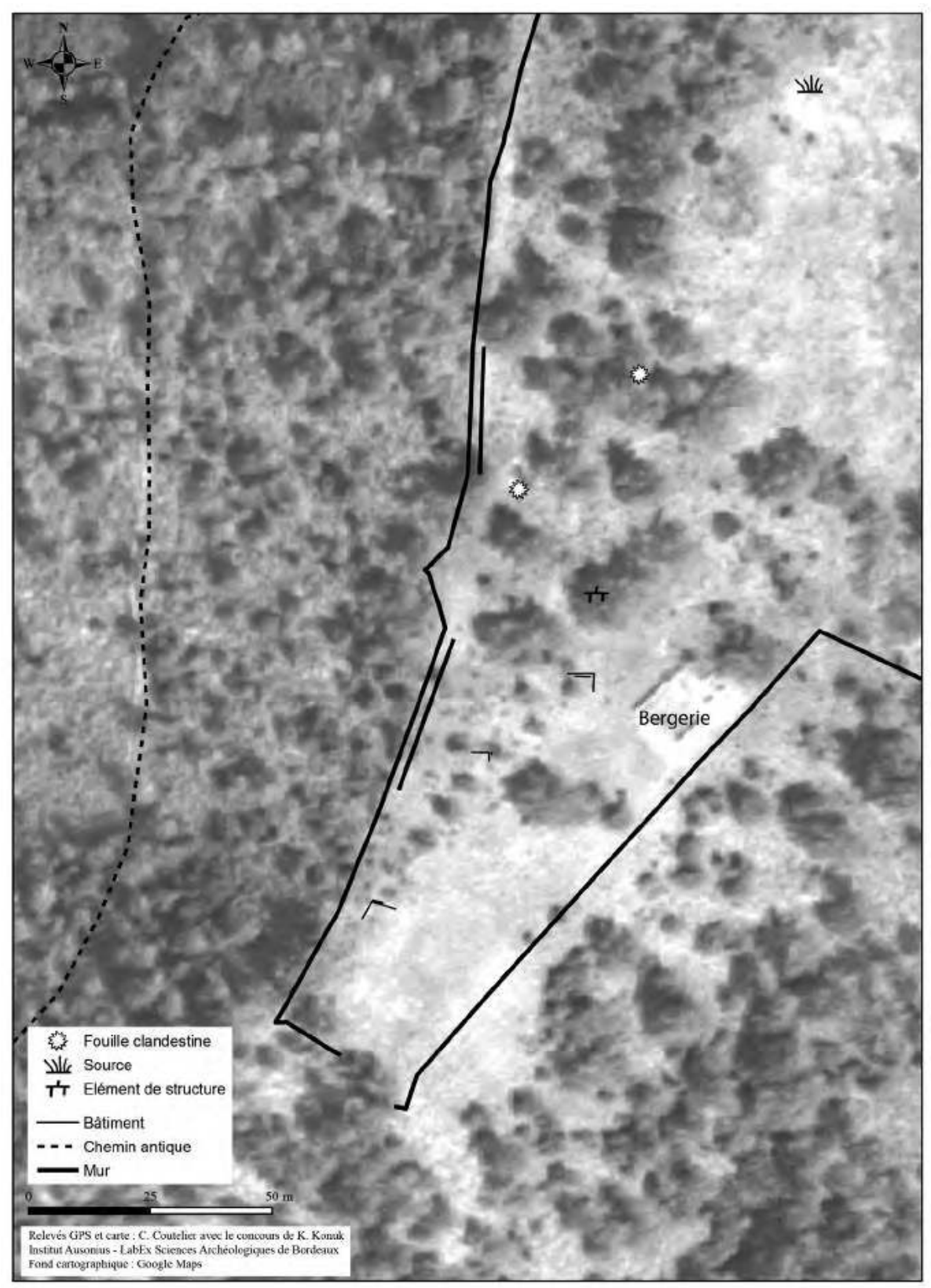

Fig. 45 : Carte de la projection rectangulaire de l'enceinte au Sud (Cl. Coutelier et K. Konuk).

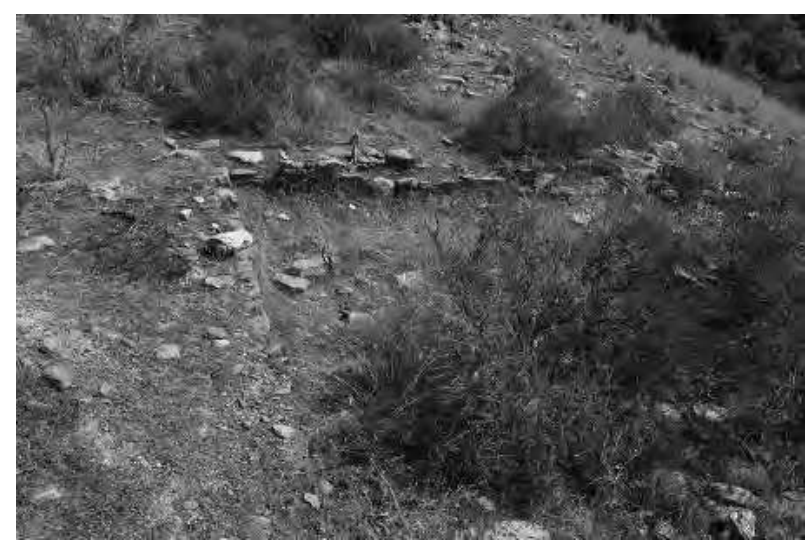

Fig. 46 : Lignes de murs de bâtiments à l'intérieur de la projection sud de l'enceinte (K. Konuk). 


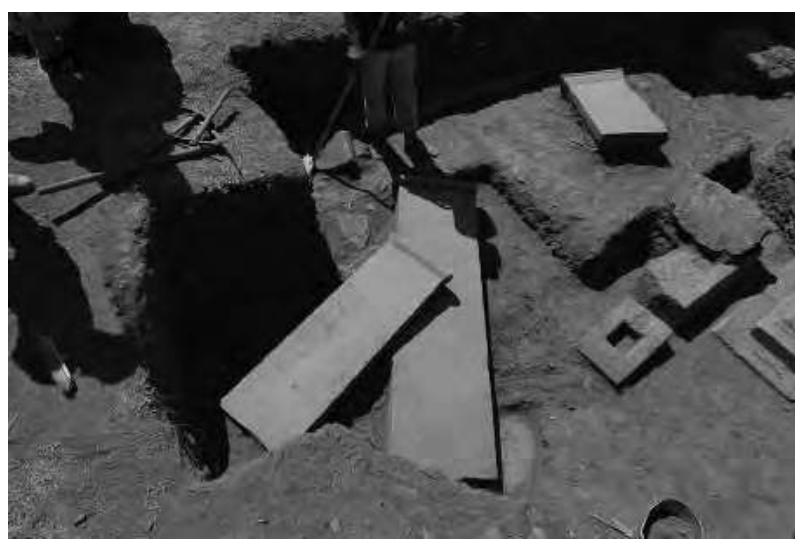

Fig. 47 : Les trois stèles hellénistiques in situ au Sud de l'autel du temple de Zeus (K. Konuk).

\section{LES INSCRIPTIONS}

(K. Konuk)

Trois inscriptions hellénistiques tout à fait remarquables ont été mises au jour en 2017 lors de la fouille du secteur sud de l'autel du temple de Zeus Lepsynos (Fig. 47-48). La première est une longue stèle intacte en marbre gris clair de 71 lignes (185 [193 avec le tenon inférieur] x 55 x $16 \mathrm{~cm}$ ) et comprend deux décrets (43 et 28 lignes) qui honorent respectivement deux officiers d'Antigone III Dôsôn (229-221 av. J.-C.), le premier, Podilos, philos du roi et déjà connu pour des méfaits plus tardifs ${ }^{29}$, et son frère Kharmadas, dont c'est la première attestation et où il est décrit comme $\varphi \rho \circ v ́ \rho \alpha \rho \chi \rho \varsigma \tau \tilde{\eta} \varsigma$ $\pi$ ó $\varepsilon \omega \varsigma$, tous deux fils de Dapanos et originaires de la cité de Lykastos en Crète.

Une seconde stèle $(136,5$ x 44,5 x $8 \mathrm{~cm})$, elle aussi intacte et en marbre gris clair, de 46 lignes, trouvée dans le même secteur, honore Lakrinès, un chef militaire de Philippe V (221-179 av. J.-C.), le successeur d'Antigone Dôsôn au trône de Macédoine. Originaire lui aussi de Crète, de la cité de Polyrrhenios, Lakrinès fils de Timoteles, est décrit

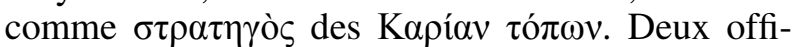
ciers de Philippe $\mathrm{V}$ dans la région, Olympichos et son subordonné Podilos, étaient déjà bien attestés à travers plusieurs inscriptions ${ }^{30}$. A ces deux noms s'ajoute maintenant celui de Lakrinès dont c'est la première attestation en tant qu'homme de confiance de Philippe V. Nous avons ainsi des documents de première importance sur l'implication des rois anti-

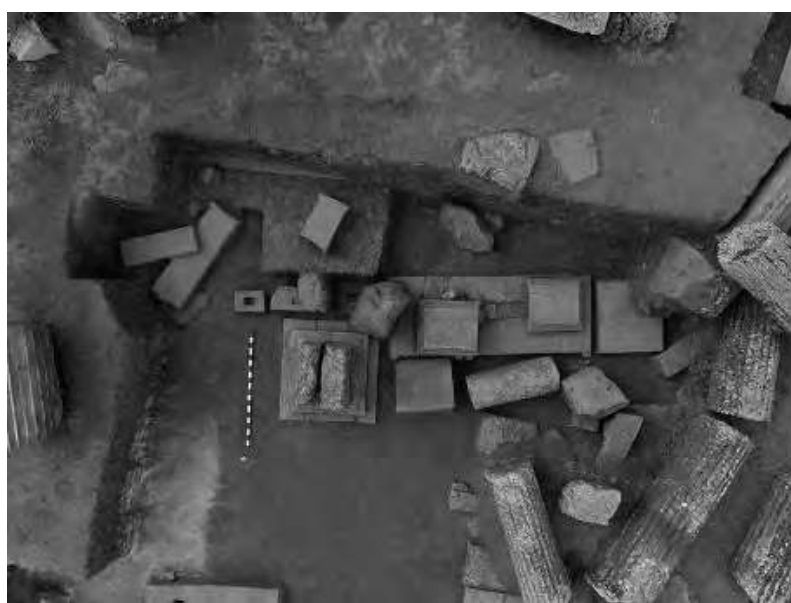

Fig. 48 : Vue zénithale du secteur avec les stèles en haut à gauche (K. Konuk).

gonides dans les affaires de la Carie dans le dernier tiers du $3^{e}$ s. av. J.-C.

Découverte dans le même secteur, la troisième inscription de 48 lignes, elle aussi en marbre gris clair $(81,5 \times 50 \times 9,5 \mathrm{~cm})$, est un peu plus tardive que les deux premières et présente quelques lacunes dans sa partie inférieure. Elle comprend deux décrets : le premier, complet, de 24 lignes ; le second, incomplet, est conservé sur 24 lignes. Ces décrets se distinguent tous deux par le fait que la charge de stéphanèphore n'est pas occupée par un mortel mais par dieu ${ }^{31}$. Le premier décret est le fait des prytanes, le second des neoi. Un certain Menoitios est célébré et de grands honneurs sont accordés à Rome en accueillant la déesse dans le temple de Zeus Lepsynos avec une fête.

Chacun de ces cinq décrets précise que les décisions qui ont été prises seront gravées sur une stèle en pierre qui sera placée dans un endroit bien en vue dans le sanctuaire de Zeus. C'est précisément à cet endroit que ces stèles inscrites ont été retrouvées in situ, chacune toujours dotée de sa base en marbre. Avec la poursuite des fouilles dans ce secteur très prometteur, nous avons l'espoir que d'autres inscriptions de ce calibre seront découvertes prochainement.

Mentionnons pour être complet la découverte de trois inscriptions fragmentaires qui proviennent $\mathrm{du}$ même secteur du temple et dont la forme des lettres indiquent une date similaire à celles des inscriptions décrites plus haut.

29) Au sujet des torts commis par Podilos envers les Iaséens, voir Holleaux 1899 ; Meadows 1996 : 255-263.

30) Sur la carrière d'Olympichos en Carie, voir dernièrement Aubriet 2012 et la nouvelle inscription de Labraunda publiée par Carless Unwin et Henry 2016.

31) Cf. Dignas $2007: 174$ 


\section{TROUVAILLES CERAMIQUES}

(V. Lungu)

Au cours des travaux sur l'Agora d'Eurômos en 2017, les fouilles ont porté sur divers secteurs. Lors de ces fouilles, d'importants vestiges antiques ont été mis au jour et parmi ceux-ci une quantité de céramiques, toutes fragmentaires, relevant de la chronologie des unités stratigraphiques. Ce mobilier a fait l'objet d'un traitement préliminaire directement sur le site. Les tessons inventoriés, reconnus et expertisés au moment de la fouille, ont été inclus dans des tableaux statistiques et les individus identifiables ont été traités essentiellement en tant que marqueurs chronologiques et typologiques en vue de l'étude archéologique de l'Agora.

On me permettra de préciser préalablement que la présente note concerne un petit groupe des fragments vus et sélectionnés l'an dernier au cours de la première saison céramologique organisée conjointement avec la campagne de fouille. Limité à une semaine, notre séjour sur place ne nous a pas permis de finir le traitement systématiquement de l'ensemble du matériel et c'est la raison pour laquelle nous n'en discuterons ici qu'une courte séquence seulement. Toutefois, les quelques dizaines de fragments céramiques étudiés -de manière partielle- pour la plupart datables, permettent d'encadrer la chronologie du site au sein d'un intervalle compris entre l'époque archaïque et l'époque protobyzantine. Les présentes trouvailles ouvrent implicitement de nouvelles perspectives sur la reconstitution de l'histoire du site et du facies céramique de cette région et ce, en l'absence totale de références locales fiables.

Il y a lieu d'abord d'insister sur l'hétérogénéité du matériel examiné, couvrant une fourchette chronologique aussi large, certaines couches stratigraphiques ayant livré des céramiques mélangées d'époques différentes. Rares sont les unités stratigraphiques témoignant d'une certaine homogénéité chronologique. Sur les 1.541 tessons collectés dans les 19 unités stratigraphiques (US) enregistrées, 193 demeurent non identifiés. Les principales classes céramiques sont représentées, à savoir : céramiques fines $(232=17,2 \%)$, céramiques communes $(177=$ $13,1 \%)$, céramiques de cuisine $(179=13,3 \%)$, amphores de transport $(420=31,2 \%)$, vases de stockage $(10=0,7 \%)$ et matériaux de construction (330 $=24,5 \%$, tuiles notamment) (Fig. 49).

En effet, on a pu identifier un certain nombre des vases que nous illustrerons ici en reproduisant

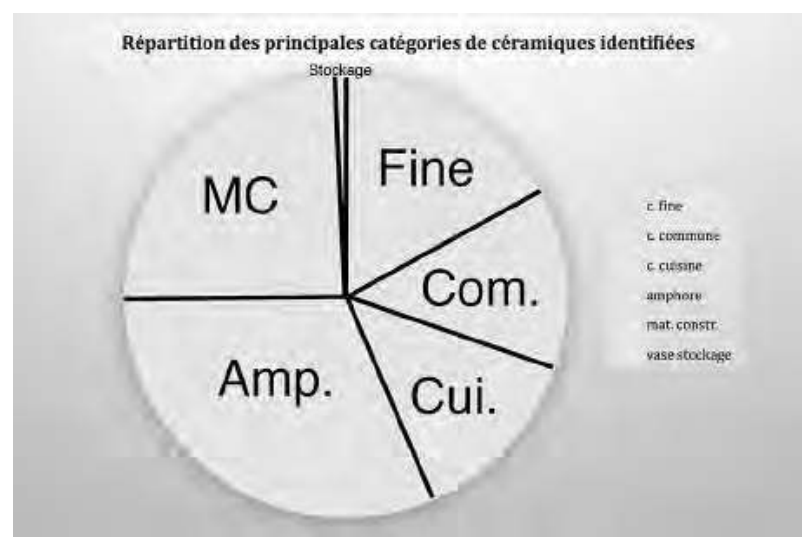

Fig. 49.

les formes les plus caractéristiques des diverses périodes chronologiques. Deux grands groupes dominent de loin; il s'agit de celui des amphores de transport et de celui des matériaux de construc$\operatorname{tion}^{32}$. Quant à la typologie du mobilier céramique, le comptage des fragments laisse apparaître la nette prépondérance des amphores de transport du $1^{\mathrm{er}} \mathrm{s}$. av. J.-C. au $2^{\mathrm{e}}$ s. ap. J.-C. La vaisselle fine est dominée par des vases de la sigillée orientale, notamment par des bols. Les autres catégories de fines comme les bolsals et les salières à vernis noir d'importation du $4^{\mathrm{e}}-3^{\mathrm{e}} \mathrm{s}$. av. J.-C. n'excèdent pas individuellement. La vaisselle commune se compose elle-même de plusieurs formes différentes, dont les cruches, les pichets et les grands bassins, inégalement représentées, sont les principales. Les vases hauts (genre olla et "round-bottomed cooking pots" ${ }^{33}$ ), fréquemment avec des anses prises près de la lèvre, dominent largement la vaisselle de cuisine, tandis que les vases bas et ouverts (genre plats à feu ou teganon) sont plutôt rares. Quant aux autres formes, leur absence ou leur rareté (comme par exemple, les unguentaria) n'a rien d'étonnant dans les conditions d'une fouille assez limitée dans la durée et l'espace.

Sur les 1.541 tessons des 23 US examinées, 173 ont été dessinés, qui forment le noyau du groupe diagnostiqué. Ils nous ont fourni les principaux repères chronologiques pour la datation des unités stratigraphiques. La situation se présente de la manière suivante :

\subsection{Sondage 1B, Portique Sud, angle avec le Portique Est (stylobate) : SE100+}

Le matériel céramique du sondage 1B - SE est abondant, mais très fragmentaire. Une description

32) Un comptage précis ne pourra être fourni qu'à la fin de notre future étude. Une estimation préliminaire de la totalité des sections ouvertes et des US fouillées nous donne des chiffres différents d'une section à l'autre.

33) Hayes $1997: 76$ 
sommaire par unités stratigraphiques se présente de la manière suivante :

SE 100 : total $=102$ fragments céramiques, de tuiles notamment ; moins nombreux sont les fragments de céramique fine et de cuisine; moins bien représentés sont les fragments d'amphores. Une chronologie plus nette nous est fournie par les fragments de bols de type Atlante II, forme 80, dont un exemplaire a été reconstitué complètement (Fig. 50) ; il est considéré comme une imitation de la forme originale d'ESB2 importé ${ }^{34}$.

SE 101 : total $=5$ fragments céramiques, correspondant pour la plupart à des fragments de panse, dont deux sont des fragments d'amphore et l'un d'un vase de cuisine ; on remarque encore un fond plat d'un bol à vernis rouge, mat, dilué, dont seulement quelques traces sont visibles, et un fragment de l'embouchure d'un bol avec le bord marqué d'une rainure en pâte demi-fine. Ils semblent appartenir à des productions locales ou locorégionales du début de l'époque romaine.

SE 102: total $=11$ tessons ; cette couche est aussi pauvre que la couche précédente ; le contenu est formé surtout par des panses lisses d'amphores, deux panses de vases de cuisine et le reste de panses de céramique commune ; une seule anse bifide fragmentaire semble provenir d'une amphore du type de Cos.

SE 103/ 104: total de deux couches $=25$ fragments céramiques ; on reconnaît ici deux anses bifides d'amphores du type Cos et quelques tessons de vases de table à engobe rouge du $1^{\mathrm{er}}-2^{\mathrm{e}} \mathrm{s}$. ap. J.-C.

\subsection{Sondage $1 \mathrm{~A}$ (partie interne), Portique Sud : SE 200+}

Le sondage 1A - SE ouvert dans le Portique Sud a livré un matériel abondant et varié. Les premiers tessons d'époque archaïque sont sans doute à interpréter comme matériel résiduel dans des niveaux plus récents. Ils sont relativement fréquents et témoignent d'une occupation antérieure, dont les niveaux n'ont pas été encore explorés. Le gros du matériel datable est assignable au $2^{\mathrm{e}} \mathrm{s}$. av. J.-C. $-2^{\mathrm{e}} \mathrm{s}$. ap. J.-C. Par unités stratigraphiques, la situation est la suivante:

\author{
SE 200 : cette US correspond à la couche vé- \\ gétale.
}

SE $201:$ total $=110$ tessons dont 62 fragments de tuiles. Quant aux autres groupes céramiques, on note trois petits fragments de panse d'un lagynos hellénistique à décor en brun sur fond blanc laiteux du $2^{\text {e }}$ s. av. J.-C. et un fragment de bol, imitation de type Atlante II, forme 8. Les deux témoignent d'une chronologie allant de la fin de l'époque hellénistique au début de l'époque romaine.

SE 202 : total $=160$ fragments céramiques; il s'agit d'une des plus riches unités stratigraphiques. Les amphores égéennes du $1^{\mathrm{er}}-2^{\mathrm{e}} \mathrm{s}$. ap. J.-C. du type Agora G199 ${ }^{35}$ et Dressel 2-4 dominent (Fig. 51) ; une anse de Rhodes du $2^{\mathrm{e}} \mathrm{s}$. av. J-C. semble être la plus ancienne; on ajoute encore quatre fragments de bols imitations du type Atlante II, forme 80 (similaires, Fig. 50); un fond de lampe datable de la fin de l'époque hellénistique ; une embouchure d'amphore de table à fond annulaire (ou plat ? Fig. 52) d'un type commun au $1^{\text {er }}$ s. ap. J.-C. ${ }^{36}$

SE 203 : total $=59$ fragments céramiques, parmi lesquels on distingue plusieurs fragments d'imitations de bols type d'Atlante II, forme 80 ; une anse bifide rhodienne, quelques fragments de panses côtelées et une anse d'amphore du type Agora G199, une anse bifide et un fragment d'épaule d'une amphore du type Dressel 2-4 ; 3 fragments (2 fonds et 1 fragment d'embouchure avec une anse) de bols de type cnidien (Fig. 53-54) (alias "Roman brittle ware" de Hallström ${ }^{37}$ ) attribués par nous à des productions d'ateliers locaux ou régionaux ${ }^{38}$, suffisamment proches les uns des autres pour poursuivre la même évolution, quoique pas nécessairement synchronisée.

SE 205: total $=55$ tessons, dont une grande partie (23) de formes fines; 9 tessons de vases à vernis noir du $4^{\mathrm{e}}-3^{\mathrm{e}} \mathrm{s}$. av. J.-C. ; un fragment d'épaule de cruche à décor du Late Wild Goat (Fig. 55) peut-être daté $c a .590-565$ av. J.-C. ${ }^{39}$; un fragment de la partie inférieure d'un unguentarium (Fig. 56) correspond à une forme du $1^{\mathrm{er}}$ s. av. J.-C., datée par analogie avec des exemplaires de l'Agora d'Athènes ${ }^{40}$.

34) Pour la forme originale, voir Agora XXXII : 38, no 316-320, fig. 12. Une pièce d'importation complète a été reconstituée sur la base des plusieurs fragments trouvés à Labraunda dans la tombe 17, voir Lungu 2017 : 242, fig. 77 .

35) Sur les identifications des amphores Agora G199 dans le basin oriental de la Méditerranée, voir Eleigne et Lemaitre 2014 : 580-581, fig. 9.

36) Gassner $1997: 94-95, \mathrm{n}^{\circ} 25, \mathrm{pl} .25$.

37) Hellström $1965:$ 38-39, $\mathrm{n}^{\circ}$ 293-313, pls. 15, 37. Variantes dans Agora XXXII : no 1618-1619, fig. 51

38) Attribution reprise par Çakmaklı $2016: 229$, fig. 66.

39) Tocra I : pl. 30, n 592 est le meilleur parallèle daté que j'ai pu trouver / Dep. II.8.

40) Agora XXXII : 286, $n^{\circ} 1761$, pl. 88. 


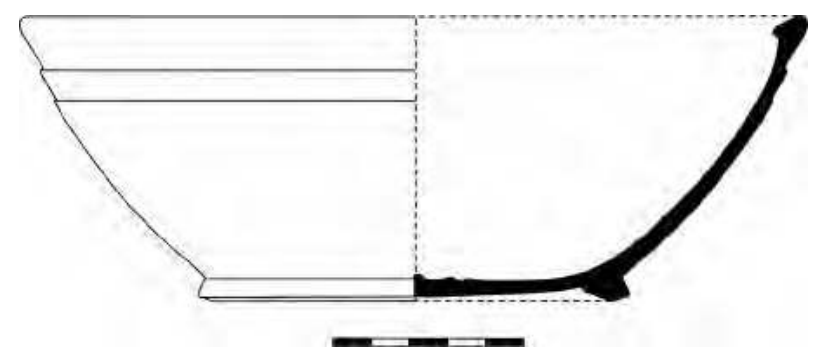

Fig. 50.

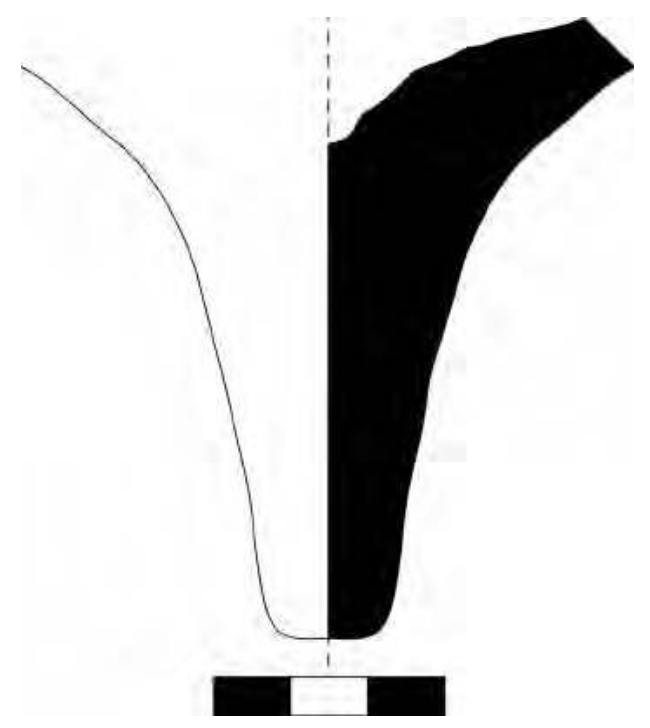

Fig. 51.
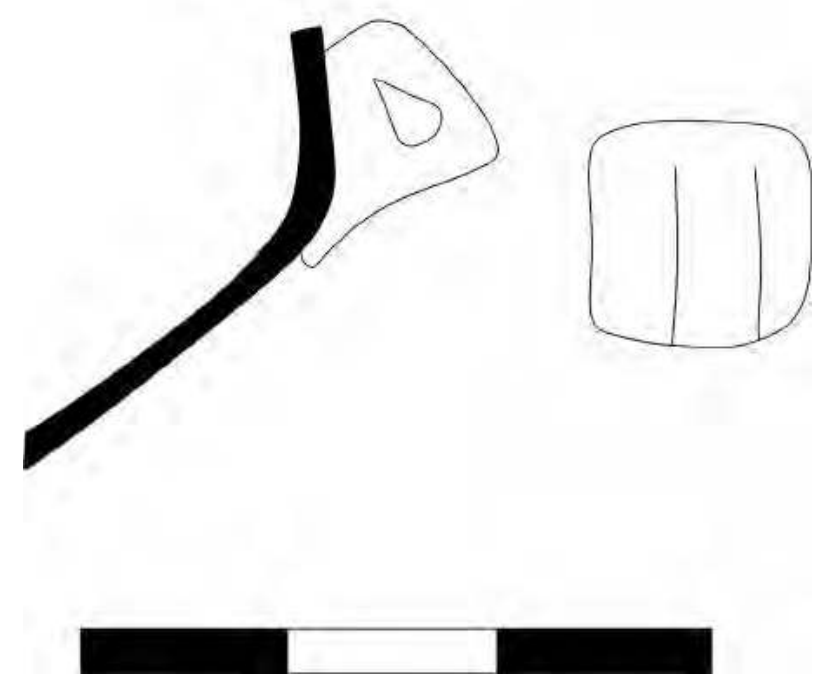

Fig. 54.

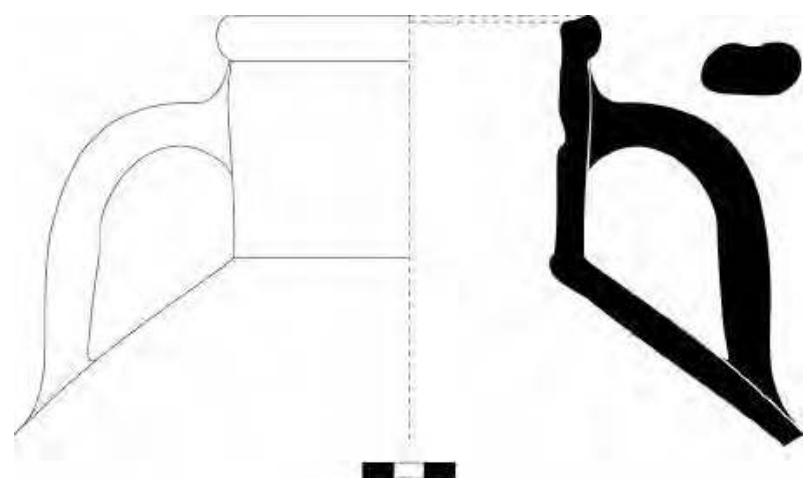

Fig. 52.

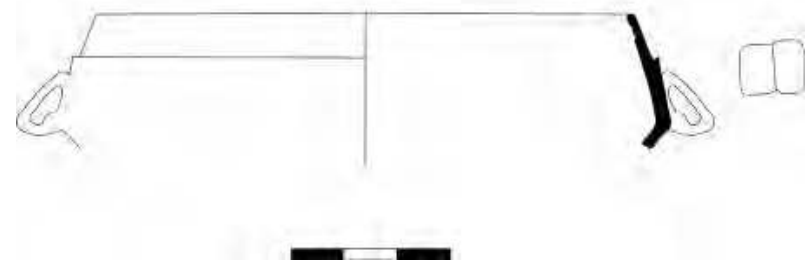

Fig. 53.
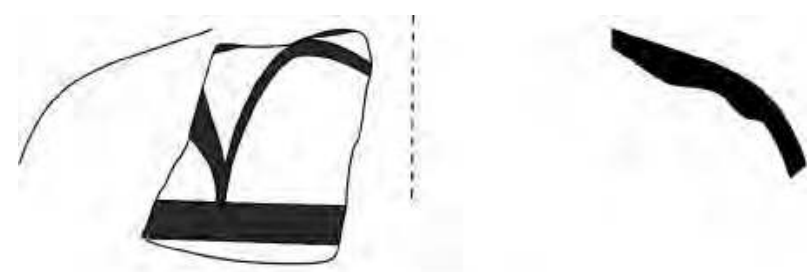

Fig. 55.
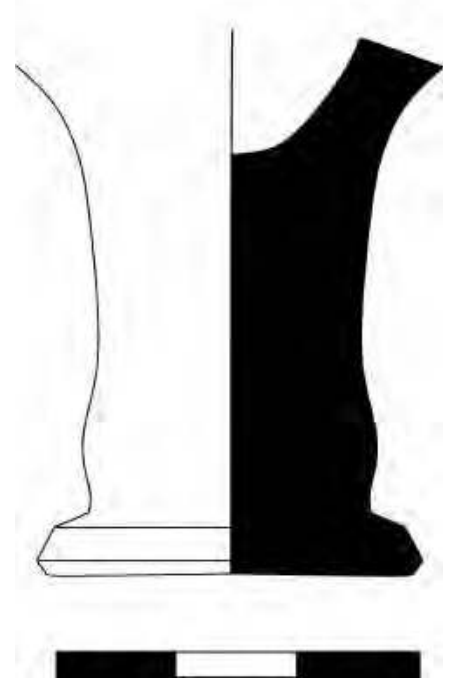

Fig. 56. 


\subsection{Sondage 2A, Portique Ouest : OS 300+}

Les couches examinées dans cette section ont livré une large variété de céramiques datables entre le $5^{\mathrm{e}} \mathrm{s}$. av. J.-C. et les $6^{\mathrm{e}}-7^{\mathrm{e}} \mathrm{s}$. ap. J.-C. La situation fournie par les US se présente comme étant assez complexe.

OS 300 : total $=200$ fragments céramiques, parmi lesquels dominent les amphores (40) et les matériaux de construction (tuiles notamment, avec 54 fragments). Pour la chronologie, il y a lieu de mentionner une grande coupe à vasque hémisphérique et bord évasé, terminé par une lèvre tombante marquée d'une feuillure du côté intérieur (Fig. 57), destinée à l'adaptation d'un couvercle, caractéristiques évoquant une jatte ; il s'agit d'une forme de tradition hellénistique ${ }^{41}$ qui devient courante à l'époque romaine ${ }^{42}$; plusieurs anses et fragments de panses d'amphore du type Agora G199 et Dressel 2-4 sont les principaux indices chronologiques.

OS $301:$ total $=114$ fragments céramiques, dont 54 correspondent à différentes parties de tuiles et 24 à des fragments d'amphores. Le reste des tessons provient de vases de poterie commune et de cuisine. Parmi les fragments de bord, on distingue quelquesuns des bols, imitations du type Atlante II, forme 80 (similaires aux précédents, Fig. 50).

OS 302 : total $=69$ fragments céramiques, parmi lesquels les tuiles et les amphores sont majoritaires ; des panses côtelés et une anse d'amphore du type Agora G199 offrent des données chronologiques. Moins bien représentés sont les vases à parois fines, dont on note un vase à vernis noir hellénistique, à coté de quelques fragments de vases de cuisine et d'un bord de bol, imitation du type Atlante II, forme 80 (similaire aux autres, Fig. 50).

OS 303 : total $=62$ fragments céramiques, dont les plus nombreux correspondent à des tuiles et à des amphores. La chronologie est assurée par une saucière avec deux anses, qui semble être la copie d'un exemplaire de céramique rouge pompéienne qui peut être daté après 146 av. J.-C. (Fig. 58) ${ }^{43}$. La chronologie descend encore plus bas avec une grande casserole datable des environs des années $50 \mathrm{du} 1^{\text {er }}$ s. ap. J. C. (Fig. 59) $)^{44}$. La plus récente des pièces datables est un fragment de bord d'une amphore byzantine assignable aux $6^{\mathrm{e}}-7^{\mathrm{e}} \mathrm{s}$. ap. J.-C. (Fig. 60) ${ }^{45}$.

OS $304:$ total $=26$ fragments céramiques, dominé par le nombre des tessons de la céramique fine, parmi lesquels on note la présence d'un bol hémisphérique à pied annulaire simple de tradition hellénistique sans vernis évoquant les bols de type ESB1 (= Atlante II, forme 66) (Fig. 61), datable, semble-t-il, du début du $1^{\text {er }}$ s. ap. J.-C. $\left.{ }^{46}\right)$.

\subsection{Sondage 2B, Portique Ouest : OS 400+}

Dans cette section le matériel se répartit entre le deuxième quart du $4^{\mathrm{e}}$ et la première moitié du $2^{\mathrm{e}} \mathrm{s}$. av. J.-C. Il s'agit là de l'un des endroits qui ont livré la plus grande quantité de matériel attique à vernis noir du $4^{\mathrm{e}} \mathrm{s}$. av. J.-C. La situation par unités stratigraphiques se présente de la manière suivante :

OS 400 : total 65 fragments céramiques qui n'ont pas été traités intégralement parmi lesquels nous avons pu reconnaître une lampe palestinienne du $6^{\mathrm{e}}-7^{\mathrm{e}}$ s. ap. J.-C. (Fig. 62).

OS 401 : total 29 fragments céramiques; les fragments de vases à parois fines sont nombreux (13); les vases de cuisine sont absents, alors que la céramique commune apparaît autant représentée que les amphores.

OS 402 : total 138 fragments céramiques. Les vases à parois fines (53) l'emportent sur les amphores (24). Les vases de cuisine et la céramique commune sont à parité, avec 14 exemplaires de part et d'autre. Les matériels de construction ne sont représentés que par 3 individus identifiés. Les indices chronologiques tirés d'un bol attique à vernis noir daté vers 380 av. J.-C. (Fig. 63) ${ }^{47}$, de deux fragments d'un bolsal attique à vernis noir daté vers 350 av. J.-C. (Fig. 64) ${ }^{48}$ et un fragment de bord d'un plat à poisson de la première moitié du $2^{\mathrm{e}} \mathrm{s}$. av. J.C. ${ }^{49}$ (Fig. 65), font remonter la période d'occupation de cette aire au $4^{\mathrm{e}} \mathrm{s}$. av. J.-C. et une continuation à l'époque hellénistique.

41) Catherine Aubert place son origine à l'époque hellénistique, Aubert $2002: 82$ et fig. 41. Elle peut avoir une fonction similaire à celle des "shallow bowls" de l'Agora d'Athènes, voir Agora XXXIII : 276-277, n 291-305, fig. 50-51, pl. 40-41.

42) Agora V : F62, G100, dans des contextes du $1^{\text {er }}$ s. av. J.-C. et de la première moitié du $1^{\text {er }}$ s. ap. J.-C.

43) Corinth VII.iii : nº 686, 128, pl. 30 ; Tekkök-Biçken 1996 : 64-65, nº A148, fig. 28.

44) Un exemplaire similaire chez Hayes $2000: 290$, fig. 14, 1-2.

45) Peacock et Williams 1986 : 187, fig. 104. Des exemplaires similaires proviennent de Milet, cf. Berndt 2003 : 248 , A418 (S.363), pl. 43, et Bodrum, cf. Alpözen et al. 1995 : 112.

46) Agora XXXII : 148, nº 266, fig. 10.

47) Agora XII : 293, no 802-803, fig. 8.

48) Agora XII : 275, no 561, fig. 6.

49) AvP XI.1 : 148, no 238, pl. 48 : 190-ca. deuxième quart du $2^{\mathrm{e}}$ s. av. J.-C. 


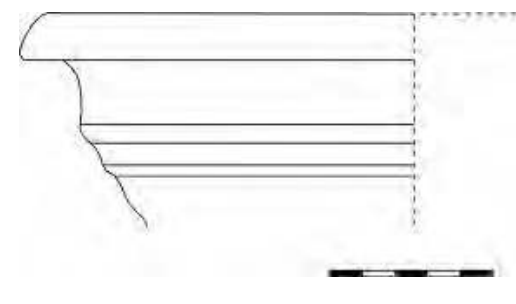

Fig. 57.

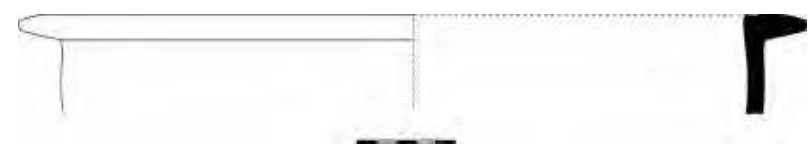

Fig. 59.
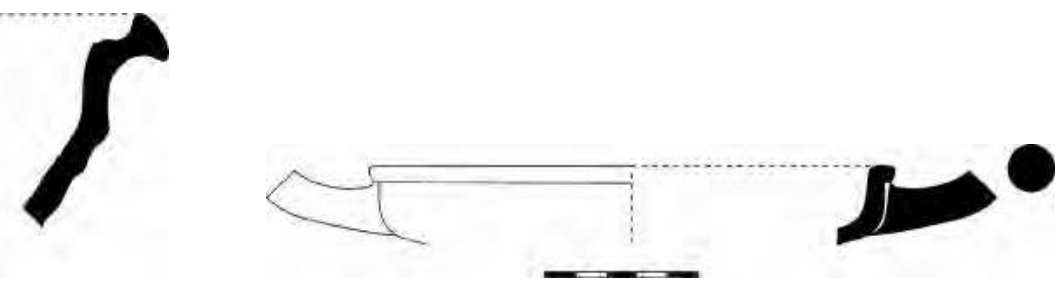

Fig. 58.

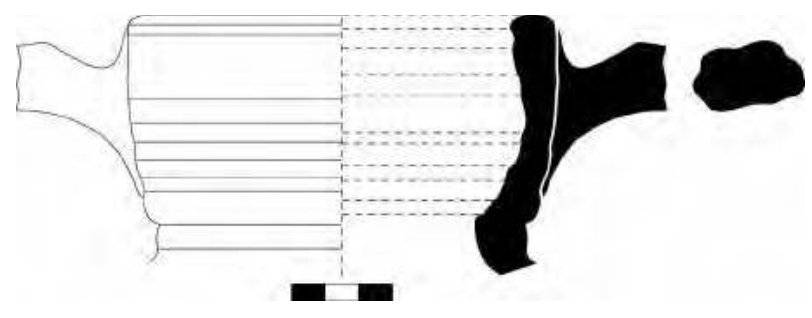

Fig. 60 .

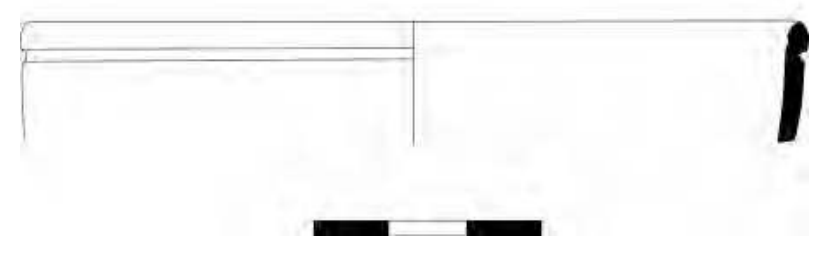

Fig. 61.

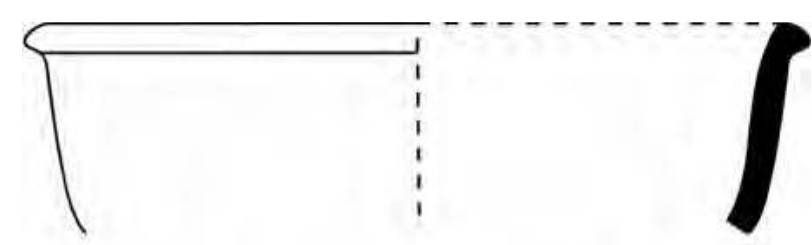

Fig. 63.

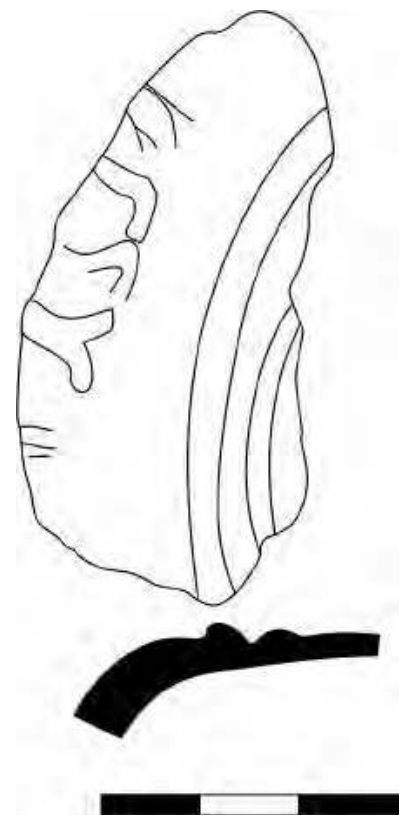

Fig. 62.

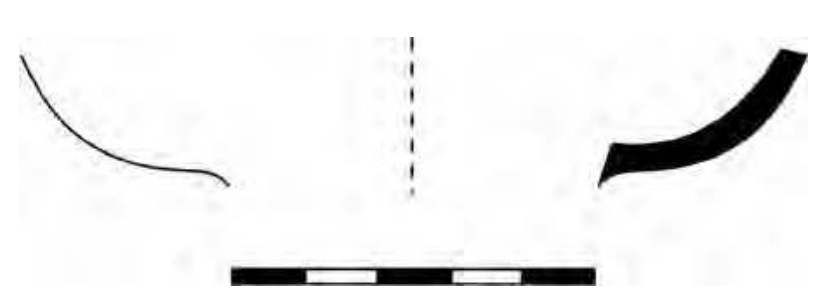

Fig. 64.

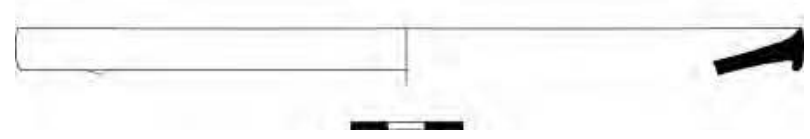

Fig. 65. 


\subsection{Sondage 5, Portique Est, angle avec le Portique Nord : EN500+}

Le matériel récolté dans cette aire est assez varié, couvrant la fourchette globale du site entre l'époque archaïque et l'époque romaine. Par unités stratigraphiques, la situation est la suivante :

EN $500:$ total $=21$ fragments céramiques, dont un plat à feu du type campanien du $2^{\mathrm{e}} \mathrm{s}$. av. J.-C. ${ }^{50}$ (Fig. 66), un fond fragmentaire d'un bol de type cnidien du 50-100 ap. J.-C. et un bol ESB Atlante 76B de 100-150 ap. J.- C. constituent les indices chronologiques les plus fiables.

EN 501 : total $=156$ tessons, dont un fragment d'épaule d'œnochoé à décor Wild Goat récent (milésien ou carien provincial ?) (Fig. 67) ${ }^{51} ; 2$ vasques et 2 anses d'un bolsal attique à vernis noir du milieu $\mathrm{du} 4^{\mathrm{e}} \mathrm{s}$. av. J.-C. ; un fond de bol de type cnidien, ainsi que plusieurs anses d'amphores du type Agora G199 et Dressel 2-4 signalent une couche bouleversée où les céramiques archaïques côtoient celles du début de l'époque romaine.

EN 502: total $=69$ fragments céramiques, dont une salière attique à vernis noir datée vers 350 av. J.-C. (Fig. 68) ${ }^{52}$; un bol de type cnidien (Fig. 53), une jarre à eau, datable vers les années $50 \mathrm{du} 1^{\mathrm{er}} \mathrm{s}$. ap. J.-C. (Fig. 69) ${ }^{53}$, un fond d'amphore de type Agora G199 (Fig. 70) et de type Dressel 2-4 (Fig. 71), tandis qu'un plat à feu signale une variante tardive, similaire à celle de Beyrouth, du "handled type" de "Eastern Roman pottery" de Hayes, trouvé dans un dépôt de 500 ap. J.-C. (Fig. 72) ${ }^{54}$, correspondent aussi à l'assemblage d'une couche mélangée, allant du milieu du $4^{\mathrm{e}}$ s. av. J.-C. jusqu'au début du $6^{\mathrm{e}} \mathrm{s}$. ap. J.-C.

EN 505: total $=43$ fragments céramiques, dont deux fragments d'embouchure de bols de type cnidien (du même type que ceux de Fig. 53-54) et quelques anses doubles d'amphores du type Dressel 2-4 et Agora G199, soit une fourchette chronologique plus resserrée vers le début de l'époque romaine.

EN $506:$ total $=25$ fragments céramiques, encore en attente d'examen.

\subsection{Commentaire sur la chronologie}

Jusqu'à une date récente, la chronologie de l'aménagement de l'ensemble de l'Agora d'Eurô- mos était datée à partir des données épigraphiques alors disponibles ${ }^{55}$. Sur la base des inscriptions du $2^{\mathrm{e}}$ s. av. J.-C., un premier point de repère a été obtenu pour la datation de diverses constructions de ce secteur. "En définitive, le programme de construction des quatre portiques est antérieur à la date de ces inscriptions, mais on ne peut guère en dire plus dans l'état actuel des connaissances" ${ }^{\prime \prime}$. Parallèlement, les dernières fouilles de 2017 ont livré une masse hétérogène de céramiques qui pourrait être exploitée dans ce sens. Une première observation a mis en évidence plusieurs époques successives, dont les pièces les plus anciennes paraissent correspondre à des vases archaïques proches du style tardif des Chèvres Sauvages et les plus récentes à la période romano-byzantine $\left(6^{\mathrm{e}}-7^{\mathrm{e}}\right.$ s. ap. J.-C.).

\subsubsection{Premières occupations du site à l'époque archaïque}

Les premiers vases céramiques de l'Agora étudiés jusqu'à présent appartiennent à la phase finale du style des Chèvres Sauvages (milésien ou carien provincial ?) à l'orée du $6^{\mathrm{e}}$ s. av. J.-C..$^{57}$. Il s'agit de 3 exemplaires du sondage 1A SE 205 et d'un autre de EN501 comptant parmi les plus anciens tessons de l'Agora. Les formes identifiées sont des cruches (Fig. 55, 67) et des fruit stands à bandes similaires à celui du secteur de la Tour Carrée (Niveau 2, Fig. 73) communs pour cette époque et produits à travers toute l'Ionie. Le type de la décoration formée de bandes et d'une frise d'arêtes rayonnantes sur l'épaule en brun foncé sur fond d'engobe clair, blanc ou jaunâtre, est assez sommaire et incomplet compte tenu des dimensions réduites des tessons. La présence d'un fond d'engobe clair est de règle pour ces tessons. La présence de mica en quantités considérables fait situer le centre de production en Ionie du Sud ou en Carie.

\subsubsection{Changement radical du faciès céramique à l'époque hécatomnide}

Cette période est attestée par quelques tessons résiduels de vases importés. Parmi les plus fréquents, on relève des tessons de vases attiques à

50) Pellegrino $2007: 6, n^{\circ} 28$, fig. 7.

51) Similaire avec ceux de l'US 205 : Tocra I, Pl. $30 n^{\circ} 592$ / Dep. II. $8=c a .590-565$ av. J.-C.

52) Agora XII : 302, $\mathrm{n}^{\circ}$ 946, fig. 9.

53) Meriç $2002:$ K 619, pl. 51, 96.

54) Hayes 2000 : 296, fig. 31.3 : "Deposit of c. AD 500".

55) Hanse et Nielsen $2004: 114, n^{\circ} 885$.

56) Kiz1l et al. $2016: 325$.

57) Cook, dans Cook et Dupont 2003 : 64-65, sur l'influence de Milet sur le style "Wild Goat" carien. 


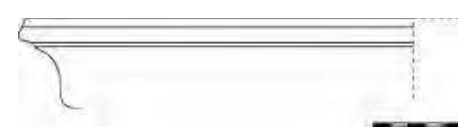

Fig. 66.

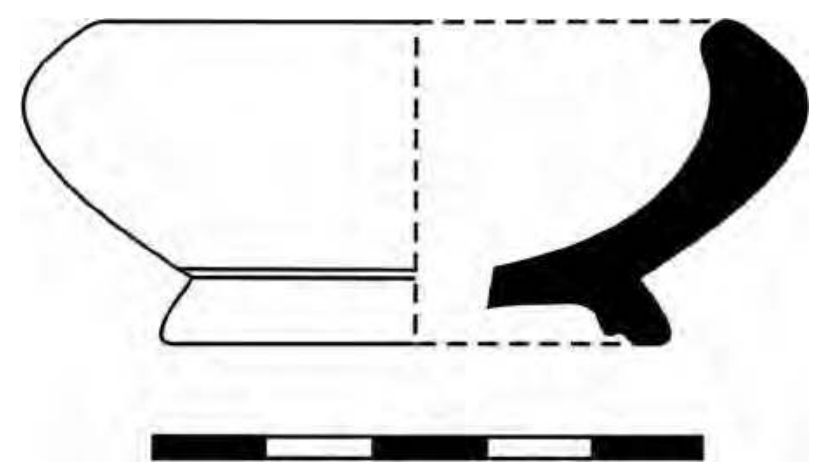

Fig. 68.

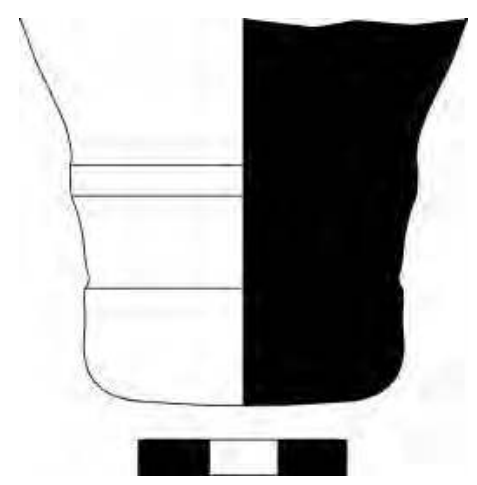

Fig. 70.

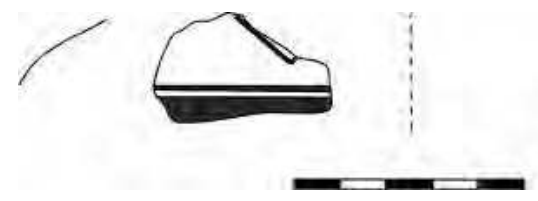

Fig. 67.
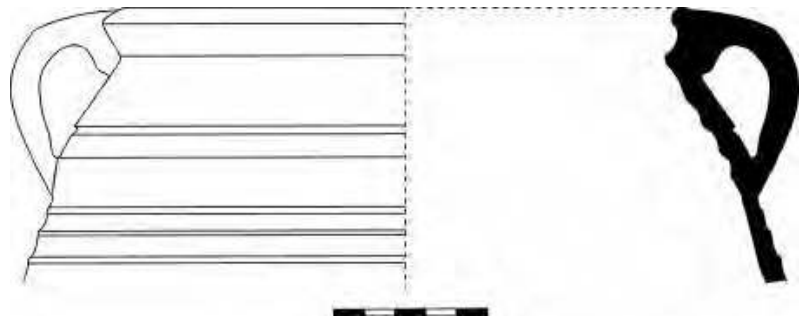

Fig. 69.

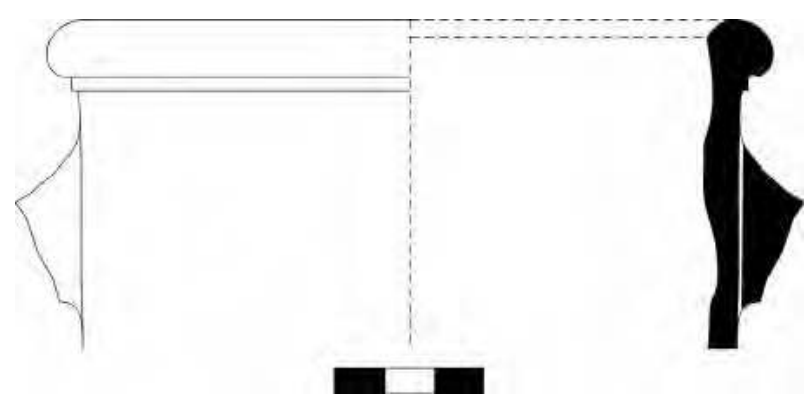

Fig. 71.

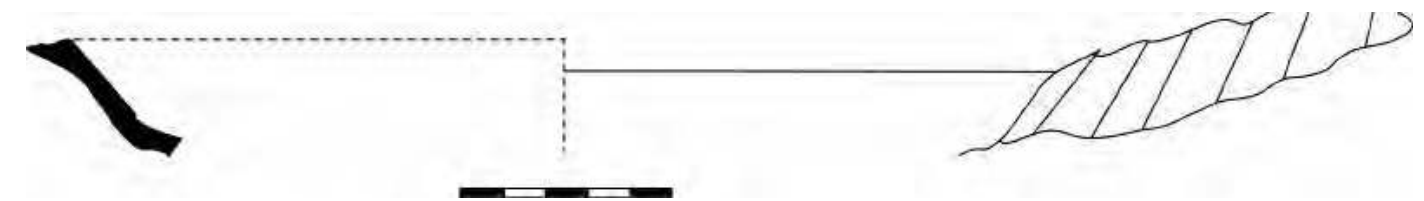

Fig. 72.

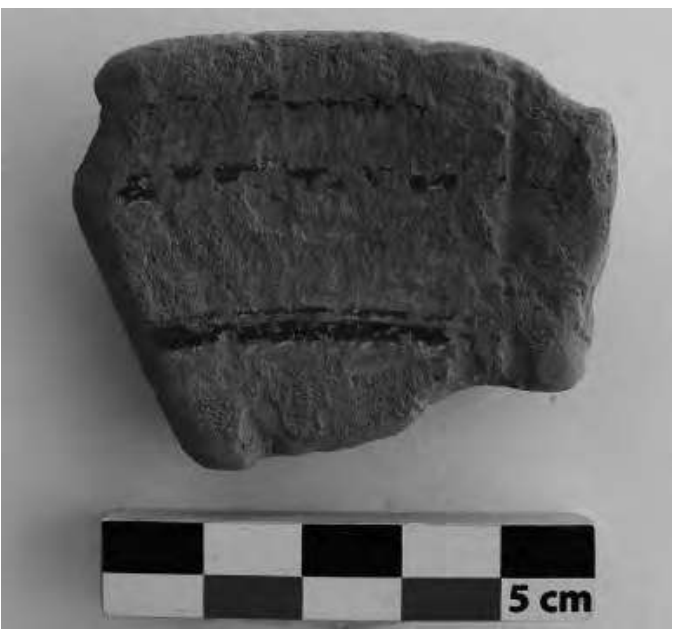

Fig. 73.

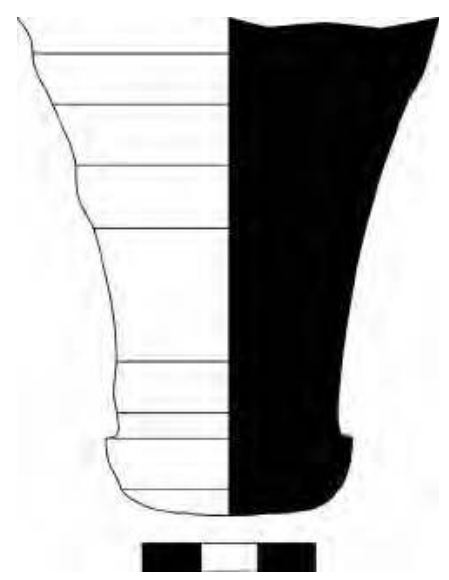

Fig. 74. 
vernis noir du $4^{\mathrm{e}}$ s. av. J.-C. Typologiquement variés, ceux-ci rassemblent des salières, des bolsals et des bols. La céramique attique à vernis noir correspond à une production de masse de diffusion générale à longue distance. Cette céramique est en effet omniprésente dans les habitats et les nécropoles de l'espace égéen. Les comparanda les plus proches se trouvent, tant dans les dépôts de l'Agora d'Athènes que dans ceux de sites voisins d'Eurômos, comme Halicarnasse, Iasos, Milet et Labraunda.

Malgré leur caractère universel, les céramiques de type attique comptent toutefois parmi les rares trouvailles dans les sections fouillées de l'Agora d'Eurômos. Mais il est bien possible qu'il s'agisse seulement là d'une fausse impression liée à la faible quantité de matériel récolté lors des campagnes de fouilles précédentes. Ces céramiques témoignent d'une ouverture vers l'extérieur de l'espace ouest-carien plus nuancée que dans l'étape précédente.

\subsubsection{Variation et imitations à l'époque hellénistique}

Quelques tessons de lagynos à fond blanc ${ }^{58}$, un fragment de plat à poisson probablement d'origine micrasiatique (ou Cnide ?, Fig. 65) et de petits tessons de vases à vernis noir non-attiques comptent parmi les plus fréquents. Une amphore de table (Fig. 52) d'un type répandu sur la côte ouest de l'Asie Mineure du $3^{\mathrm{e}}$ au $1^{\mathrm{er}}$ s. av. J.-C. ${ }^{59}$ complète l'assemblage pour cette époque. Des fragments d'amphores de Rhodes (fonds et anses notamment) du $3^{\mathrm{e}}-2^{\mathrm{e}}$ s. av. J.-C. apparaissent sans être trop fréquents. D'autre part, les imitations de vases à vernis noir de type attique rassemblés sous l'appellation "non-attique", correspondant probablement à des imitations d'Asie Mineure mal conservées et dont les dimensions des fragments exhumés n'ont pas permis une identification claire. Ces imitations sans centres de production localisés doivent correspondre à des imitations régionales. Les différences qualitatives ne correspondent pas obligatoirement à une succession chronologique quelconque, mais elles traduisent plutôt la capacité de savoir-faire des imitateurs.

De la fin de l'époque hellénistique et du début de l'époque romaine est attestée une forme rare de la céramique de table. Il s'agit de la saucière mise au jour en EN 303 (Fig. 58). L'étude de cette forme ("saucepan”) demeure peu avancée, hormis les exemples publiés de Corinthe ${ }^{60}$ et de Troie ${ }^{61}$ datés du milieu du $2^{\mathrm{e}} \mathrm{s}$. av. J.-C., les trouvailles étant peu nombreuses et les contextes de datation relativement rares. Il est possible d'établir un parallèle avec les plats de la production à vernis rouge pompéienne, dont cet objet semble dériver ou être une interprétation locale ou régionale. On peut y reconnaître un pendant de l'exemplaire $n^{\circ} 4$ de la typologie de Christian Goudineau ${ }^{62}$, qui date de la période augustéenne. Parmi les proches parallèles, on note encore un spécimen sans anse trouvé en Orient, à Beyrouth ${ }^{63}$ où la forme est importée dès le milieu du $2^{\mathrm{e}} \mathrm{s}$. av. J.-C.

\subsubsection{Transformation du répertoire céramique à l'époque romaine}

Les bols de type cnidien (Fig. 53-54) ainsi que des fragments d'amphores pseudo-Cos de type Dressel 2-4 et Agora G199, datables du $1^{\text {er }}$ s. av. J.-C au $1^{\text {er }}$ s. ap. J.-C. apportent des données chronologiques plus nettes ${ }^{64}$. Connu également à Iasos au sein du groupe de la céramique à parois fines du $2^{\mathrm{e}}$ S. av. J.-C. au $1^{\text {er }}$ s. av. J.-C. ${ }^{65}$, le bol que nous appelons "de type cnidien" est décrit comme vase à boire / "Trinkschale" à Cnide ${ }^{66}$ ou simplement "coppa". Son origine micrasiatique n'est pas tout à fait claire en dehors du modèle du bol hellénistique cnidien à parois carénés, anses en "pi" et noires, diffusé sur divers sites micrasiatiques et reproduit en divers endroits à partir de 200 av. J.-C. ${ }^{67}$

Neuf individus représentés par des fragments de fond ou de bord ont été récupérés de même que quelques autres de vasque. La forme se présente comme une petite coupe profonde, à parois carénées, vasque conique, bord légèrement inversé et marqué d'une ou deux arêtes; le pied annulaire est de faible diamètre $(4 \mathrm{~cm})$. La pâte est fine et mi-

58) Similaire à Ephèse, Gassner 1997 : 70, n 206, pl. 13.

59) Pour d'autres exemplaires similaires, voir celui d'Ephèse, publié par Gassner 1997 : 94-95, nº 25, pl. 25.

60) Corinth VII.iii : $\mathrm{n}^{\circ}$ 686, 128, pl. 30 ( $c a .146$ av. J.-C.).

61) Tekkök 1996 : 64-65, nº A148, fig. 28.

62) Goudineau $1970: 166, \mathrm{n}^{\circ} 4$, daté vers $80-70$ av. J.-C. d'après la date du naufrage établie par Lamboglia.

63) Pellegrino 2007 : 155, fig. 16, $\mathrm{n}^{\circ}$ 4, de Bey 002 de Beyrouth.

64) Bezeczky $2004: 91, n^{\circ}$ 13; Şenol 2003 : 48. Des exemplaires similaires ont été publiés récemment, voir K1zıl et Yaman 2017 : $\mathrm{n}^{\circ} 5,6, \mathrm{pl} .3: 5$.

65) Gasperetti $2003: 146-147$ et $\mathrm{n}^{\circ} 23-24$, pl. XCI.

66) Kögler $2010:$ Kn.265, Type $1 \mathrm{~A}$, forme à décor d'appliques du $2^{\mathrm{e}}-1^{\mathrm{er}} \mathrm{s}$. av. J.-C.

67) Mandel et al. $1996: 64$, pl. 20, nº 1. 
cacée. La paroi très mince, de l'ordre de $1 / 2 \mathrm{~mm}$, parfois grise à cœur en section. Les exemplaires sont revêtus d'un engobe rougeâtre, brun rougeâtre ou brun, qui est toujours mat et dilué, mal cuit, peu couvrant. On peut y voir une version locale ou régionale plus réduite du fameux bol cnidien, que l'on retrouve à l'identique à Labraunda. Ensemble, ils annoncent une production de masse à diffusion régionale. Une quantité énorme de ces vases retrouvée dans divers secteurs fouillés de la zone du sanctuaire, tout comme dans la nécropole de Labraun$\mathrm{da}^{68}$, témoignant ainsi d'un certain succès régional de la forme que nous avons proposé d'assigner à un centre, situé quelque part autour de Milas, ou entre Milas et Labraunda ou encore à mi-chemin entre Labraunda et Eurômos, lequel aurait pu alimenter les deux sites à la fois. En tenant compte de leur rayonnement un peu au-delà de la zone de production, ces céramiques montrent une diffusion régionale.

La forme dominante demeure toutefois le type du bol de la sigillé orientale du groupe ESB2 : ("Shallow bowl footed without rim = Atlante II, forme 80 : late $1^{\text {st }}$ to the first half of the $2^{\text {nd }}$ c. $A D$ " $)^{69}$. Seize individus, provenant de différentes unités stratigraphiques, ont été inventoriés en 2017 (voir Fig. 50). Pour la plupart, les bols de type ESB2 présentent tous une vasque profonde, un pied bas massif, à semelle large, légèrement concave, une paroi galbée à bord arrondi ou en biseau, plus ou moins resserrée vers le bas. Le profil de vasque apparaît scandé de deux/trois ressauts, une tendance que l'on retrouve sur les bols de type cnidien attribués aux ateliers de la région. Le diamètre d'embouchure varie de 16 à $26 \mathrm{~cm}$. La pâte, grise à cœur $(2.5 \mathrm{YR}$ 3/1) est beige clair ou rosée du côté extérieur (5 YR 8/4). Elle contient des inclusions calcaires, petites et arrondies de couleur blanche et gris foncé, ainsi que des particules brillantes de mica et, parfois, des paillettes de schiste. Un trait commun réside dans la présence en couche mince d'un engobe dilué aux nuances allant du rouge $10 \mathrm{YR}$ 5/8 au brun $10 \mathrm{YR}$
4/4 sur les surfaces intérieure et extérieure de la paroi. A l'intérieur, un cercle imprimé délimite un tondo central en fond de vasque. On pourrait dire en résumé que la technique de fabrication de ces vases apparaît plutôt comme de type provincial (ou même local); que la préparation de la pâte et du vernis n'est pas très élaborée, ni la cuisson complète, sans rapport avec la technique de fabrication des céramiques sigillées connues. Le mica et les paillettes de schiste de ces tessons sont très caractéristiques de ces vases. La forme est connue sur d'autres sites voisins $\mathrm{s}^{70}$, et se prolonge vraisemblablement dans les "Late Roman B Ware" et "Late Roman C Ware" du $2^{\mathrm{e}}-3^{\mathrm{e}}$ s. ap. J.-C. ${ }^{71}$

Comme à Labraunda ${ }^{72}$, ce bol de type ESB 2 témoigne de la présence de la forme III de $\mathrm{Hayes}^{73}$, datable entre la fin du $1^{\text {er }}$ et le milieu du $2^{\mathrm{e}} \mathrm{s}$. ap. J.-C. Cette situation tend à suggérer une période florissante de l'histoire du site dans cet intervalle. De plus, des fragments de ce bol ont été retrouvés en compagnie de plusieurs fragments de bols de type cnidien à parois fines, semblables à ceux de Labraunda discutés plus haut, et d'amphores de type Agora G199 (Fig. 74) à certains traits morphologiques qu'on présume identifiables dans la sphère de production sud-anatolienne $\mathrm{e}^{74}$. Ces dernières fournissent des éléments de datation plus précis : entre 50 av. J.-C. et 100 ap. J.-C. ${ }^{75}$

Aux catégories que l'on vient de passer en revue, il convient d'ajouter encore un unique plat à feu (Fig. 66), (C1), compte tenu de la rareté des fragments de poterie culinaire. La forme est caractérisée surtout par son profil, même incomplet, inspiré de celui des céramiques communes italiques. La pâte est orangée (2.5 YR 6/8), avec des inclusions calcaires et une quantité importante d'autres particules, tandis que l'extérieur a viré au gris. Les surfaces interne et externe sont bien lissées. Le profil galbé de la panse est légèrement incurvé vers l'intérieur, tandis que le fond est plan. Le bord saillant en corniche est surmonté d'un méplat. Il s'agit d'une forme dont l'origine est indéniablement italique,

68) Lungu $2017: 239$, T16.04, 242, huit tombes contenaient de tels vases. La plupart du matériel se concentre toutefois dans le secteur "Basin Romain", conduit par Ömür Çakmaklı, dans des couches du début de l'époque romaine beaucoup plus nettes que celles rapportées des autres secteurs.

69) Hayes $2008: 38,152-153, n^{\circ} 316-320$, fig. 12.

70) Labraunda, cf. Lungu $2017: 242$, fig. 77 : une pièce d'importation complète a été reconstituée sur la base de plusieurs fragments trouvés dans la tombe 17 de la nécropole de Labraunda. Pour la forme, voir aussi Agora XXXII, 38, $\mathrm{n}^{\circ} 316-320$, fig. 12 et Lungu dans le présent volume. A Iasos, la forme exacte d'Eurômos manque, mais d'autres variations sont attestées, voir Gasperetti $2003: 145$ et $\mathrm{n}^{\circ} 4$ et 14 , pl. XC.

71) Voir les exemplaires de Samaria, cf. Crowfoot et al. $1957: 361, \mathrm{n}^{\circ} 21$, fig. 84.

72) Lungu $2017: 242$, fig. 77.

73) Agora XXXII : 152-153, n 319-320, pl. 13, et fig. 12.

74) Ce type d'amphore est fabriqué dans plusieurs ateliers identifiés en Cilicie et localisés sur la côte à Anemurium, Syedra, Biçkici et Antioche ad Cragum, aussi bien qu'à Chypre, cf. Elaigne et Lemaître 2014 : 581-582.

75) Pour des productions assimilées dans la Méditerranée orientale, voir Empereur et Picon 1989 ; Sibella 2002. 
comme reproduisant une forme campanienne du $2^{\mathrm{e}} \mathrm{s}$. av. J.-C. exportée vers l'Orient surtout après le milieu du même siècle ${ }^{76}$ et dont la diffusion et l'utilisation se sont poursuivies à l'époque romaine.

Parmi les formes fermées, il convient de mentionner encore pour EN 502, une olla (Fig. 69) qui offre un profil plus complet de la moitié supérieure, se rapprochant d'un exemplaire de l'Agora d'Athènes décrit par Robinson ${ }^{77}$ et d'autres d'Ephèse publiés par Ladstätter ${ }^{78}$ dans le groupe des vases de cuisine. Un autre exemplaire non-illustré vient de EN 500.

\subsubsection{Dernières occupations de l'espace à l'époque protobyzantine}

Les tessons d'époque protobyzantine sont plutôt rares. Un plat à feu tardif provenant de EN 502 (Fig. 72) peut être rapproché d'exemplaires de Beyrouth retrouvés dans une couche contemporaine du tremblement de terre de 497 ou 502 ap. J.-C. et attribué par Hayes à la production d' "Eastern Roman pottery" "79. Une autre forme byzantine est illustrée par un fragment de bord d'amphore trouvé dans l'OS 303, témoignant d'une date encore plus tardive $\left(6^{\mathrm{e}}-7^{\mathrm{e}} \text { s. ap. J.-C. }\right)^{80}$ et par une lampe palestinienne de la même époque (Fig. 62).

\subsection{Observations préliminaires}

Même si l'étude céramique n'a pu être achevée en 2017 , quelques premiers résultats ont déjà pu être obtenus. Ils confirment pleinement les potentialités du site à livrer des quantités importantes de céramiques assignables à différentes périodes chronologiques et de production tant locorégionale qu'importée. Cet aspect n'est pas contradictoire compte tenu de la situation du site sur le long d'un des grands axes de circulation entre Milas et le lac Bafa (Latmos) ou le long de la côte égéenne, depuis le port de Iasos vers l'arrière-pays anatolien. C'est peut-être pour cette raison que la collection de céramiques de diverses époques issue des fouilles du secteur "Agora" d'Eurômos se présente comme assez hétérogène, du fait de fortes influences extérieures sur la constitution du faciès céramique local. S'agissant de matériel fragmentaire, l'identification typologique de détail de la totalité des pièces n'a pu être menée totalement à bien pour ce qui est de l'affinage des formes et des variantes.

Les catégories dominantes appartiennent aux époques achéménide, hellénistique et romaine. Or, à l'échelle macro-régionale, cette période renvoie à la mise en place des grandes entités politiques de l'Ouest anatolien, entreprise par les Hécatomnides, les dynastes hellénistiques et jusqu'aux chefs romains, responsables à l'évidence des dynamiques politiques et économiques de ces diverses époques. La mise en perspective des principaux groupes céramiques de cette période avec les formes assignables à la production régionale témoignant de disponibilités particulières de ce site, pose la question des goûts de la population locale pour les formes identifiées et de la place de celles-ci dans les acquisitions de vases et produits bon marché, importés sur de longues distances.

L'assemblage comporte des céramiques fines, associées à des céramiques communes et culinaires. La prédominance des productions locales ou régionales de céramiques de table ne saurait être forcément interprétée comme un signe d'involution économique ou culturelle de la zone, mais bien au contraire comme celui du développement d'un artisanat axé sur l'imitation des produits de qualité appartenant au fond commun propre au monde hellénistico-romain. Si peu nombreuses que soient encore les formes identifiées, ces céramiques ont le mérite de témoigner de l'existence dans la région proche de centres d'artisanat potier, dont les productions sont essaimées sur les centres de consommation situés à proximité immédiate. Il faut souligner la présence fréquente du bol imité de type Atlante II, forme 80, qui pourrait bien être issu des ateliers de l'aire d'Eurômos, de par sa chronologie voisine de celle des autres centres de production. L'approvisionnement semble suggérer le quasi-monopole d'un atelier, ou d'un groupe d'ateliers très dynamiques, utilisant une source commune d'argile. Justement, le type trouve des parallèles avec les originaux d'ESB2 mais le profil scandé de la paroi ajoute une note d'originalité. Le dynamisme des potiers locaux ou régionaux se manifeste également dans les quantités de bols de type cnidien de production commune à Labraunda et Eurômos. Ceci met en évidence une certaine capacité et disponibilité de s'adapter aux changements des pratiques alimentaires et de fournir

76) Di Giovanni 1996.

77) Agora V : 42, G193, pl. 7. ap. J.-C.

78) Ladstätter 2005 : K700, pl. 191, qui montre que la forme continue au $2^{\mathrm{e}}-3^{\mathrm{e}}$ s. ap. J.-C. ; Meriç 2002 : K619, pl. 51, $96, c a .50$

79) Hayes 2000 : 296, fig. 31.3 : "Deposit of c. AD 500".

80) Peacock et Williams $1986: 187$, fig. 104. Des exemplaires similaires sont attestés à Milet, cf. Berndt $2003: 248$, A418 (S.363), pl. 43, et Bodrum, cf. Alpözen et al. $1995: 11$. 
de nouveaux produits se substituant immédiatement aux importations. Entre Labraunda et Eurômos, le programme de recherches mis en place depuis l'an dernier s'attachera essentiellement à étudier et à expliciter la variété des céramiques identifiées dans ces sites et leurs traits communs.

En dépit du faible nombre de céramiques étudiées, on se rend toutefois compte que nous sommes encore loin d'avoir passé en revue tous les multiples aspects permettant de reconstituer le faciès céramique d'Eurômos. Il est aussi encourageant que l'étude comparative de sites proches comme ceux de Labraunda et d'Eurômos, tous deux situés dans la même zone carienne, ait commencé à fournir des informations concernant les céramiques régionales et pas seulement celles d'importation de zones plus éloignées. Une réflexion sur ces problèmes s'avère d'autant plus nécessaire que les enjeux portent sur la distinction entre les céramiques de factures locale, régionale et d'importation tout au long de plusieurs siècles avant et après J.-C. dans une microrégion carienne centrée sur les deux grands sites antiques d'Eurômos et Labraunda.

\section{PROSPECTION DANS L'EURÔMIDE}

(A. Kızıl, K. Konuk, P. Brun, L. Capdetrey et R. Descat)

L'année 2016 avait vu la mise en place d'un projet de prospection accepté par la Direction des biens culturels et des musées et placé sous la direction d'Abuzer Kızıl. Il se propose d'étudier le territoire de la cité d'Eurômos et ses frontières avec les cités voisines. La seconde mission s'est donc tenue du 25.09.17 au 04.10.17 sous la supervision de Tuğba Çavuşoğlu, représentante du Ministère et conservatrice au musée archéologique d'Izmir, dont la bienveillance a grandement facilité notre travail et à qui nous adressons nos plus vifs remerciements. L'objectif de la campagne 2017 était de poursuivre la prospection des zones frontières de l'Eurômide, en particulier dans les parties occidentales et méridionales de la plaine (Fig. 75). Elle a permis d'identifier plusieurs nouveaux sites et, par ailleurs, d'avancer dans la compréhension de la répartition de l'occupation de certains autres.

\subsection{Hisarcık et Kale Yıkı}

Dans l'Ouest de la plaine d'Eurômos, au niveau du village d'Hisarcık, le cimetière actuel, situé au pied du village au contact de la plaine, accueille quelques pierres antiques remployées comme marqueurs de tombes. Aucune inscription n'a pu être repérée. En revanche, la présence de céramique signe la présence d'une occupation et, même, de ce qui pourrait avoir été un atelier céramique (beaucoup d'éléments d'amphores). A proximité immédiates, une concentration de rebuts de pâte de verre pourrait également signaler la présence d'un atelier de verre. A un peu plus d'un kilomètre au Sud-Est, au lieu-dit Kale Y1k1 ("forteresse en ruines"), des traces d'occupation antique sont aisément repérables, avant tout par la présence d'une ligne de fortifications en appareil grossier qui domine la plaine d'une vingtaine de mètres (Fig. 76). Elle remonte ensuite le

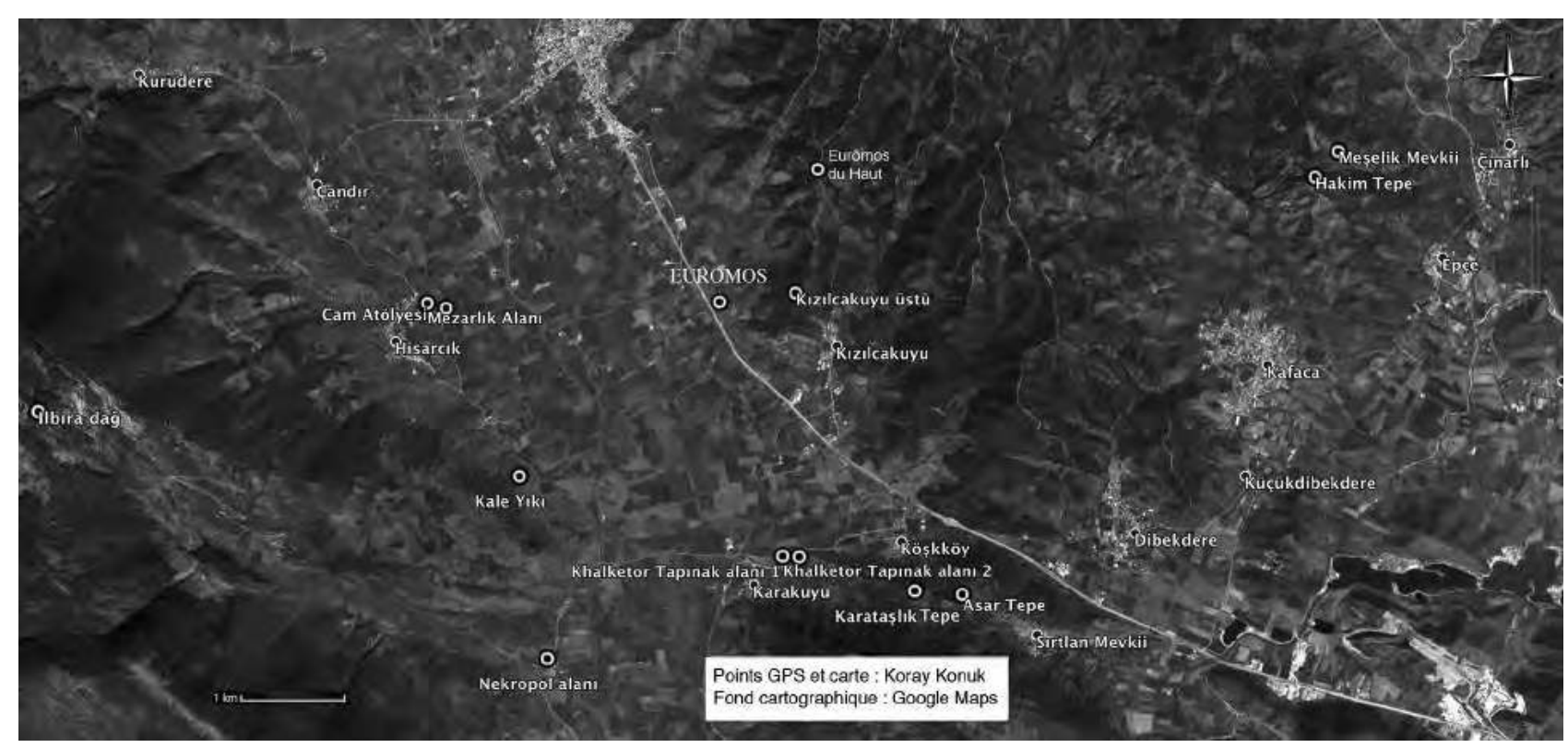

Fig. 75 : Carte indiquant les sites visités en 2017 (K. Konuk). 
long de la pente sur environ deux cents mètres pour constituer une sorte de quadrilatère à flanc de colline. L'apparence de ces murs oriente plutôt vers une fortification pré-classique en rapport avec une petite communauté dont le nom est pour l'instant inconnu. Ce qui frappe, en comparaison des autres structures fortifiées de la région, c'est sa position "basse", à quelques dizaines de mètres au-dessus de la plaine. L'absence d'autres éléments visibles ne permet pas d'aller plus loin pour l'instant dans l'analyse.

\subsection{La frontière entre l'Eurômide et le territoire d'Iasos}

En continuant vers le Sud la bordure occidentale de la plaine de l'Eurômide, nous arrivons à un élargissement considérable à l'Ahmetli bahçesi, au débouché d'une vallée très nette venant des hauteurs de l'Ouest, le Göbek Dere. Il existe de nombreuses traces d'une occupation d'époque romaine dans ce secteur, dont une importante tombe à sarcophage. A partir de ce point bas, et après s'être engagés sur une très longue route forestière qui monte en direction de l'Ouest sur une dizaine de kilomètres, on parvient à un épaulement quasi-sommital situé à 850-900 m d'altitude à l'extrémité de la chaîne de l'Ilbıra Dağ. La zone est contrôlée par une très puissante forteresse de forme trapézoïdale orientée selon un axe nord-ouest/sud-est. Une brève description en avait été faite par A. Peschlow (1980 : 216) qui mentionnait une construction de type "lélège" qui par son plan était probablement un fort hellénistique (Fig. 77). Bien qu'elle soit effondrée sur elle-même, la muraille, de style effectivement "lélège", garde une belle élévation, parfois de plusieurs mètres, en particulier sur la partie sud-est (Fig. 78). Il est possible de repérer sur la façade est quelques tours (quatre en tout) et une porte. La façade nord est longue d'environ 140 $\mathrm{m}$, la façade est d'environ $70 \mathrm{~m}$. Si une partie (en particulier à l'Ouest) a été détruite pour les besoins d'une exploitation minière dans les années 1980, la structuration d'ensemble de cette fortification reste visible. Cette structure, dans cette situation d'altitude, donnait un contrôle au moins visuel sur une partie de la plaine de l'Eurômide et, au SudOuest, sur la cité d'Iasos qu'il était possible de rallier par un chemin toujours utilisé. On peut imaginer qu'il puisse s'agir d'une forteresse de frontière entre le territoire d'Iasos et, peut-être, celui de Mylasa. Nous en ferons l'étude dans une analyse d'ensemble des frontières de la cité d'Eurômos à l'époque hellénistique.

\subsection{Olymos}

A l'Est de Chalkètor se situe la communauté des Olymeis connue par les vestiges du temple d'Apollon et d'Artémis et les inscriptions qui y ont été trouvées autour du village de Kafaca. Mais le site ancien de la cité est resté inconnu. A. Akarca et T. Akarca (1954 : 133) ne savent pas où il se trouve et signalent seulement la possibilité d'une acropole au-dessus du village. G. Bean (1971 : 48) note la possibilité d'une cité ancienne sur les collines au-dessus du village, mais aucune ruine n'y a été trouvée. Les habitants du village interrogés ont confirmé l'absence de ruines au Nord immédiat du village (Bozbelen Tepe, Hacı İbrahim Tepe). En revanche, au NordEst, sur une ligne de hauteurs séparée du village par la petite vallée du Çakmak Dere, nous avons trouvé sur une petite éminence surplombant à environ $300 \mathrm{~m}$ (Hakim Tepe), un site ancien, délimité par une muraille d'un type rustique carien traditionnel (Fig. 79). L'emprise de cette structure n'est pas très importante, sans être négligeable. Il semble que ce soit la seule fortification dans les environs immédiats et c'est probablement le lieu de fixation "haut" de la communauté des Hylimeis (nom de la communauté au $5^{\mathrm{e}} \mathrm{s}$. av. J.-C.) avant l'époque hellénistique, sur un modèle qui rappelle l'exemple d'Eurômos et aussi celui de Pidasa. Partout, on note la présence de céramique commune.

En contrebas de cette position, à 600 ou $700 \mathrm{~m}$ vers le Nord-Est, au Meşelik Tepe, nous avons pu voir une belle tour hellénistique elle-même orientée vers la plaine plus à l'Est et qui devait correspondre aux confins du territoire d'Olymos et de celui de Mylasa (Fig. 80). Cette tour carrée (environ $8 \mathrm{~m}$ de côté) conserve encore une élévation respectable (2,70 m, Fig. 81). On constate de visu que sa construction a connu deux phases. Après un premier moment de construction correspondant aux 5 ou 6 premières assises, une extension a été imposée à la structure pour augmenter d'environ un tiers l'emprise au sol. La tour a ensuite été achevée selon ce dernier plan avec une unification de la partie supérieure de l'élévation qui est parfaitement continue. On notera que le mur sud du bâtiment porte une inscription grecque, irrégulière, peu soignée, composée de quatre lignes très effacées (Fig. 82).

Une inscription de Labraunda récemment publiée et datant de la seconde moitié du $3^{\mathrm{e}} \mathrm{s}$. av. J.-C. 


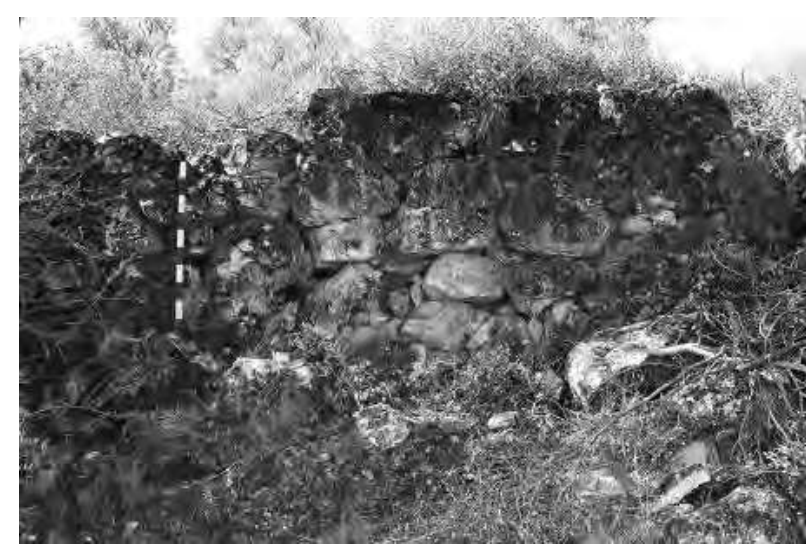

Fig. 76 : Tronçon ouest de la muraille du site de Kale Yıkı (K. Konuk).

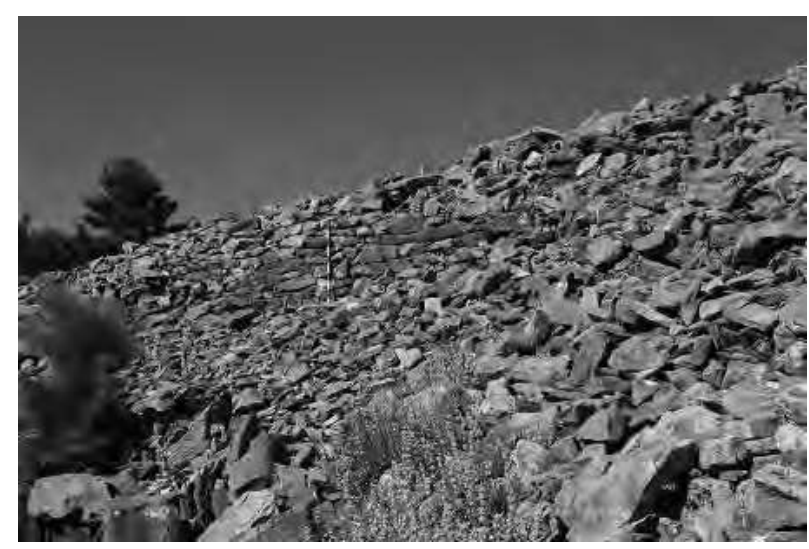

Fig. 78 : Tronçon sud-est de la muraille du site l'Ilbıra Dă̆ (K. Konuk).

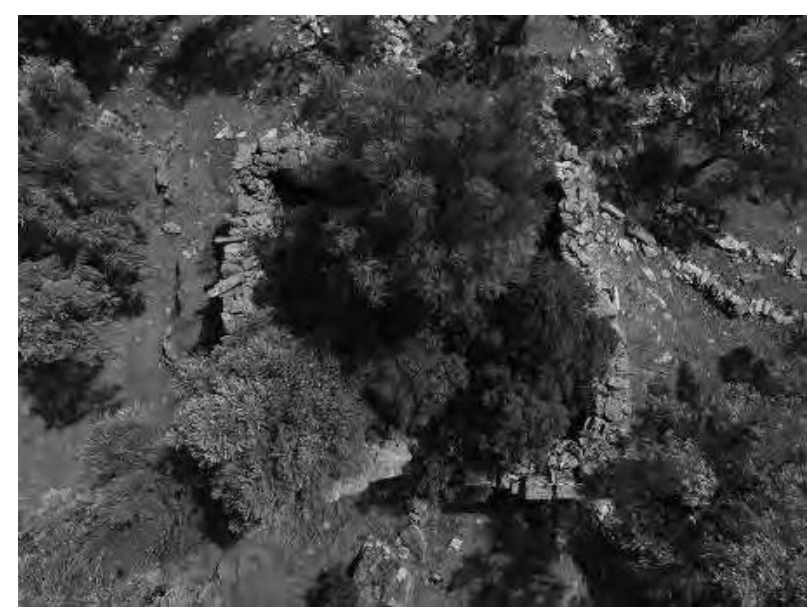

Fig. 80 : Vue zénithale de la tour hellénistique de Meşelik Tepe (K. Konuk).

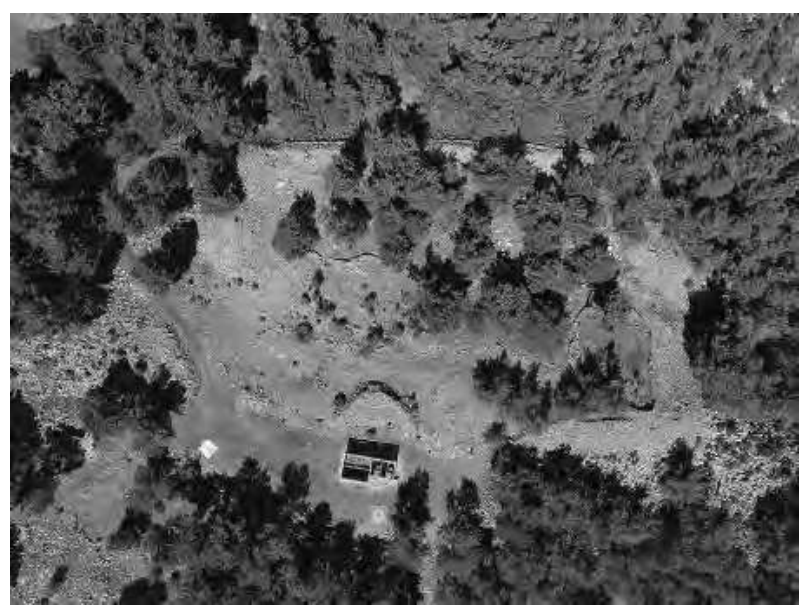

Fig. 77 : Vue zénithale du site de l'Ilbıra Dağ (K. Konuk).

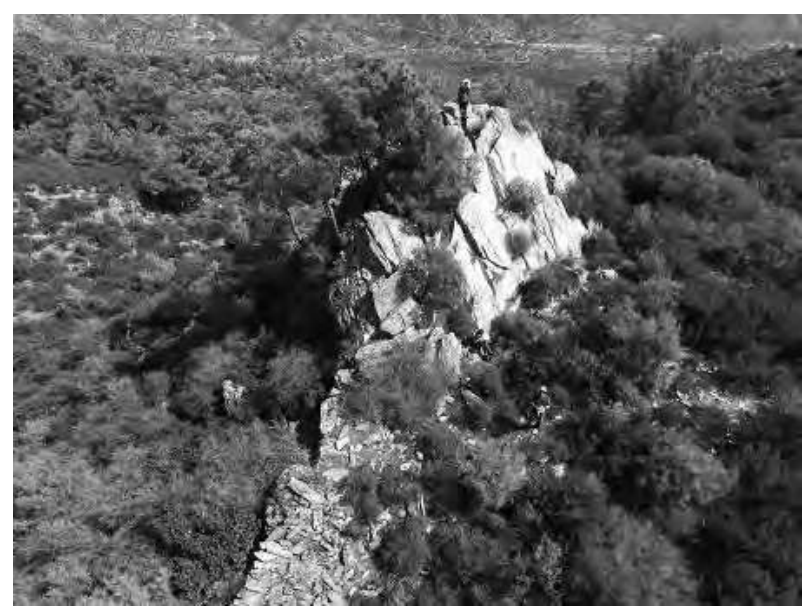

Fig. 79 : Piton rocheux fortifié à Hakim Tepe (K. Konuk).

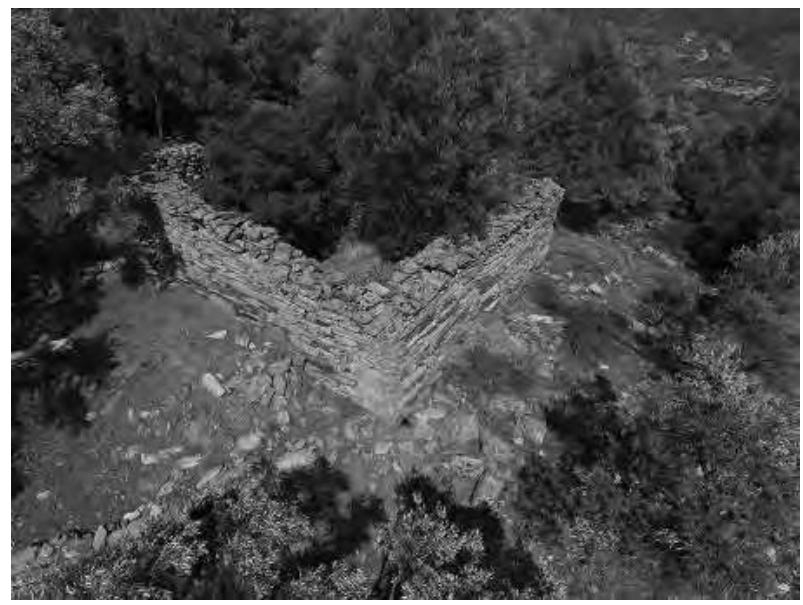

Fig. 81 : Tour hellénistique de Meşelik Tepe (K. Konuk). 


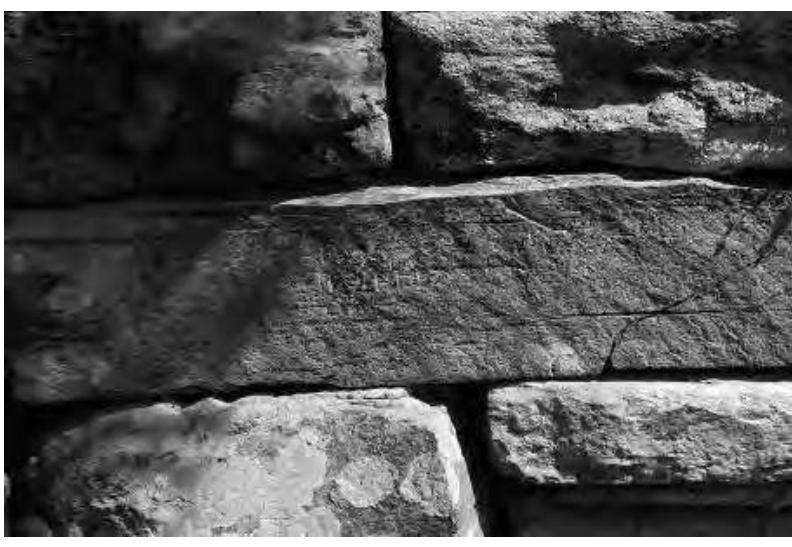

Fig. 82 : Inscription gravée sur un bloc de la tour de Meşelik Tepe (K. Konuk).

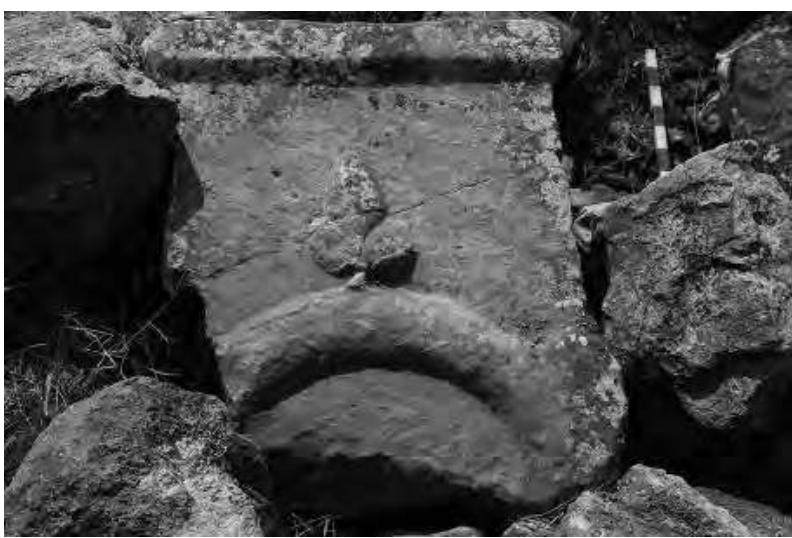

Fig. 84 : Fragment de sarcophage dans la nécropole de Chalkètor (A. Kizıl).

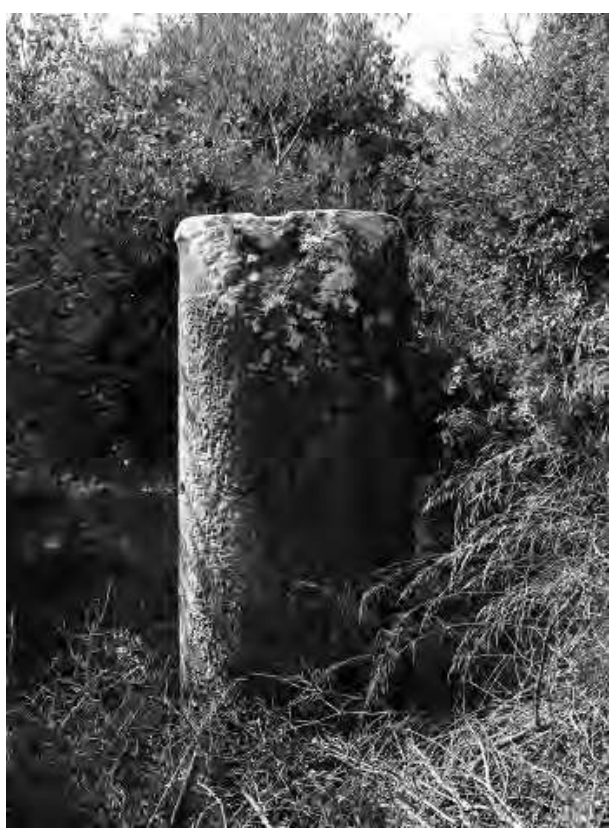

Fig. 86 : Colonne en place appartenant au second temple de Chalkètor (K. Konuk).

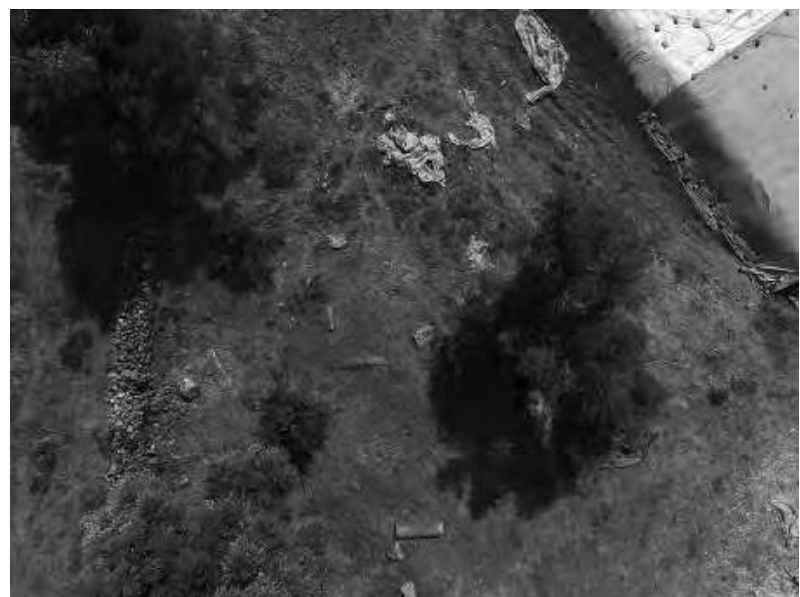

Fig. 83 : Vue zénithale du secteur du premier temple de Chalkètor (K. Konuk).

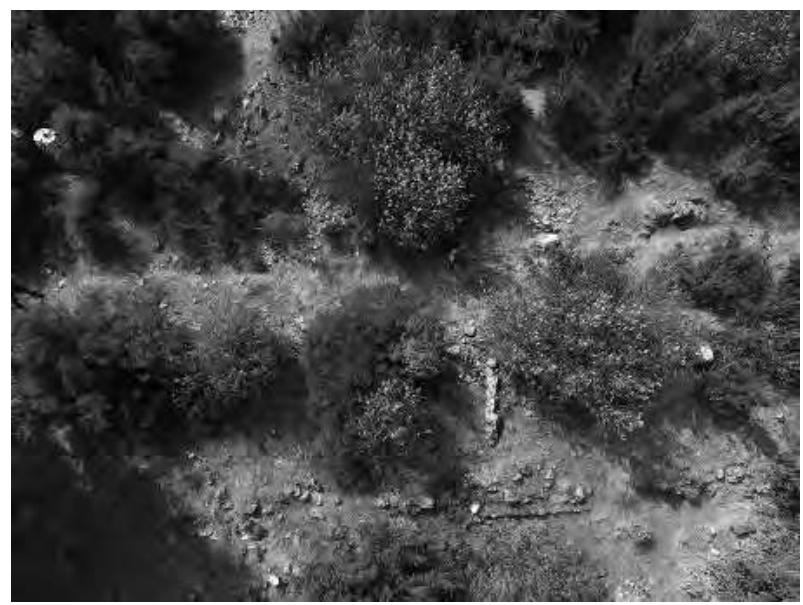

Fig. 85 : Vue zénithale du secteur au second temple de Chalkètor (K. Konuk).

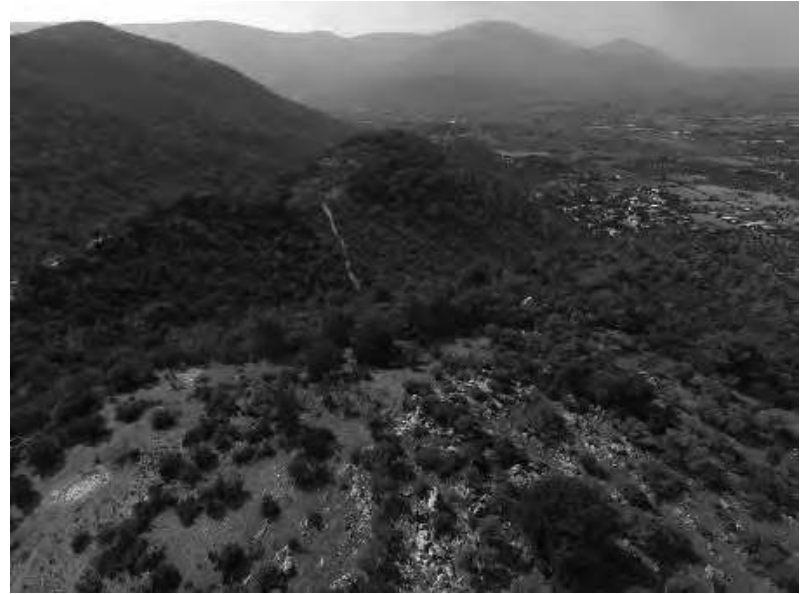

Fig. 87 : Vue aérienne avec le Asar Tepe (Chalkètor) au premier plan et le Karataşlık Tepe (Chalkètor) derrière (K. Konuk). 


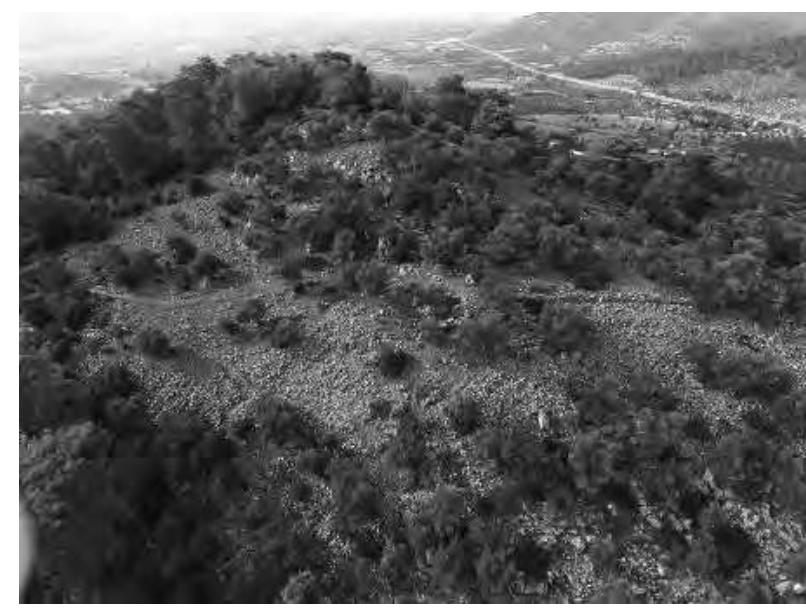

Fig. 88 : Vue aérienne de la partie sud-est du Karataşlık Tepe (Chalkètor) avec le tracé de la muraille (K. Konuk).

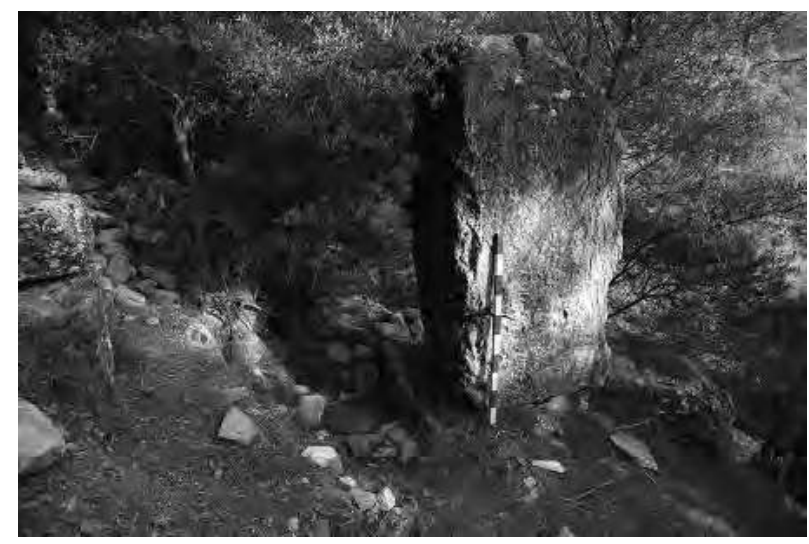

Fig. 90 : Poterne de la muraille du Karataşlık Tepe (Chalkètor) (A. Kızıl).

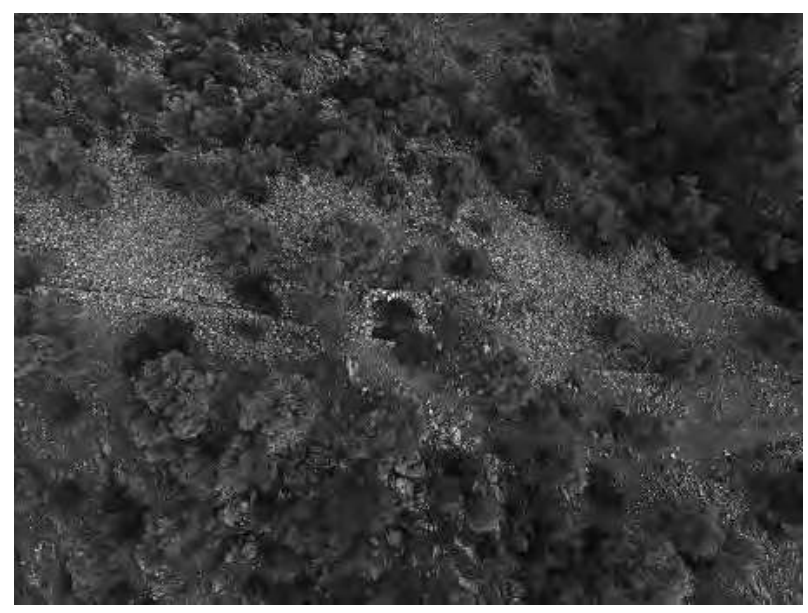

Fig. 89 : Vue zénithale de la partie sud-est de la muraille (avec une tour) du Karataşlık Tepe (Chalkètor) (K. Konuk).

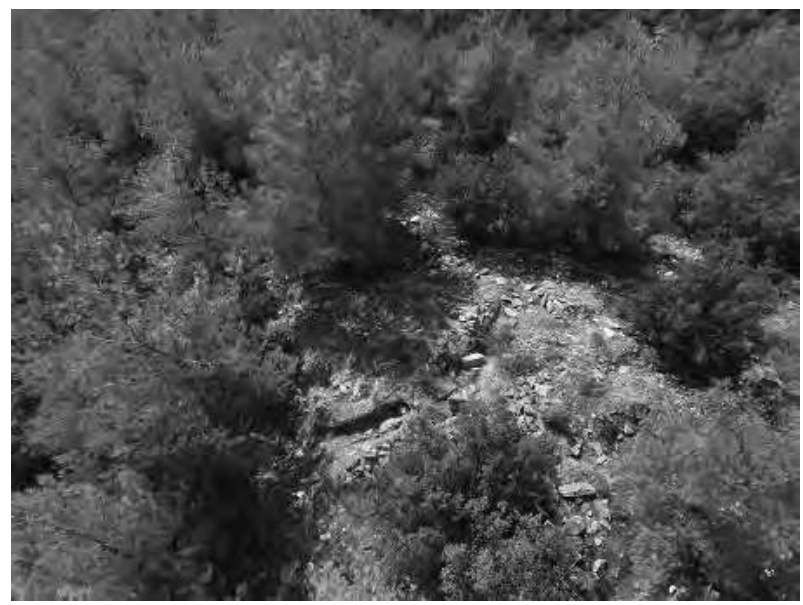

Fig. 91 : Vue aérienne des fouilles clandestines du site de Kızllcakuyu (K. Konuk).

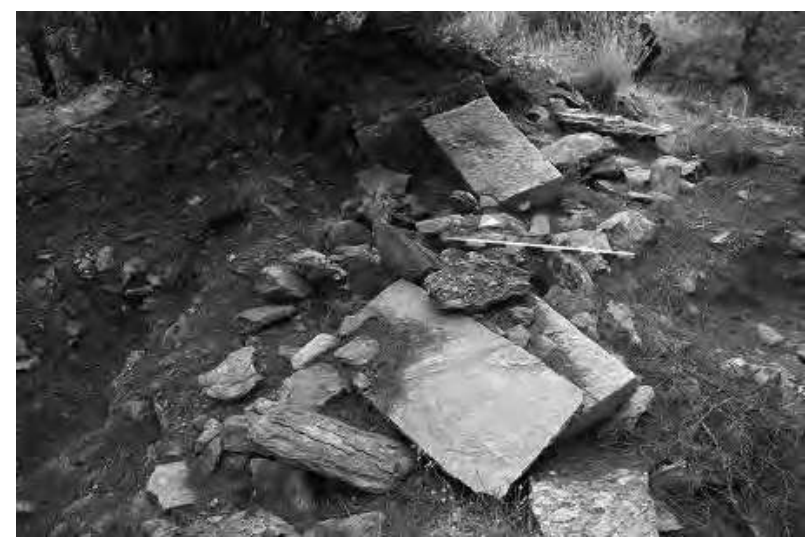

Fig. 92 : Blocs en pierre taillés du site de Kızılcakuyu (A. Kızıl). 
mentionnant dans le territoire d'Olymos, une Petra et un phrourion voisin est à mettre en relation avec notre découverte ${ }^{81}$. Nous en ferons le commentaire historique dans un prochain article.

\subsection{Chalkètor : les sanctuaires et les forteresses}

Dans la partie méridionale de l'Eurômide, nous avons porté notre attention sur le site de l'ancienne Chalkètor autour du village actuel de Karakuyu. A quelques centaines de mètres du village, sur la route de Köşk, au niveau d'un seuil entre une modeste colline, à l'Ouest, et les premières pentes du Karataşlık Tepe à l'Est, se trouve une nécropole déjà documentée. C'est ici que les inscriptions cariennes de Chalkètor avaient été découvertes, à droite de la route lorsque l'on quitte Karakuyu. Nous avons pu prendre les dimensions approximatives d'un temple d'ordre dorique orienté E-O $(15$ x $8 \mathrm{~m})$. Une dizaine de colonnes lisses sont visibles avec parfois des débuts de cannelures ( $\varnothing 0,57$ à $0,62 \mathrm{~m}$ ) (Fig. 83). La nécropole est située juste au-dessus du temple.

De l'autre côté de la route, au Nord, sur le flanc est de la petite colline, la présence d'un imposant sarcophage (couronne et vigne, Fig. 84) indique que la nécropole s'étendait au moins jusque-là. La céramique est ici très abondante. Surtout, sur une terrasse qui domine de quelques mètres la plaine, on a pu repérer d'autre structures, sans doute un second temple, de taille assez modeste, dont seules les colonnes situées sur la face orientale semblent avoir été cannelées (Fig. 85). Plusieurs blocs d'assise sont en place, ainsi que quelques colonnes (Fig. 86).

Un peu plus à l'Est, à partir du village de Köşk, une courte route forestière monte dans la pente et permet d'accéder aux deux éminences qui dominent le Sud de l'Eurômide et la route qui conduit à Milas : le Karataşlık Tepe et l'Asar Tepe, à l'Est. Deux forteresses ont été très brièvement décrites par A. Akarca et T. Akarca (1954: 133) et de nouveau mentionnées par G. Bean (1971: 49) qui se contente de reprendre le texte des Akarca. L'ensemble du sommet de l'Asar Tepe est en effet enserré dans un vaste mur de fortification en appareil irrégulier et dans l'ensemble très ruiné même si l'on voit clairement que l'épaisseur des murs est parfois considérable (Fig. 87). Au moins une porte peut être repérée. On est cependant bien en peine de trouver de la céramique dans l'espace intérieur. Cette position offre un contrôle visuel sur toute l'Eurômide mais aussi sur la plaine située au Nord de Milas, jusqu'à la région de Labraunda.
Le sommet immédiatement voisin, le Karataşlık Tepe (appelé kale par les villageois) est lui aussi fortifié, et de façon remarquable (Fig. 88). C'est en effet une puissante muraille qui en protège le sommet et qui court tout autour de la hauteur sur un périmètre d'ensemble d'environ 800 m (Fig. 89). Des élévations de trois ou quatre mètres sont encore en place dans la partie sud-ouest. Une porte avec ce qui semble avoir été une poterne $(1,95 \times 1,15 \mathrm{x}$ $0,65 \mathrm{~m}$ ) a pu être identifiée (Fig. 90). On a là un ensemble tout à fait exceptionnel dans la région.

Ce double verrou au-dessus de Chalkètor, qui remonte très probablement au moins à l'époque classique, constituait à coup sûr à l'époque hellénistique un point de fixation de garnisons qui pouvaient aisément contrôler la circulation entre Mylasa et l'Eurômide et, au-delà, vers le golfe Latmique, mais aussi vers Iasos à l'Ouest.

\subsection{Le site de Kızılcakuyu}

Ce site fortifié surplombe au Nord le petit village de Kızılcakuyu et à l'Ouest le centre urbain d'Eurômos situé à peine à environ $600 \mathrm{~m}$ de distance à vol d'oiseau. Niché à la pointe d'une petite ligne de crête à une hauteur de $170 \mathrm{~m}$, ce site occupe une position dominante qui permet de contrôler la circulation vers Eurômos et la plaine environnante. Nous pourrions être en présence d'un phrourion d'Eurômos dont le rôle aurait été de surveiller un point de passage d'une importance stratégique pour la cité. Le site a malheureusement été complètement saccagé par des fouilles clandestines récentes et l'on compte des dizaines de trous et de tranchées dont certains semblent avoir été creusés au moyen d'une pelleteuse (Fig. 91). Ce pillage a eu pour effet d'exhumer et de déplacer de nombreux blocs en pierre taillés (Fig. 92), ce qui témoigne de la présence de constructions soignées. Très peu de céramique a pu être retrouvée, ce qui est sans doute lié à la présence de pins dont les aiguilles recouvrent le sol. Le tracé de la muraille n'est pas très lisible mais les restes de ce qui semble être une tour sont visibles à la limite sud-est du site. 


\section{BIBLIOGRAPHIE}

Agora V = Robinson, H.S., 1959 : Pottery of Roman Period Chronology, The Athenian Agora V, Princeton.

Agora XII = Sparkes, B.A. et Talcott, L., 1970 : Black and Plain Pottery of the $6^{\text {th }}, 5^{\text {th }}$ and $4^{\text {th }}$ Centuries B.C., The Athenian Agora XII, Princeton.

Agora XXXII = Hayes, J., $2008:$ Roman Pottery: Fine-Wares Imports, The Athenian Agora XXXII, Princeton.

Agora XXXIII = Rotroff, S., $2006:$ Hellenistic Pottery. The Plain Wares, The Athenian Agora XXXIII, Princeton.

Atlante $=$ AAVV, Enciclopedia dell'arte antica classica e orientale: Atlante delle forme ceramiche I, II, Istituto della Enciclopedia Italiana, Rome 1981, 1985/6. Tipologia (Hayes) : vol. II, 1-96 e 2 pp.

AvP XI.1 = Ziegenaus, O. et Luca, G.Fr., $1968:$ Das Asklepieion 1: Der südliche Temenosbezirk in hellenistischer und frührömischer Zeit, Berlin.

Abadie-Reynal, C. (éd.), 2003 : Les céramiques en Anatolie aux époques hellénistique et romaine. Actes de la Table Ronde d'Istanbul, 22-24 mai 1996, Varia Anatolica XV, Paris.

Akarca, A. et Akarca, T., 1954 : Milâs: coğrafyası, tarihi ve arkeolojisi, Milas.

Alpözen R.O., Berkaya, B. et Özdaş, A.H., 1995 : Commercial Amphoras of the Bodrum Museum of Underwater Archaeology. Maritime Trade of the Mediterranean in Ancient Times, Bodrum.

Amy, R. et Gros, P., 1979 : La Maison Carrée de Nîmes, Paris.

Ateşlier, S., 2006 : "Euromos Arkaik Mimarî Terracottaları Üzerine İlk Gözlemler (First Preliminary Report on the Archaic Architectural Terracottas from Euromos)", ArkDer 8 : 59-78.

- 2011 : "Euromos Arkaik Mimari Terrakottaları", AST 28 : 123-139.

Aubert, C., 2000 : "Les céramiques hellénistiques de Beyrouth, caractéristiques des productions locales", in F. Blondé, P. Ballet et J.-F. Salles (dir.), Céramiques hellénistiques et romaines, productions et diffusion en Méditerranée orientale (Chypre, Egypte et côte syropalestinienne), Travaux de la Maison de l'Orient 35, Lyon : 73-84.

Aubriet, D., 2012 : "Olympichos et le sanctuaire de Zeus à Labraunda (Carie) : autour de quelques documents épigraphiques", in Chr. Feyel et al. (éds.), Entités locales et pouvoir central : la cité dominée dans l'Orient hellénistique, (Université Nancy II, 3-5 juin 2010), Nancy : 185-209.

Bean, G.E., 1971 : Turkey beyond the Maeander: An Archaeological Guide, Totowa, NJ.

- 1987 : Karia, Istanbul.

Berndt, M., 2003 : Funde aus dem Survey auf der Halbinsel von Milet (1992-1999). Kaizerzeitliche und frühbyzantinische Keramik, Internationale Archäologie, Band 79, Rahden/Westf.

Bezeczky, T., 2004 : "Early Roman Food Import in Ephesus: Amphorae from the Tetragonos Agora", in
J. Eiring et J. Lund (éds.), Transport Amphorae and Trade in the Eastern Mediterranean, Acts of the International Colloquium at the Danish Institute at Athens, September 26-29, 2002, Athènes : 85-97.

Çakmakl1, Ö.D., 2017 : "Preliminary results from the ceramics at the Water Pool excavations", in Henry, O. et al., "Labraunda 2016", Anatolia Antiqua XXV : 227-229.

Carless Unwin, N. et Henry, O., 2016: "A new Olympichos inscription from Labraunda", Epigraphica Anatolica 49: 27-45

Cook, R.M. et Dupont, P., 2003 : East Greek Pottery, Londres - New York.

Corinth VII.iii = Edwards, G.R., 1975 : Corinthian Hellenistic Pottery, Princeton.

Crowfoot, J.W., Crowfoot, J.M. et Kenyon, K., 1957 : Samaria-Sebaste III. The Objects from Samaria, Londres.

Di Giovanni, V., 1996 : "Produzione e consumo di ceramica da cucina nella Campania romana (IIa.C.-II d.C.)", Les céramiques communes de Campanie et de Narbonnaise ( $I^{\text {er }}$ s. av. J.-C.- II ${ }^{e}$ s. ap. J.-C.). La vaisselle de cuisine et de table. Actes des journées d'étude organisées par le centre Jean Bérard et la soprintendanza archeologica per la Province de Napoli e Caserta, Naples, 17-28 mai 1994, Naples : 65-104.

Dignas, B., 2007 : "Porter la couronne d'un dieu : titre civique, charge religieuse, pouvoir ou fardeau?", Kernos 20: 173-187.

Elaigne, S., 2007 : "La circulation des céramiques fines hellénistiques dans la région égéenne : un aperçu à partir du mobilier de Délos et de Thasos", BCH 131/1 : 515-557.

Elaigne, S. et Lemaître, S., 2014 : "De la vaisselle et du vin chypriote au Létôon de Xanthos à l'époque romaine", Topoi 19.2 : 565-593.

Empereur, J.-Y. et Picon, M., 1989 : "Les régions de production d'amphores impériales en Méditerranée orientale", CEFR 114 : 223-248.

Erder, C., 1967 : Hellenistik Devir Anadolu Mimarisinde Kyma Rekta-Kyma Reversa, Ankara.

Gasperetti, G., 2003 : "Osservazioni preliminari sulla ceramica romana di Iasos di Caria. Materiali dal quartiere a sud del Teatro", in Abadie-Reynal (éd.) 2003 : 141-163.

Gassner, V., 1997 : Das Südtor der Tetragonos-Agora. Keramik und Kleinfunde, FiE XIII/1/1, Vienne.

Goudineau, Ch., 1970 : "Note sur la céramique à engobe interne rouge-pompéien ('Pompejanisch-Roten Platten')", Mélanges de l'Ecole Française de Rome 82/1 : 159186.

Hansen, M.H. et Nielsen, T.H. (éds.), 2004 : An Inventory of Archaic and Classical Poleis. An Investigation conducted by the Copenhagen Polis Centre for the Danish National Research Foundation, Oxford.

Hayes, J., 1972 : Late Roman Pottery, Londres.

- 1997 : Handbook of Mediterranean Roman Potte$r y$, Londres.

- 2000 : "From Rome to Beirut and Beyond: Asia 
Minor and Eastern Mediterranean Trade Connections", Rei Cretariae Romanae Acta 36 : 285-297.

- 2005 : "Late Hellenistic and Roman pottery in the eastern Mediterranean - an overview of recent developments", in M.B. Brise et L.E. Vaag (éds.), The Relations in the Eastern Mediterranean from the Late Hellenistic Period to Late Antiquity : The Ceramic Evidence, Halicarnassus Studies III, Odense : 11-26.

Hellström, P., 1965 : Labraunda II.1. Pottery of Classical and Later Date, Terracotta, Lamps and Glass, Lund.

Historia Numorum Online : http://hno.huma-num.fr/ Holleaux, M., 1899 : "Trois décrets de Rhodes", REG 12 : 20-37.

Kızıl, A., Konuk, K., Brun, P., Capdetrey, L., Descat, R., Fröhlich, P., Laroche, D., Le Quéré, E., Prost, Fr. et Vergnaud, B., 2016 : "Eurômos : rapport préliminaire sur les travaux réalisés en 2015", Anatolia Antiqua XXIV : 321-338

Kızıl, A., Konuk, K., Alemdar, S., Capdetrey, L., Descat, R., Laroche, D., Le Quéré, E., Prost, Fr. et Vergnaud, B., 2017 : "Eurômos : rapport préliminaire sur les travaux réalisés en 2016", Anatolia Antiqua XXV : 161185.

Koçhan, N., 1995 : Hellenistik Çă̆ Anadolu Mimarisinde Lotus-Palmet ve Yumurta Bezekleri, Erzurum.

Kögler, P., 2010 : Feinkeramik aus Knidos vom mittleren Hellenismus bis in die mittlere Kaiserzeit (ca. 200 v. Chr. bis 150 n. Chr.), Wiesbaden.

Kürüm, N., 2006 : Hellenistik Çağ Anadolu Mimarisindeki Karia Bölgesinde Ion Kymationu'nun Gelişimi (Yayınlanmamış Yüksek Lisans Tezi : Selçuk Üniversitesi), Konya.

Ladstätter, S., 2005 : "XIV. Keramik", in H. Thür (éd.), Hanghaus 2 in Ephesus, Die Wohneinheit 4. Baubefund, Ausstattung, Funde, Forschungen in Ephesos VIII.6, Vienne : 230-350, pls. 147-227.

Lungu, V., 2016 : "Céramique", in O. Henry et al., "Labraunda 2015", Anatolia Antiqua XXIV : 363-383.

- 2017 : "Les céramiques de la nécropole de Labraunda ", in O. Henry et al., Anatolia Antiqua XXV : 233-245.

Mandel, U., Kögler, P., Dotterwich, P. et Happel, G., 1996 : "Keramik aus Knidos. Ein Vorbericht", in M. Herfort-Koch, U. Mandel et U. Schädler (éds.), Hellenistische und kaiserzeitliche Keramik des östlichen Mittelmeergebietes, Kolloquium Frankfurt 24-25 April 1995, Francfort : 61-69.

Meadows, A., 1996 : "Four Rhodian Decrees. Rhodes, Iasos and Philip V", Chiron 26 : 251-266.
Meriç, R., 2002 : Späthellenistisch-römische Keramik und Kleinfunde aus einem Schachtbrunnen am Staatsmarkt in Ephesos, Forschungen in Ephesos IX/3, Vienne.

Mitchell, S. et McNicholl, A.W., 1978-79 : "Archaeology in Western and Southern Asia Minor 197178", Achaeological Reports 25 : 59-90.

Peacock, D.P.S. et Williams, D.F., 1986 : Amphorae and the Roman Economy: an Introductory Guide, Londres.

Pellegrino, E., 2007 : "Les céramiques de Beyrouth secteur Bey 002 au début de l'époque romaine", Syria 87 : 143-168.

Peschlow, A., 1980 : "Recent Archaeological Research in Turkey", AS $30: 215-226$.

Reynolds, P., 2013 : "Transport Amphorae of the First to Seventh Centuries: Early Roman to Byzantine Periods", in W. Aylward, (éd.), Excavations at Zeugma, Conducted by Oxford Archaeology, The Packard Humanities Institute, Los Altos, California, Volume II : 93-161, pl. 43-74.

- 2000 : "The Beirut amphora type, $1^{\text {st }}$ century BC$7^{\text {th }}$ century AD: an outline of its formal development and some preliminary observations of regional economic trends", Acta RCRF 36 : 387-395.

Roux, G., 1961 : L'architecture de l'Argolide aux IV et III siècles avant J.-C., Paris.

Sibella, P., 2002 : "Promontoire d'Uluburun, Turquie : amphores non identifiées", in L. Rivet et M. Sciallano (éds.) 2002 : Vivre, produire et échanger : reflets méditerranéens. Mélanges offerts à Bernard Liou, Montagnac : 425-428.

Serdaroğlu, Ü., 1971 : "Euromos 1969”, 1970, Anatolian Studies $21: 47-48$

- 2004 : Lykia-Karia’da Roma Dönemi Tapınak Mimarisi, Istanbul.

Tocra I = Boardman, J. et Hayes, J., 1966 : Excavations at Tocra, 1963-1965 U. The Archaic Deposits, British School of Archaeology at Athens Suppl. 4, Londres.

Tekkök-Biçken, B., 1996 : The Hellenistic and Roman Pottery from Troia: Second Century BC to Sixth Century AD, Ann Arbor.

Whitbread, I.K., 1995 : Greek Transport Amphorae: a Petrological and Archaeological Study, Londres.

Whitbread, I.K., 2004 : "Dressel 2-4 and the eruption of Vesuvius. Transport Amphorae and Trade in the Eastern Mediterranean", in J. Eiring et J. Lund (éds.), Transport Amphorae and Trade in the Eastern Mediterranean, Acts of the International Colloquium at the Danish Institute at Athens, September 26-29, 2002, Athènes : 441-450. 


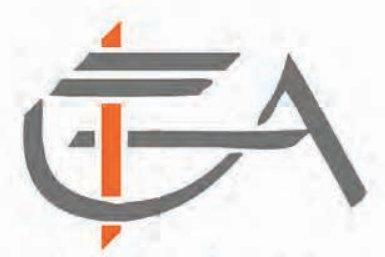

Institut Français d'Etudes Anatoliennes

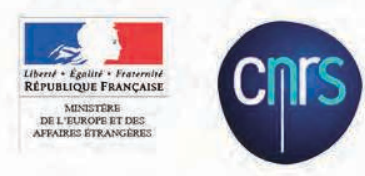

La citadelle de Tushpa (Van, Turquie).

ISBN: 978-2-36245-074-7

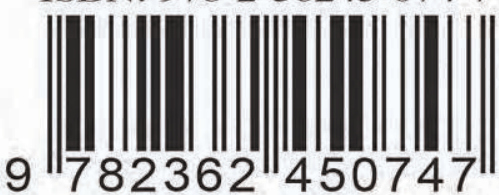

